\title{
WestVirginiaUniversity
}

THE RESEARCH REPOSITORY @ WVU

Graduate Theses, Dissertations, and Problem Reports

2007

\section{Investigation of the stress induced properties of coke during carbonization}

James Joshua Maybury

West Virginia University

Follow this and additional works at: https://researchrepository.wvu.edu/etd

\section{Recommended Citation}

Maybury, James Joshua, "Investigation of the stress induced properties of coke during carbonization" (2007). Graduate Theses, Dissertations, and Problem Reports. 1959.

https://researchrepository.wvu.edu/etd/1959

This Thesis is protected by copyright and/or related rights. It has been brought to you by the The Research Repository @ WVU with permission from the rights-holder(s). You are free to use this Thesis in any way that is permitted by the copyright and related rights legislation that applies to your use. For other uses you must obtain permission from the rights-holder(s) directly, unless additional rights are indicated by a Creative Commons license in the record and/ or on the work itself. This Thesis has been accepted for inclusion in WVU Graduate Theses, Dissertations, and Problem Reports collection by an authorized administrator of The Research Repository @ WVU. For more information, please contact researchrepository@mail.wvu.edu. 
Investigation of the Stress Induced Properties of Coke during Carbonization

James Joshua Maybury

\begin{abstract}
Thesis submitted to the College of Engineering and Mineral Resources at West Virginia University in partial fulfillment of the requirements for the degree of
\end{abstract}

\author{
Master of Science \\ in \\ Mechanical Engineering \\ W. Scott Wayne, Ph.D., Chair \\ Thomas R. Long, Ph.D. \\ Peter G. Stansberry, Ph.D. \\ Alfred H. Stiller, Ph.D. \\ Department of Mechanical and Aerospace Engineering \\ Morgantown, West Virginia \\ 2007
}

Keywords: Coke, Texture, Anisotropic, Coking, Needle Coke, Pitch Coke, Metallurgical Coke 


\section{Abstract \\ Investigation of the Stress Induced Properties of Coke during Carbonization \\ James J. Maybury}

The large polycyclic aromatic plates within coal tar pitches do not flow freely enough to organize into large anisotropic domains during pyrolytic carbonization. It was hypothesized that mechanical shear stress might accomplish that orientation. To test the hypothesis a reactor and stirring mechanism were designed and constructed to test crystalline formation behavior during carbonization. The work shows a unique method for manipulating the crystalline structure of coke. The coke was derived from a coal tar pitch with an initial softening point of $147^{\circ} \mathrm{C}$. During the pyrolytic devolatilization of the pitch, a shearing stress was applied mechanically. The stress promoted oriented texture in the direction of the applied stress as observed by polarized light microscopy. Powder $\mathrm{x}$-ray diffraction was performed on the green coke samples. The crystalline intensity value was determined by integration of the diffraction intensity for the 002 peak of the amorphous green coke. The crystallite width, Lc, was calculated and found to be within 12 and $19 \AA$. The insulating nature of the coke affected the temperature control system, which altered the thermal treatment of the samples. The optical results proved that the mechanically induced stress affected the pore size, shape, and anisotropic domain size. The texture of the coke ranged from fine lenticular to fine ribbon. 


\section{Acknowledgements}

The author happily acknowledges the committee members: Dr. Long, Dr. Stansberry, Dr. Stiller, and Dr. Wayne. Their combined support for the author's graduate school candidacy as well as academic and professional growth is unparalleled and much appreciated.

The author would like to thank the Department of Energy (DOE) for funding with which this research was made possible through the Carbon Products Research Group of West Virginia University.

The Carbon Products Research Group of the Chemical Engineering Department at West Virginia University was very supportive. Program Coordinator, Elliot Kennel, was very encouraging and forthcoming. Also, the author would like to thank coworkers of Carbon Products.

The author would like to thank various departmental employees of the College of Engineering and Mineral Resource. James Hall, Marilyn Host, Clifford Judy, Jean Kopasko, Linda Rogers, and Deborah Willis were exceptionally supportive throughout the term of this research.

The aids of the industrial partners for the DOE sponsored contract were forthcoming with materials, services, and technical advice. Koppers and GrafTech International were very helpful supplying materials, services, and advice.

Ken Krupinski, Dan Gray, and Ralph Gray were most helpful, providing literature and technical assistance.

Finally, the author would like to thank his family and friends. Research requires

much time and energy. May the sacrifices of so many be repaid with an improved quality of life for society; especially those so dearly loved, and so immensely missed. 


\section{Table of Contents}

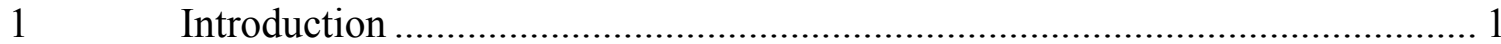

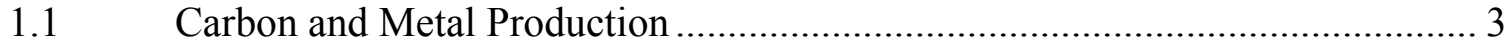

$1.2 \quad$ Synthetic Graphite Production ................................................................. 5

$1.3 \quad$ Statement of the Problem............................................................................ 7

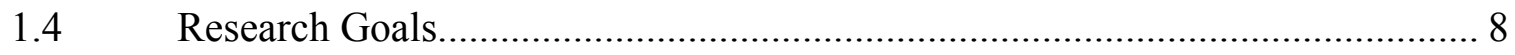

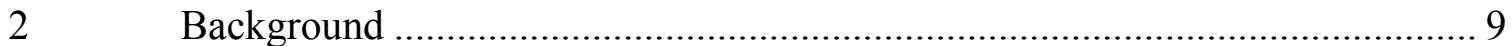

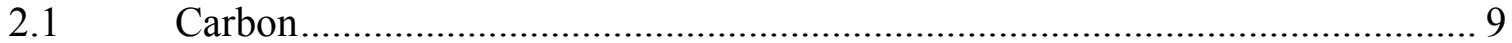

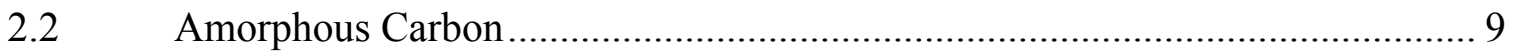

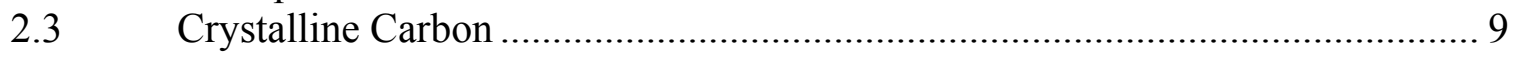

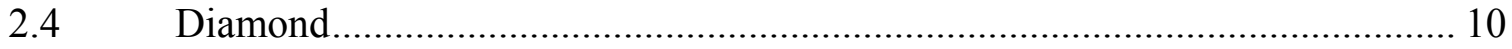

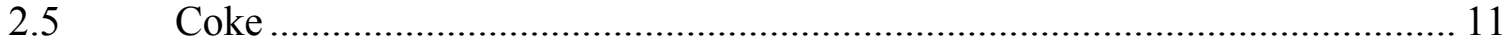

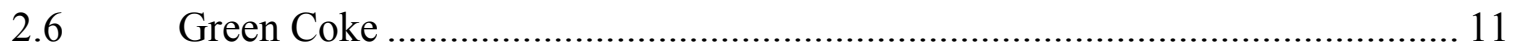

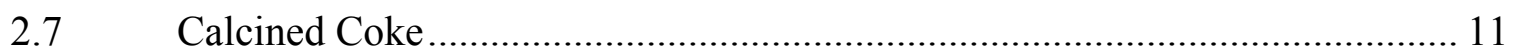

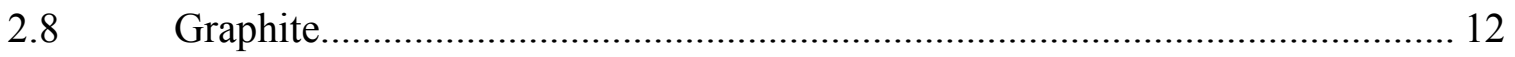

$2.9 \quad$ Isotropic Versus Anisotropic Carbon Material ............................................... 16

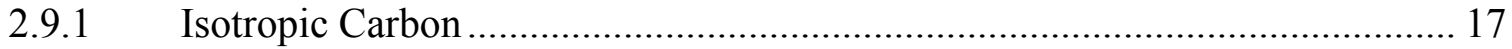

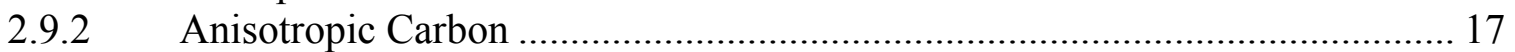

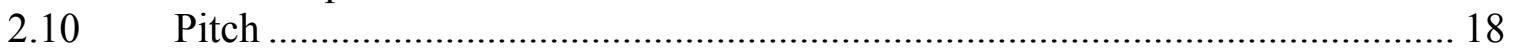

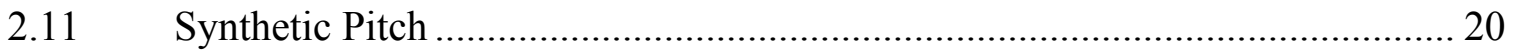

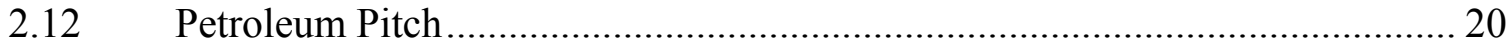

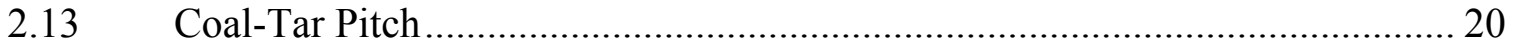

2.14 Coal-Derived Pitch....................................................................................... 21

2.15 Formation of Coke from Mesophase Growth during Carbonization................ 21

$2.16 \quad$ Coke Processes........................................................................................... 26

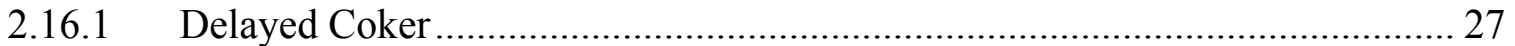

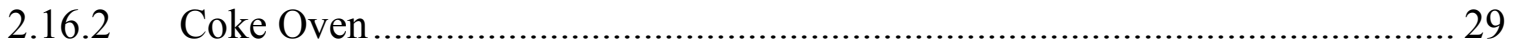

2.17 Graphitic Carbon Characterization …………….......................................... 30

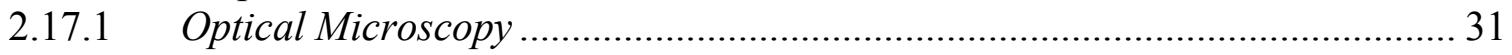

2.17.2 Scanning Electron Microscopy (SEM) …………....................................... 33

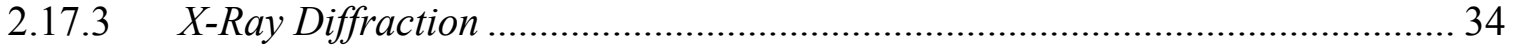

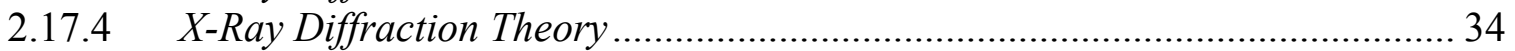

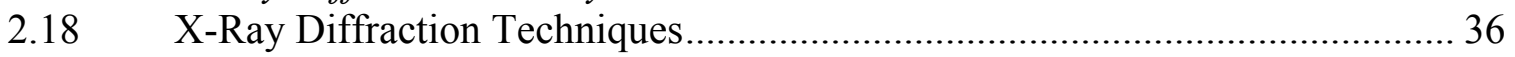

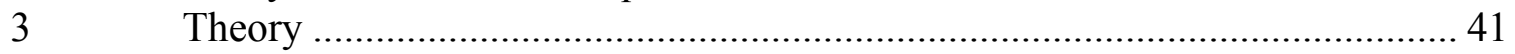

$4 \quad$ Reactor Design and Instrumentation ............................................................ 44

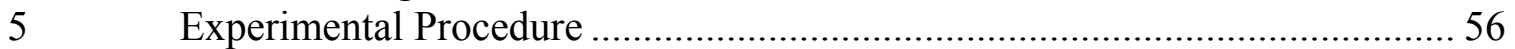

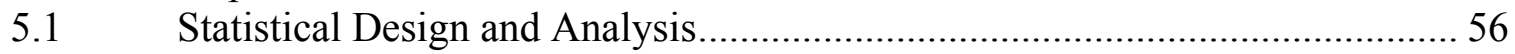

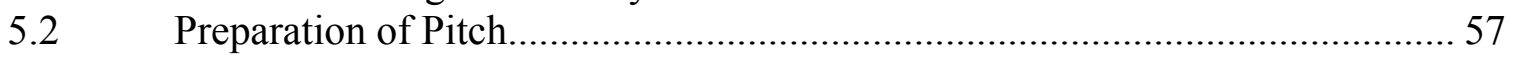

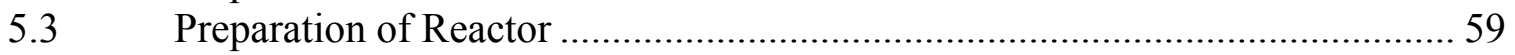

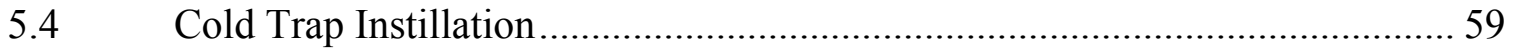

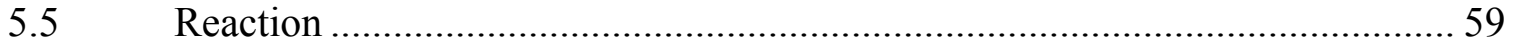

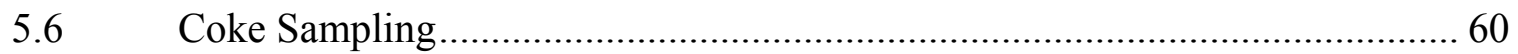

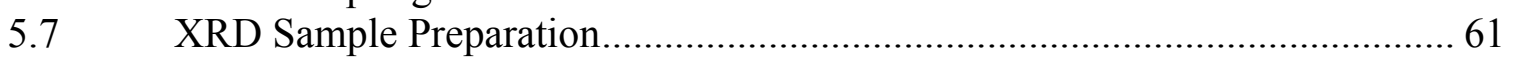

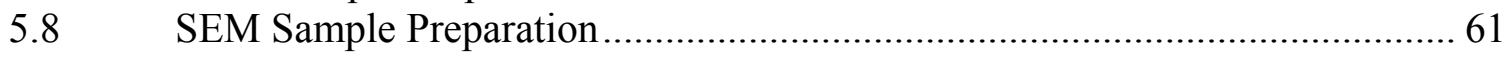

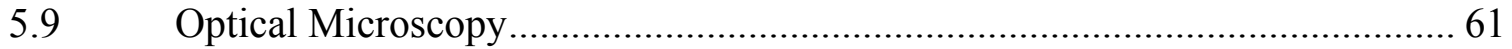




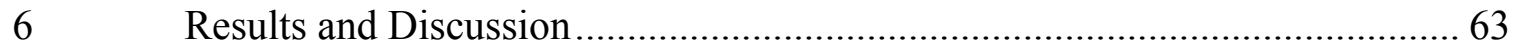

6.1 SEM Micrograph Image Analysis of Coke Structure .........................................6 63

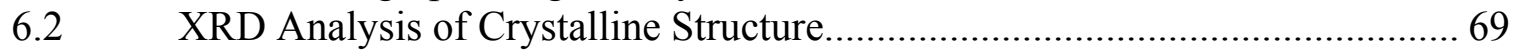

$6.3 \quad$ Polarized Light Optical Microscopy ……….................................................. 81

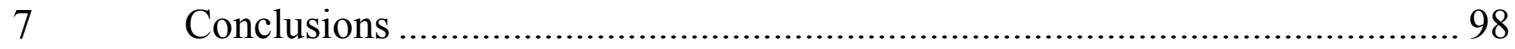

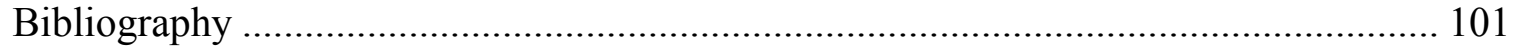

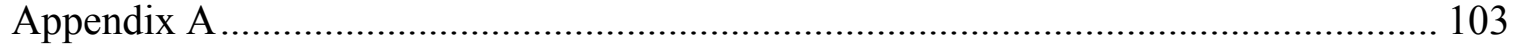




\section{List of Figures}

Figure 2.1 Tetrahedral Arrangement of a Diamond Crystal (Marsh, 1989) .................... 10 Figure 2.2 Pyrolytic Formation of Synthetic Graphite from Graphitic Carbon (Marsh, 1989) 12

Figure 2.3 Hexagonal Arranged Graphene Planes of Graphite (Marsh, 1989) ............... 13

Figure 2.4 Rhombohedral Arranged Graphene Planes of Graphite (Marsh, 1989) ......... 13

Figure 2.5 CTE as a Function of Temperature of Graphite Parallel to the Planes (Orac and Chang, 1991) ........................................................................................ 14

Figure 2.6 Graphite Tensile Strength as a Function of Temperature (Mantell, 1979)..... 16

Figure 2.7 SEM Micrograph of Calcined Needle Coke................................................. 18

Figure 2.8 Mesogens and Mesophase Domain Formation in a Pitch Matrix while Carbonizing (Marsh, 1989) 22

Figure 2.9 Lamellar Form of Coalesced Mesophase Observed by Optical Microscopy

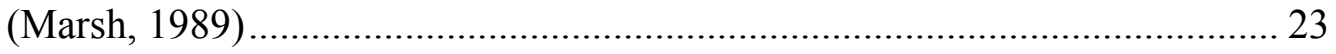

Figure 2.10 Simple Mesophase Coalesces (Brooks and Taylor, 1968) .......................... 24

Figure 2.11 Viscosity as a Function of Carbonization Temperature of Pitch (Marsh, 1989)

Figure 2.12 Formation of Coke in a Delayed Coking Drum. (Marsh, 1989)

Figure 2.13 By-Product Coke Battery (Gallaher, 2002) ................................................ 30

Figure 2.14 Polarized Light Microscopic Optical Arrangement (Marsh, 1989).............. 31

Figure 2.15 Interference Hues from Reflected Light on Graphene Planes (Marsh, 1989)32

Figure 2.16 Basic X-Ray Diffraction Configuration (Callister, 1994) ........................... 35

Figure 2.17 Interference of X-Rays Patterns through an Aperture (Bragg, 1975) .......... 36

Figure 2.18 Debye-Sherrer X-Ray Diffraction Schematic (Askeland, 1958) ................. 37

Figure 2.19 Schematic of a Powder X-ray Diffractometer (Jenkins and Snyder, 1996) .. 38

Figure 2.20 Diffractogram of Graphitic Material (Bennet, 2000) ................................. 39

Figure 2.21 Spacing of $\mathrm{d}_{002}$ Planes as a Function of Proportional Disorder Using XRD

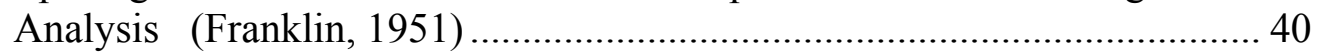

Figure 3.1 SEM Image of Oriented Coke Layers ...................................................... 42

Figure 3.2 SEM Image of an Amorphous Coke Structure............................................ 43

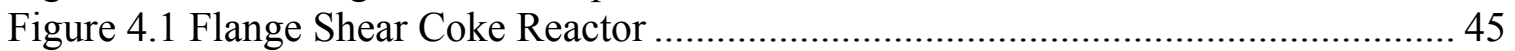

Figure 4.2 Shear Coke Reactor after Final Modifications ........................................... 47

Figure 4.3 Inner View of the Shear Coking Reactor Thermocouple Probe at the Base ... 47

Figure 4.4 Original Wiper Blade Design (used) ....................................................... 49

Figure 4.5 Cold Traps and Activated Charcoal Filter................................................... 50

Figure 4.6 Reactor Lid with Volatile Port, Stirring Shaft Bearing, and Nitrogen Gas

Coupling (from left to right) ............................................................... 51

Figure 4.7 Stirring Shaft with Stainless Steel Wiper Blade.......................................... 52

Figure 4.8 Wiper Blade Fixed to the Stirring Shaft inside the Reactor .......................... 52

Figure 4.9 Assembled Reactor (Nitrogen Purge Line and Volatile Vent Line not

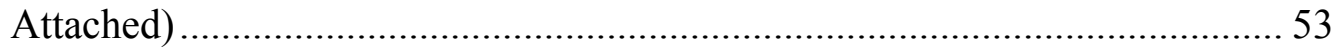

Figure 4.10 Shear Coking Reactor Secured in the Test Apparatus................................. 54

Figure 4.11 Complete Test Apparatus .......................................................................... 55

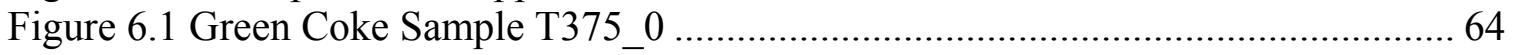




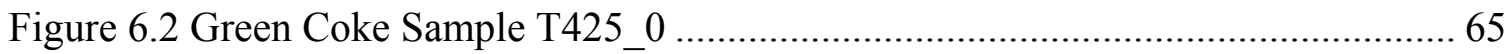

Figure 6.3 Green Coke from Alternative Process Sample T375 50 …………….......... 67

Figure 6.4 Green Coke from Alternative Process Sample T375_100 ……..................... 67

Figure 6.5 Green Coke from Alternative Process Sample T425_50 ………………...... 68

Figure 6.6 Green Coke from Alternative Process Sample T425_100 …………………... 68

Figure 6.7 Irradiation as a Function of Angle (Bennet, 2000)....................................... 69

Figure 6.8 Cones of Reflection as a Function of Diffraction Angle (Bennet, 2000) ....... 70

Figure 6.9 X-Ray Diffraction of Green Coke Samples as Processed (shown from 20 to 31

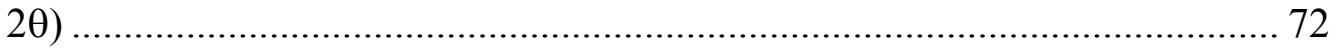

Figure 6.10 U Series XRD Data as Tested ............................................................... 74

Figure 6.11 T-Series XRD Data as Tested. There is a peak at $32.5^{\circ}$ due to contamination. .74

Figure 6.12 XRD Intensity Curve with Separated Crystalline and Background Region.. 75

Figure 6.13 Parameter Set Points and Block Comparison Configuration ......................... 77

Figure 6.14 Crystalline Intensity Value as a Function of Temperature (T-Series as

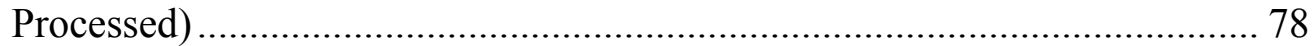

Figure 6.15 Crystalline Intensity Value as a Function of Wiper Speed (T-Series as

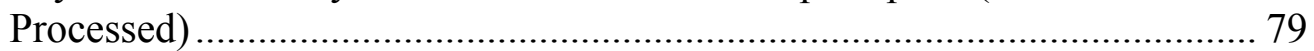

Figure 6.16 Temperature Effects on Crystallinity of Green Coke................................... 80

Figure 6.17 Effect of Stirring Rate on Crystallinity of Green Coke................................ 81

Figure 6.18 Coal Tar Pitch from Koppers Inc. Magnification 200X Note: Carryover QI in Glassy Coal Tar Pitch Matrix and Fine Mesophase Spherules .................. 82

Figure 6.19 Coal Tar Pitch from Koppers Inc. Magnification 500X Note: Large

Carryover QI in Glassy Coal Tar Pitch Matrix. 82

Figure 6.20 Coal Tar Pitch from Koppers Inc. Magnification 500X Note: Mesophase Spherule Structures.

Figure 6.21 Green Coke Texture Induced by Heat Treatment. Magnification 50X ........ 84

Figure 6.22 Green Coke Texture Induced by Heat Treatment. Magnification 100X ...... 84

Figure 6.23 Green Coke Texture Induced by Heat Treatment. Magnification 200X ...... 84

Figure 6.24 Green Coke Texture Induced by Heat Treatment. Magnification 200X ...... 85

Figure 6.25 Green Coke Texture Induced by Heat Treatment. Magnification 500X ...... 85

Figure 6.26 Green Coke Texture Induced by Heat Treatment. Magnification 50X ........ 86

Figure 6.27 Green Coke Texture Induced by Heat Treatment. Magnification 200X ...... 86

Figure 6.28 Green Coke Texture Induced by Heat Treatment. Magnification 500X ...... 86

Figure 6.29 Green Coke Texture Induced by Heat Treatment. Magnification 500X ...... 87

Figure 6.30 Green Coke Texture Produced from Thermal and Shear Stress.

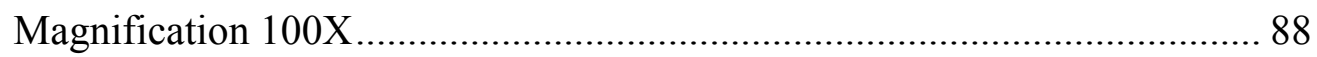

Figure 6.31 Green Coke Texture Produced from Thermal and Shear Stress.

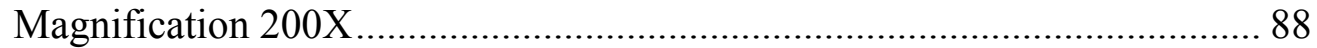

Figure 6.32 Green Coke Texture Produced from Thermal and Shear Stress.

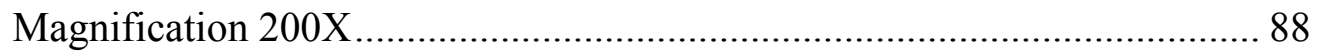

Figure 6.33 Green Coke Texture Produced from Thermal and Shear Stress.

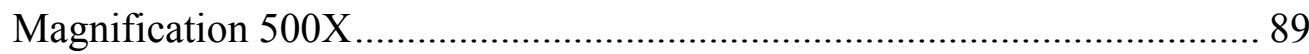

Figure 6.34 Green Coke Texture Produced from Thermal and Shear Stress. Magnification 100X 
Figure 6.35 Green Coke Texture Produced from Thermal and Shear Stress.

Magnification 200X.

Figure 6.36 Green Coke Texture Produced from Thermal and Shear Stress.

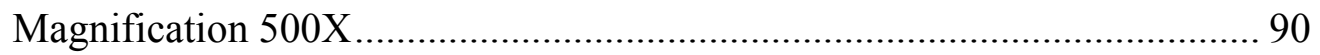

Figure 6.37 Green Coke Texture Produced from Thermal and Shear Stress.

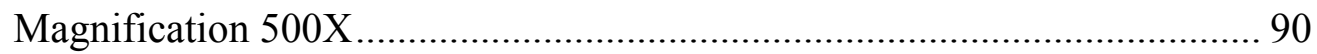

Figure 6.38 Green Coke Texture Produced from Thermal and Shear Stress.

Magnification 100X

Figure 6.39 Green Coke Texture Produced from Thermal and Shear Stress.

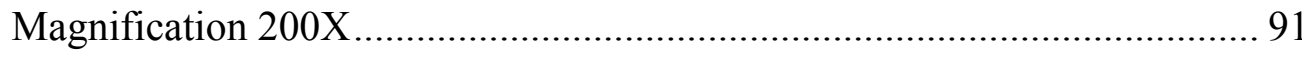

Figure 6.40 Green Coke Texture Produced from Thermal and Shear Stress.

Magnification 200X.

Figure 6.41 Green Coke Texture Produced from Thermal and Shear Stress.

Magnification 500X.

Figure 6.42 Green Coke Texture Produced from Thermal and Shear Stress.

Magnification 100X...

Figure 6.43 Green Coke Texture Produced from Thermal and Shear Stress.

Magnification 100X.

Figure 6.44 Green Coke Texture Produced from Thermal and Shear Stress.

Magnification 200X.

Figure 6.45 Green Coke Texture Produced from Thermal and Shear Stress.

Magnification 200X.

Figure 6.46 Green Coke Texture Produced from Thermal and Shear Stress.

Magnification 500X.

Figure 6.47 Green Coke Texture Produced from Thermal and Shear Stress.

Magnification 500X...

Figure 6.48 Green Coke Texture Produced from Thermal and Shear Stress.

Magnification 100X.

Figure 6.49 Green Coke Texture Produced from Thermal and Shear Stress.

Magnification 200X.

Figure 6.50 Green Coke Texture Produced from Thermal and Shear Stress.

Magnification 500X.

Figure 6.51 Green Coke Texture Produced from Thermal and Shear Stress.

Magnification 500X. 96

Figure 6.52 Green Coke Texture Produced from Thermal and Shear Stress.

Magnification 100X.

Figure 6.53 Green Coke Texture Produced from Thermal and Shear Stress.

Magnification 200X.

Figure 6.54 Green Coke Texture Produced from Thermal and Shear Stress.

Magnification 500X.

Figure 6.55 Green Coke Texture Produced from Thermal and Shear Stress. Magnification 500X.

Figure A.1 Thermal Plot of the Outer Skin Temperature and Torque Curve for the

Reactions Processed at $375^{\circ} \mathrm{C}$ and at $0 \mathrm{rpm}$ 104

Figure A.2 Thermal Plot of the Outer Skin Temperature and Torque Curve for the Reactions Processed at $375^{\circ} \mathrm{C}$ and at $35 \mathrm{rpm}$.... 104 
Figure A.3 Thermal Plot of the Outer Skin Temperature and Torque Curve for the Reactions Processed at $375^{\circ} \mathrm{C}$ and at $75 \mathrm{rpm}$

Figure A.4 Thermal Plot of the Outer Skin Temperature and Torque Curve for the Reactions Processed at $425^{\circ} \mathrm{C}$ and at $0 \mathrm{rpm}$........................................... 105

Figure A.5 Thermal Plot of the Outer Skin Temperature and Torque Curve for the Reactions Processed at $425^{\circ} \mathrm{C}$ and at $35 \mathrm{rpm}$ 106

Figure A.6 Thermal Plot of the Outer Skin Temperature and Torque Curve for the Reactions Processed at $425^{\circ} \mathrm{C}$ and at $75 \mathrm{rpm}$ 106 


\section{List of Tables}

Table 1.1 Desired Properties of Needle Coke (Ellis, 2000)......................................... 4

Table 2.1 Pitch Classification and Characterization Test Method (McHenry, 1998)...... 19

Table 2.2 Mesophase Classification by Optical Microscopy Properties (Marsh, 1989) .. 26

Table 2.3 Classification of Optical Texture (Marsh, 1989) .......................................... 33

Table 4.1 Standard Equipment for the Shear Coker Reactor .......................................... 46

Table 5.1 2k Factorial Experimental Test Sequence (a) Experimental Values (b).......... 56

Table 5.2 Proximate analysis of the Coal Tar Pitch Material ......................................... 58

Table 5.3 Elemental Analysis of Coal Tar Pitch Material ............................................. 58

Table 5.4 Mettler Softening Point of the Pitch Material by ASTM-3104 ...................... 58

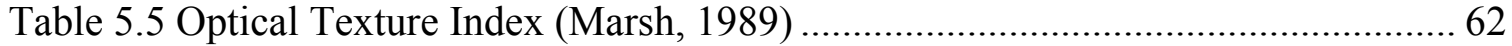

Table 6.1 Crystallite Dimensions of XRD 002 Peak (Samples were Tested as Processed)

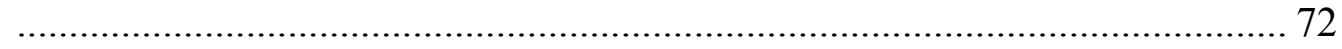

Table 6.2 Crystallite Dimensions of XRD 002 Peak (Samples were as Tested) .............. 74

Table 6.3 Effects of Parameter Change as a Function of Crystallinity (Samples as

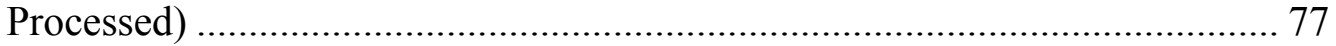

Table 6.4 Effects of Parameter Change as a Function of Crystallinity (Samples as Tested) 


\section{Introduction}

In the industrial world carbon is perhaps one of the most important elements. Of course all of life is based on carbon but in the industrial world, engineering metals cannot be manufactured without reactions of carbon. It is the great reducer of all metals except the noble metals: copper, silver, and gold. Carbon reacts with the oxides of most metals thereby producing carbon dioxide and pure metal. These reactions usually occur in high temperature environments such as blast furnaces or electrolytically where carbon is used as an anode.

Carbon as a reducing agent must have unique properties. In the blast furnace application the carbon must have significant mechanical strength and yet be porous. The suitable material is metallurgical coke. This is made by pyrolizing coal in coke ovens. During this process the coal is melted, devolatilized where molecules crosslink to form a hard porous solid. For the electrolytic reduction of aluminum the carbon is in the form of a composite made from anisotropic coke and binder pitch. A blend of these two materials is pressed into a block and baked to $1000^{\circ} \mathrm{C}$ to make it conductive. The anisotropy of the coke promotes both thermal shock resistance and electrical conductivity. For the reprocessing of steel the carbon must be in the form of graphite electrodes. The graphite is manufactured by baking a composite made from calcined anisotropic coke and binder pitch. Billets of this composite are baked at $2800^{\circ} \mathrm{C}$ until the amorphous calcined coke composites are crystallized. The anisotropic crystallized graphite is thermally shock insensitive and has low electrical resistance. For the reprocessing of steel the electrodes are not chemical reactants but serve only as electrical current transfer agents. 
As described above carbon, as a reducing agent, exists in several different forms. Metallurgical coke is made by pyrolizing coal in a coke oven. The coke produced is isotropic because the molecules of coal are reactive and in the fluid state do not flow far enough to produce large domains which would be anisotropic. Binder pitch is one of the other products of coke manufacturing. Pitch is the distillation resids of coal tar- the organic volatiles distilled from the coal in the coke oven. Anode coke and graphite are typically made from cokes produced from petroleum processing units. As the distillation of petroleum is processed the heavier organic molecules become more concentrated. In the final steps of fuel processing the heavy molecules are heated to cracking and transported to a coker. This process is called a delayed coking because the cracking occurs outside of the heating unit. The volatiles produced during this cracking process flow through the molten organic mass until it solidifies to form coke. The bubbles orient the coke forming molecules such that the product is anisotropic. The higher the degree of anisotropy, the more valuable the coke becomes. Although, anode coke used for the manufacture of aluminum is less anisotropic than needle coke use to make synthetic graphite. The anode coke is consumed during the production of aluminum and so it is cost prohibitive to use carbon that has been heat treated to form graphite. Instead the performance and economical compromise is the use of pregraphitic calcined coke.

As the quantity and quality of petroleum decreases refiners concentrate more on the production of fuels and less on anisotropic coke. Another factor to be considered, is that the petroleum imported into the United States is sulfur and metal rich. Nickel and vanadium seem to be increasing in the petroleum resources. These elements reduce the quality of cokes needed for metal refining. It was hypothesized that coal pitches and 
hydrogenated coal liquids might be a suitable source for the manufacture of anisotropic cokes. The large polycyclic aromatic plates within the coal pitches do not flow freely enough to organize into large anisotropic domains. It was felt that mechanical shearing might accomplish that orientation. That is the focus of this research. A more complete discussion of cokes, their applications, and carbon material must be given before the implications of this research can be fully realized.

\subsection{Carbon and Metal Production}

Synthetic graphite is used by the metallurgy industry in electric arc furnaces to melt and refine steel. This is done by passing a high voltage current through conductive synthetic graphite rods. An electrical arc, not only melts the reprocessed steel, but mixes the contents of the pot for uniform alloy distribution. The conductive rods used in arc furnaces are often referred to as graphite electrodes. The main constituent for the manufacture of synthetic graphite and graphite electrodes is highly oriented coke referred to as needle coke. The name "needle coke" is due to the characteristic needle-like striations that clearly dominate the texture of the material. Needle coke is a very special material that meets stringent industrial standards and commands a price of 500 USD per ton (Ellis, 2000). "The principle requirement for needle coke is that the CTE must be 2.0 $\left[(\mathrm{cm} / \mathrm{cm}) /\left({ }^{\circ} \mathrm{C} \times 10^{\wedge}-7\right)\right]$ or below..."(Ellis, 2000). Even though the industry has shown that these properties are desirable for performance, ultimately a slow consumption rate will greatly increase profits. This seems self evident with a feedstock cost of 500

USD/ton. The desired properties of needle coke can be seen in Table 1.1. 
Table 1.1 Desired Properties of Needle Coke (Ellis, 2000)

\begin{tabular}{|l|c|c|l|}
\hline \multicolumn{1}{|c|}{ Property } & Value & Unit & \multicolumn{1}{c|}{ Purpose } \\
\hline CTE & $<2.0$ & $\mathrm{~cm} / \mathrm{cm} /{ }^{\circ} \mathrm{C}^{*} 10^{\wedge}-7$ & prevents spalling \\
\hline Sulfur & $<0.6$ & wt $\%$ & prevents puffing during graphitization \\
\hline Ash & $<0.3$ & wt $\%$ & causes voids during graphitization \\
\hline Coarse sizing & $>6$ & $\mathrm{~mm}$ & \\
\hline Fines & $<1$ & $\mathrm{~mm}$ & \\
\hline density & $>78$ & $\mathrm{~g} / 100 \mathrm{ml}$ & \\
\hline real density & 2.13 & $\mathrm{~g} / \mathrm{cc}$ & \\
\hline
\end{tabular}

Aluminum refining uses carbon in a completely different manner. In steel production carbon electrodes are used to conduct the current through an arc in order to melt steel, whereas in aluminum refining carbon anodes are used as a chemical reactant to reduce aluminum ore, bauxite, into aluminum metal while producing carbon dioxide. Non-graphitic carbon is used in anodes in the aluminum industry. As the aluminum ore is melted the carbon anode is consumed by reacting with the oxygen from the bauxite forming carbon dioxide. It requires about one pound of carbon anode to produce two pounds of aluminum metal (Ellis, 2000).

Aluminum anodes require the use of sponge coke. It was coined sponge coke due to the periodic arrangement of pores that resemble a sponge. To be used for anode production, the coke must have low metal content, low volatile matter (VM), low coefficient of thermal expansion (CTE), high density, and still be slightly porous (Ellis, 2000). Some porosity is required to allow for the penetration of binders and also to act as gas channels during devolitalization. An anode of low metallic content produces aluminum of higher purity. This is because the metals within the coke tend to mix with the aluminum during production. Having low values of CTE and VM promote efficient anode operation and better structural stability. This is important to the continuous and economic operation of the foundry industry. 
The reduction of iron ore to cast iron is also accomplished by carbon.

Metallurgical coke, produced by pyrolizing coal in coke ovens is the primary reductant. In this case, the metallurgical coke is produced by pouring high swelling coal into heated coke oven chambers called batteries. The chambers were coined 'batteries' because the cells have the physical appearance of cells in a wet cell battery. The wall temperature of the battery is about $1400^{\circ} \mathrm{C}$. At this temperature the coal becomes molten. Some molecular fragments are evaporated while other molecular fractions are broken from the coal matrix. These volatile materials are labeled collectively as coal tar. In recovery coke ovens these coal tars are condensed and refined to produce coal chemicals. This is done by traditional distillation. The heavier tars are referred to as coal tar binder pitch. This is the primary adhesion component used in carbon composite production. In the coke battery cells, as this devolatilization process continues the coal molecules crosslink and polymerize. A solid hard, porous, material is produced. This material is metallurgical coke. It is fed into blast furnaces along with layers of iron ore, usually iron oxide mixtures, and lime stone that serve as a flux. Super heated air is blown through the layered ingredients. The coke burns in the super heated air to produce carbon monoxide that removes additional oxygen from the iron ore to produce elemental iron and carbon dioxide. The molten elemental iron reacts with additional carbon producing cast iron. Steel is made from cast iron by oxidizing out the reacted carbon from cast iron.

\subsection{Synthetic Graphite Production}

Graphite can be found in nature, but most natural graphite is highly disordered and regarded as having bulk isotropic properties. It is important to realize that graphite is a hexagonal crystal and crystallographic hexagonal systems are anisotropic - that is not 
the same in all directions. Therefore it would be expected that all graphite would be anisotropic; but if the dimensions of individual crystals are very small and in the bulk phase they are blended homogenously then the anisotropy is lost and the bulk material seems isotropic - the same in all directions. Synthetic graphite is produced commercially by crystallizing coke composites that are produced using pyrolytic reactions that decompose highly carbonaceous-high molecular weight hydrocarbons; or pitch, into carbon artifacts or synthetic carbon products. The graphitizable carbon artifacts can be heat treated in steps to obtain synthetic graphite. After an initial carbonization process, green coking, of less than $900 \mathrm{~K}$ the material is then calcined. Calcinations occur at temperatures up to $1600 \mathrm{~K}$ (Fitzer, 1995). The final heat treatment occurs when the calcined coke is heated to $2500-3300 \mathrm{~K}$ at which time synthetic graphite is formed. Highly anisotropic and ordered synthetic graphite is required by the steel industry to process steel. Graphite has unusual properties such as increased mechanical strength at elevated temperatures, but it still remains electrically conductive.

Aluminum is refined using anodes made from anisotropic cokes too. The degree of anisotropy is not nearly as great as needle coke, but anisotropy is required to facilitate electrical conductivity and thermal shock resistance. High purity cokes are required to reduce oxidation by air. In the electrolytic pots, the hot cokes are exposed to air and any metals that favor catalytic oxidation of the carbon. This is a waste of both electricity and carbon and must be reduced. The materials used to make these anodes are an anisotropic coke usually made from petroleum resids in a delayed coker. Coal based materials are too reactive and produce isotropic cokes not suitable for such electrolytic reductions. Because of the quality of petroleum imported to the United States, it would be desirable to have a 
path way through which coal and ore coal liquids could be processed to make anode coke.

\subsection{Statement of the Problem}

As stated previously the metallurgical industries require synthetic graphite or calcined coke to refine metals. The cokes used for these processes are typically obtained as a petroleum cracking byproduct. As heavy petroleum residuum is cracked during thermal distillation in delayed coking units to produce light fuel oils, polygranular cokes (anode, needle, and shot coke) are produced. Sponge coke is produced from coke ovens where coal is pyrolytically devolatilized to form coke and coal tars, from which coal tar pitch is made. The sponge coke can be pulverized and later used as polygranular filler material for anodes, but cannot be graphitized. Therefore sponge coke is not used to make electrodes needed for the steel industry. For both petroleum and coal precursors, the coke formed is controlled by the chemical composition and the thermal heat treatment. Pressure is typically used to increase the coke yield, but in the case of delayed coking, it also reduces the quantity of fuel oils that can be recovered.

Synthetic graphite has a crystalline structure that can be oriented to increase electrical conductivity and decreased thermal expansion. This is facilitated by the used of highly anisotropic cokes in synthetic graphite production. Needle coke has large domains that exhibit anisotropy. Despite the best efforts to control the feedstock and the heat treatments of these cokes, some constituents prevent the formation of the oriented crystalline structures (Manganaro, 1971). It was proposed that a mechanically induced stress may assist the formation of oriented crystalline carbon structures. 
The issue of a stress oriented crystalline growth requires further investigation. Will an applied shearing stress aid the orientation of the forming liquid crystals, or mesophase? As the mesophase begins to form green coke, will the coke maintain the formation or will it fracture from the stress? If coke can be produce with a higher degree of orientation, particularly from materials that do not usually form anisotropic cokes such as coal liquids, then the dependence on petroleum resids will be reduced. The use of more highly anisotropic cokes will increase the efficiency of the metallurgical processes and reduce the energy requirements.

\subsection{Research Goals}

It has been shown that precursors and thermal treatments greatly affect the crystallinity of carbon artifacts. The most influential carbonization step is during green coking (Bennet, 2000). It was hypothesized that the crystal domains of the liquid mass containing mesogens in this, or mesophase precursors could be oriented by the application of shear stress. The objectives of this research are listed below.

1. Design and construct a system capable of applying a shearing stress to a graphitizable material during pyrolytic carbonization.

2. Measure the applied torque during mesophase domain growth and green coke formation.

3. Assess the effects of a varied shear rate on the degree of anisotropy of cokes produced under such conditions.

4. Use polarized light microscopy to determine the characteristics of the coke domains. 
5. Using X-Ray Diffraction (XRD), determine if there is an increase to the graphene sheet length $\left(\mathrm{L}_{\mathrm{c}}\right)$, and relative crystallinity change.

\section{Background}

\subsection{Carbon}

Carbon is arguably the most valuable element to mankind. It is the key element in an area of science referred to as organic. Carbon, with its ability for single, double, and triple bonding formations, has the potential to form an infinite number of organic molecules. Furthermore elemental carbon exists in nature in two allotropic crystalline forms: graphite and diamond. Additionally elemental carbon can exist in disordered carbonaceous arrangements. The disordered arrangements of carbon material are called amorphous carbon. Elemental carbon is found in nature or it can be synthesized from carbonaceous feed materials.

\subsection{Amorphous Carbon}

A carbon that does not possess long-range atomic order is an amorphous carbon material (Callister, 1994). These include soot and chars. "The chars are obtained from the devolatilization of complex organic material or biomass composed of high molecular weight molecules" (Bennet, 2000). Soots are produced by burning organic compounds, particularly aromatic liquids, in an oxygen deficient environment.

\subsection{Crystalline Carbon}

Crystalline material has X-Ray diffraction patterns indicative of repeated motifs of atomic planes within the solid structure. By that definition simply the existence of those patterns indicates that the examined material is crystalline. Mineralogical crystalline carbon exists in the allotropic form of carbon: diamond and graphite. Diamond 
has tetrahedral planar arrangement indicative of three dimensional covalent bonding. Graphitic carbon includes all the varieties of carbon that possess a hexagonal crystalline structure as analyzed using x-ray diffraction methods (Fitzer, 1995). The crystallinity of graphitic carbon can be altered through a series of carbonizing heat treatments known as calcinations and graphitization. Coke is carbon that has a randomly distributed crystalline structure and by the definition aforementioned is not truly an amorphous material.

\subsection{Diamond}

The diamond structure is a formation of tetrahedral arrangement of carbon atoms. The tetrahedral structure can be seen in the Figure 2.1. It is three dimensionally stable with covalent bonding creating the hardest natural known material. The electron configuration causes diamonds to have low electrical conduction and yet have a high thermal conductivity (Bennet, 2000).

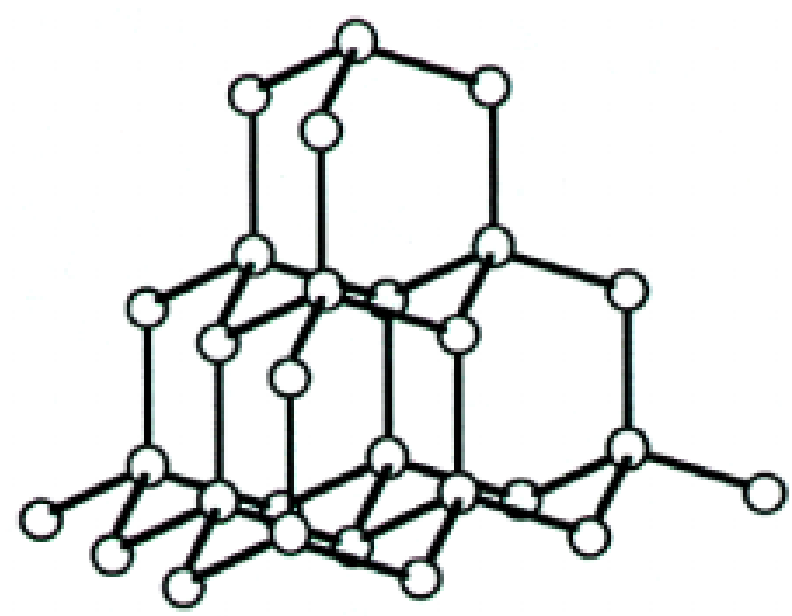

Figure 2.1 Tetrahedral Arrangement of a Diamond Crystal (Marsh, 1989)

Diamonds are prized for an optically clear structure that refracts light in a manner that is aesthetically pleasing. While diamonds have a strong presence in the jewel 
market, they are also used industrially for their hardness and abrasive properties (Callister, 1994).

\subsection{Coke}

Coke is a solid carbonaceous material produced by a pyrolytic devolatilizing reaction of organic material that, at least in part, transforms through a liquid and/or a liquid-crystalline state (Fitzer, 1995). Coke can be formed in the raw or green state and

further heat treated to be calcined and some grades of coke can be processed to graphite. Coke was once an unwanted byproduct of thermal cracking of heavy petroleum residuum to produce lighter fuel fractions but now is used for a fuel source and as a feed for the production of synthetic graphite.

\subsection{Green Coke}

Initially formed as a non-graphitic carbon material, raw or green coke can then be calcined or even graphitized to a highly graphitic material. Green coke is formed at temperatures below $900 \mathrm{~K}$ during pyrolysis of high boiling hydrocarbon fractions petroleum pitch or coal tar pitch. The pitch typically decomposes to coke with 4 to $15 \%$ volatile matter during the thermal heat treatment (Fitzer, 1995).

\subsection{Calcined Coke}

Heat treatment of green coke causes it to further devolatilize to less than $0.1 \%$ volatile matter as it reaches temperatures of about $1600 \mathrm{~K}$ forming calcined coke. This is the raw material for the production of carbon electrodes (Fitzer, 1995). Calcined shot coke is essential for the carbon anodes used in the aluminum industry. And isotropic calcined coke can be further heat treated for the production of synthetic nuclear graphite. These steps are illustrated in the following cartoon in Figure 2.2. 


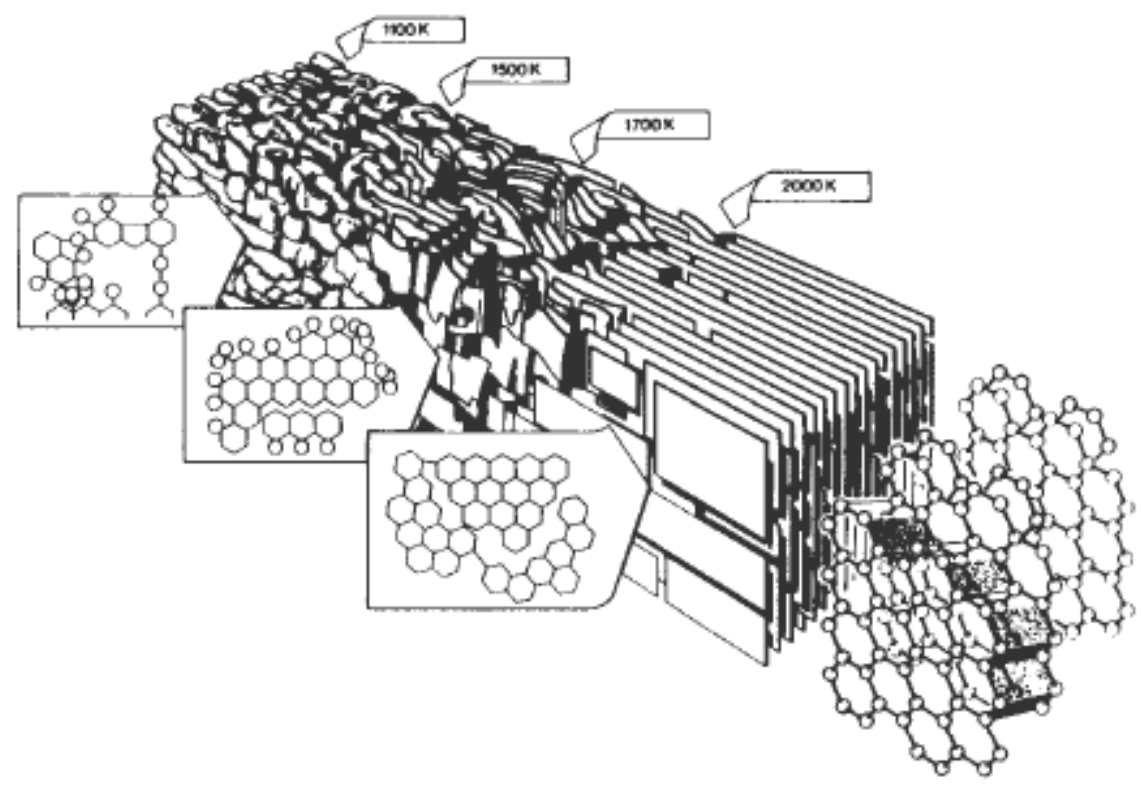

Figure 2.2 Pyrolytic Formation of Synthetic Graphite from Graphitic Carbon (Marsh, 1989)

\subsection{Graphite}

There are many useful properties of graphite. It acts as a dry lubricant, has a low modulus of elasticity, high electrical and thermal conductivity, high thermal shock resistance, high sublimation temperature, and its strength increases with temperature (Callister, 1994; Bennet, 2000). Graphite can be found in nature and can be synthesized by chemical vapor deposition (CVD) or by pyrolytic decomposition of carbonaceous organic material known as pitch.

"Graphite consists of layer upon layer of two-dimensional, connected, sixmember carbon rings. An individual sheet of carbon within the lamellar structure is called a graphene sheet or layer (Charlier, 1994; Bennet, 2000)." Graphene planes can be found in hexagonal or rhombohedral formation, whose layers are of the patterns $\mathrm{ABAB}$ and ABCABC respectively. The hexagonal arrangement or Bernal crystal structure, can be seen in Figure 2.3. 


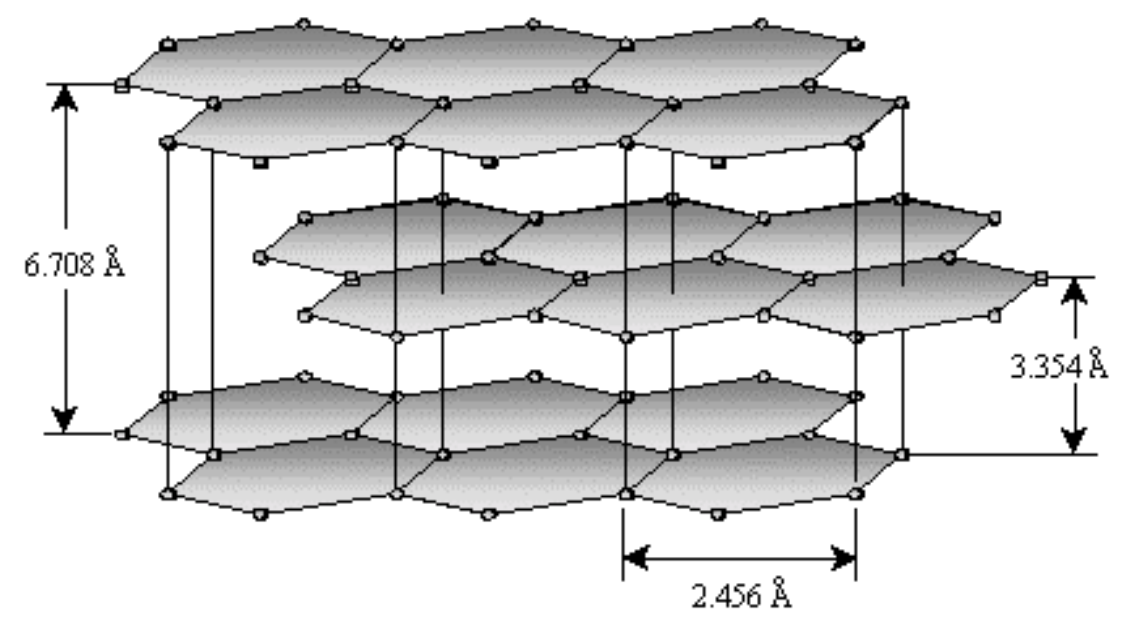

Figure 2.3 Hexagonal Arranged Graphene Planes of Graphite (Marsh, 1989)

Both the hexagonal and rhombohedral stacking arrangements are allotropic forms of elemental carbon. The graphene layers are bonded covalently where the inter graphene bonding is attributed to van der Waals forces (Bennet, 2000). The rhombohedral arrangement with the ABCABC stacking arrangement can be seen in Figure 2.4.

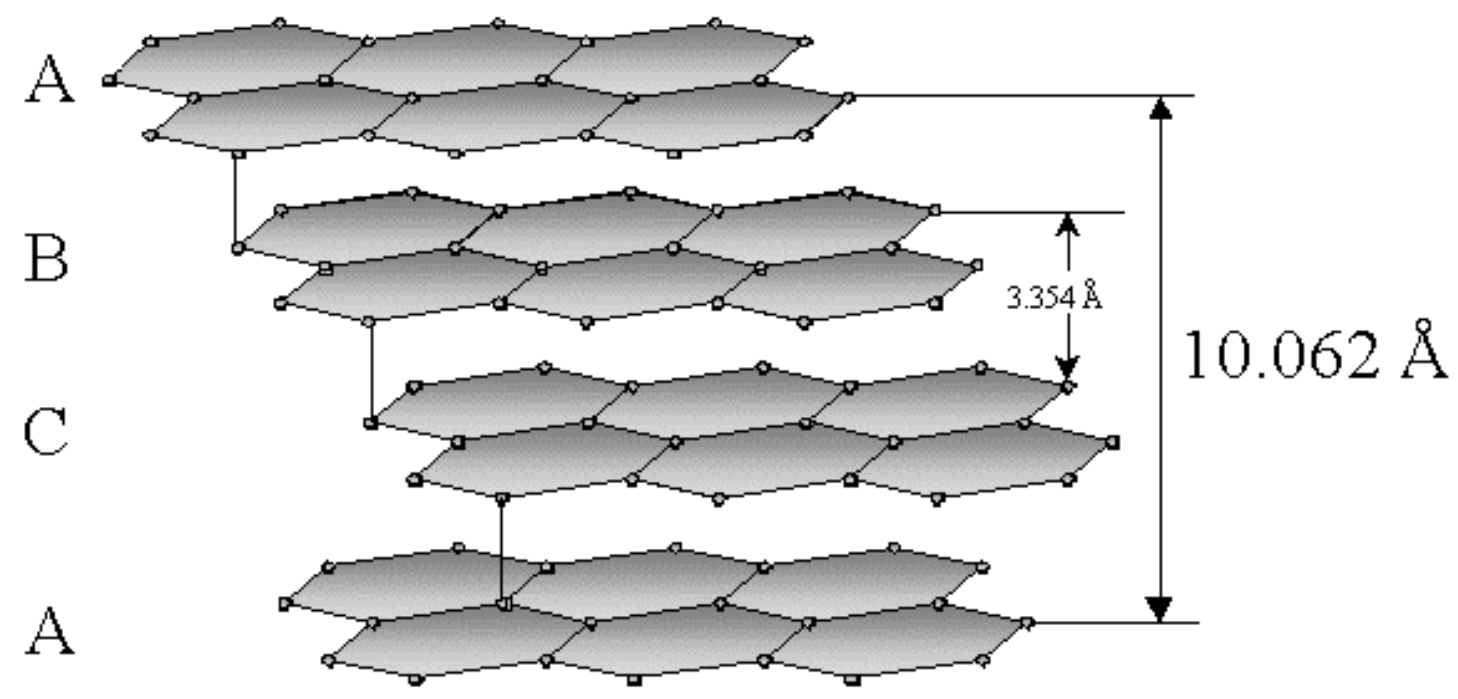

Figure 2.4 Rhombohedral Arranged Graphene Planes of Graphite (Marsh, 1989) 
The covalent bonding causes delocalized electrons, which attribute to high electrical and thermal conductivity along the graphene sheets. Perpendicular to the graphene sheets weak bonding cause electrical and thermal conductivity to be two orders of magnitude less than those parallel to the graphene sheets (Thomas, 1993; Bennet, 2000). It is due to the stacking arrangement of the graphene sheets and their mechanisms of bonding that cause natural and pyrolytic graphite to be anisotropic.

The anisotropic properties can be evaluated by comparing the coefficient of thermal expansion (CTE) parallel to the graphene planes to the CTE perpendicular to the planes. The CTE perpendicular to the graphene planes remains constant at about 28 um $/ \mathrm{m}^{\circ} \mathrm{C}$ (Orac and Chang, 1991; Bennet, 2000). Parallel to the planes the CTE is lower and variable as a function of temperature as seen in Figure 2.5.

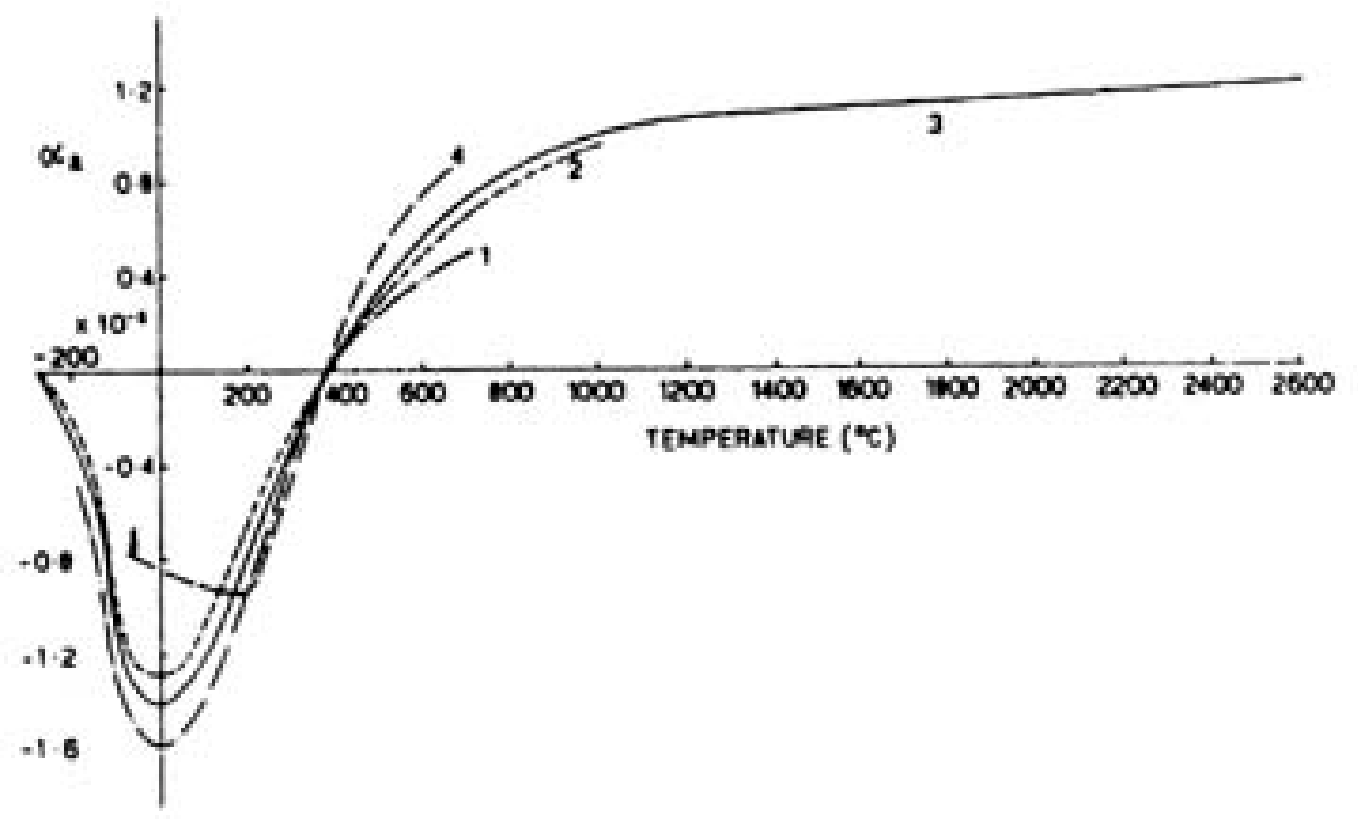

Figure 2.5 CTE as a Function of Temperature of Graphite Parallel to the Planes (Orac and Chang, 1991)

Graphite exists in multiple forms, a mixture of configurations, and orientations. The weak inter-layer bonding allows graphite to be used as a dry lubricant, but also 
allows the graphene layers to be arranged in a less ordered manner. When the layers are rotated or translated out of hexagonal or rhombohedral arrangement, it is then known as turbostratic graphite (Charlier, 1994; Bennet, 2000). This is evident when noting that natural graphite typically has only $5-15 \%$ rhombohedral crystal structures with the remainder comprised of turbostratic and hexagonal arrangements (Charlier, 1994, Bennet, 2000).

The graphite market demand is high for the production of steel. Graphite electrodes must conduct very high voltages at high temperatures to produce enough heat to melt steel in an arc furnace. Graphite has the ability to operate at temperatures above $2000^{\circ} \mathrm{C}$ and in fact its strength increases as a function of temperature. This property can be seen in Figure 2.6. 


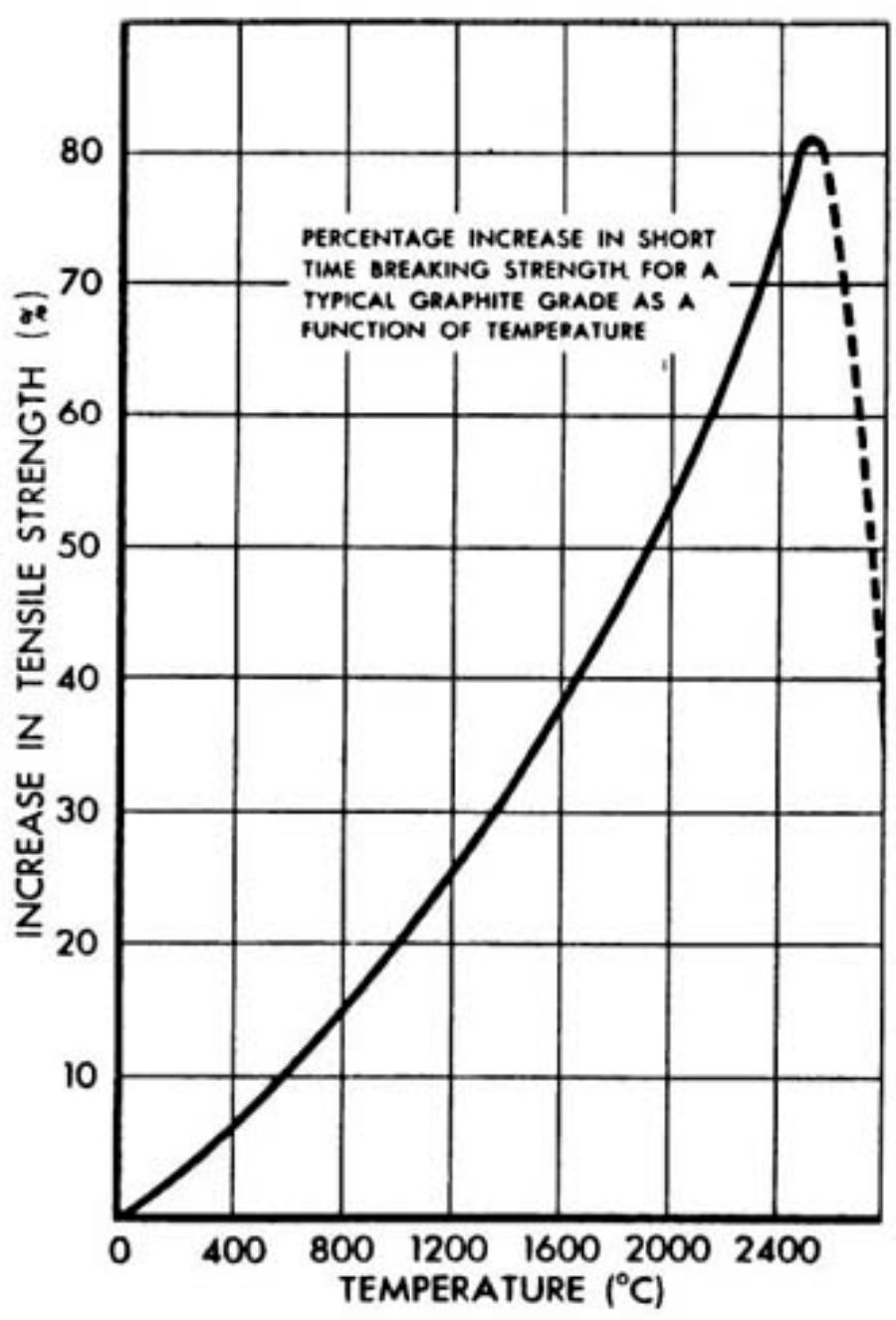

Figure 2.6 Graphite Tensile Strength as a Function of Temperature (Mantell, 1979)

Synthetic graphites and other carbon composites are frequently classified as isotropic and anisotropic. This topic demands a discussion of those properties and how they are used in the carbon materials industry.

\subsection{Isotropic Versus Anisotropic Carbon Material}

"Carbon materials are, in general, a mixture of well-ordered material, often short range $(<100 \mathrm{~nm})$, surrounded by less-ordered material (Marsh, 1989)." The anisotropy is often referred to as carbon with a higher degree of order. Similarly, isotropic carbons are regarded as having less order. Carbon materials and subsequent artifacts are, in large 
part, a combination of ordered structures and less ordered structures. The degree of order as well as the amount of ordered carbon at the scale of interest will be indicative of the relative isotropic or anisotropic properties of the material (Marsh, 1989).

\subsubsection{Isotropic Carbon}

"Isotropic carbon is a monolithic carbon material without preferred crystallographic orientation of the microstructure (Fitzer, 1995)." Materials are considered isotropic if the bulk material properties are isotropic for the intended application.

\subsubsection{Anisotropic Carbon}

The degree of the ordered carbon is a measure of anisotropy. The desired anisotropy varies with application. In aerospace graphite, the bulk isotropic properties are obtained through random orientation of the graphitic structures (Fitzer, 1995). Carbon electrodes for the steel industry require highly graphitic coke known as needle coke or acicular coke. Needle coke is highly anisotropic and identified by its parallel grain structure which is strongly oriented as seen in Figure 2.7. The needle like structures is obtained when the coke is ground to be used as filler for carbon electrodes. 


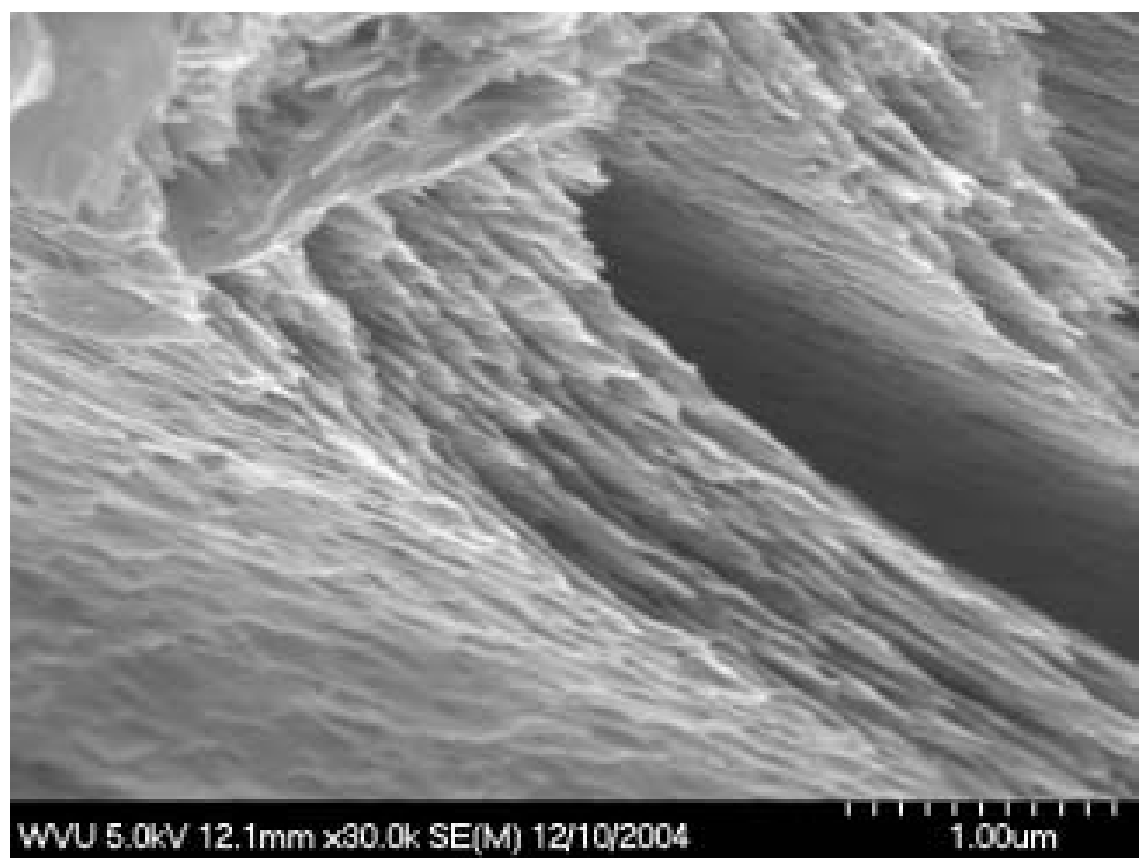

Figure 2.7 SEM Micrograph of Calcined Needle Coke

Dr. Rosalind Franklin, using x-ray diffraction (XRD), discovered a relationship between interlayer spacing of carbon structure and the degree of order for the carbon material.

\subsection{Pitch}

Graphitic carbon is typically produced using precursor material known as pitch. The International Union of Pure and Applied Chemistry (Fitzer, 1995), lists the definition of pitch as " ... a residue from pyrolysis of organic material or tar distillation which is solid at room temperature, consisting of a complex mixture of numerous, essentially aromatic hydrocarbons and heterocyclic compounds. It exhibits a broad softening range instead of a defined melting temperature. When cooled from the melt, pitches solidify without crystallization."

The softening of the material is defined at a temperature at which the pitch is liquid enough to be drawn through an orifice by gravity. This testing procedure is described as the Mettler Softening Point defined in ASTM Standard D3104-99. There 
are many methods that pitch may be characterized. Table 2.1 shows a list of standard methods used by Koppers Inc. to characterize and classify pitch. There are other methods and constituents that can be tested for experiment specific needs.

Table 2.1 Pitch Classification and Characterization Test Method (McHenry, 1998)

\begin{tabular}{|l|c|}
\hline \multicolumn{2}{|c|}{ Standard Pitch Testing Methods } \\
\hline \multicolumn{1}{|c|}{ Property } & Test Method \\
\hline Softening Point (SP), ${ }^{\circ} \mathrm{C}$ & ASTM D-3104 \\
\hline Toluene Insoluble (TI), wt.\% & ASTM D-4072 \\
\hline Quinoline Insoluble (QI), wt.\% & ASTM D-2318 \\
\hline$\beta$-resin, wt.\% & (TI-QI) \\
\hline $\begin{array}{l}\text { Modified Conradson Carbon } \\
\text { (MCC), wt.\% }\end{array}$ & ASTM D-2416 \\
\hline Alcan Coking Value (ACV), wt.\% & ASTM D-4715 \\
\hline Ash, wt.\% & ASTM D-2415 \\
\hline Sulfur, wt. $\%$ & Leco* \\
\hline Relative Density, $25^{\circ} \mathrm{C} / 25^{\circ} \mathrm{C}$ & ASTM D-71 \\
\hline Viscosity, cps & ASTM D-5018 \\
\hline Distillation to $360^{\circ} \mathrm{C}$ wt. $\%$ & ASTM D-2469 \\
\hline Metals, ppm & AA** \\
\hline * Leco Sulfur Analyzer & \\
\hline ** Atomic Absorption Spectroscopy & \\
\hline
\end{tabular}

One of the classic analyses used to classify pitch used in this research is proximate analysis. Proximate analysis is a multiple step method to determine the weight percent of coal and/or pitch constituents. The weight of the sample material is measured as it is heated to $105^{\circ} \mathrm{C}$. The weight change is attributed to water or moisture. The sample is then pyrolized at $800^{\circ} \mathrm{C}$ in an oxygen free atmosphere to remove the volatile matter. The remaining material is termed fixed carbon. Heating the sample to $750^{\circ} \mathrm{C}$ with oxygen combusts the remaining carbon and leaves inorganic matter coined ash.

The ability of a coal or pitch to form a graphitic material is, in part, dependant upon the heteroatoms in the material. Heteroatoms are essentially any atom that is not 
carbon or hydrogen. In the manufacture of carbon artifacts, nitrogen, and sulfur are of the greatest concern. The reactivity of the heteroatoms limit or alter the reorganization of the carbon structure during carbonization. Due to these undesirable effects, ultimate analysis is conducted on feedstock materials. Ultimate analysis through a series of analytical techniques is able to determine the weight percent of carbon, hydrogen, nitrogen, oxygen, and sulfur.

\subsection{Synthetic Pitch}

By condensing or polymerizing cyclic or aromatic compounds, synthetic pitch can be formed. The advantage of this procedure is that the feed material can be controlled and the pitch produced has a smaller range of molecules. Its chemistry is much more uniform than with natural pitches. Further this enables the production of a binder pitch that meets restrictive measures of heteroatoms.

\subsection{Petroleum Pitch}

Petroleum pitch is produced as a by-product of thermal cracking or distillation of petroleum. The heavier fractions can be further processed to produce pitch by distillation, steam stripping, heat treatments, oxidation, or some combination of the fore mentioned (Marsh, 1989). Because of the chemistry petroleum pitches tend to be more aliphatic in nature. It tends to be more turbostratic and so form mesophase with larger domains.

\subsection{Coal-Tar Pitch}

Coal tar pitches are formed by distillation of the tar produced during carbonization of coal in coke batteries. "Coal tar pitch is a residue produced by distillation or heat treatment of coal tar. It is a solid at room temperature, consists of a 
complex mixture of numerous predominantly aromatic hydrocarbons and heterocyclics, and exhibits a broad softening range instead of a defined melting temperature (Fitzer, 1995)." Koppers Inc. is a world wide leader in coal tar pitch production. Coal tar pitch is used as the adhesive or binder in the manufacture of nearly all carbon composite materials. Because it has appreciable quantities of quinoline insolubles (QI) when coal tar pitch is calcined very little mesophase is produced. Therefore, it produces isotropic graphite. When the QI's are removed to less than $2.5 \mathrm{wt} \%$, then mesophase can be produced and more anisotropic graphite can be produced (Manganaro, 1971).

\subsection{Coal-Derived Pitch}

Pitches can be obtained from coal more directly. Using solvent extraction of coal or a coal residue, a suitable coal-derived pitch can be made (Bennet, 2000). The fluidity of the pitch and anisotropy of the coke produced by thermal decomposition of the pitch can be enhanced by a hydrogenation process. Researchers at the Chemical Engineering Department of West Virginia University have manufactured batches of this pitch for carbon material research. Because the pitch has almost no QI's and is very fluid, when it is thermally processed it produces anisotropic graphite. It is not commercially produced but is a very interesting material.

\subsection{Formation of Coke from Mesophase Growth during Carbonization}

The production of anisotropic graphite is due primarily to the growth of mesophase in the liquid phase produced during thermal processing of pitches. Therefore it is imperative that some knowledge of the mesophase process be discussed here. As discussed earlier, pitch is thermally devolatilized and essentially carbonized into coke. When the pitch is slowly heated in an inert atmosphere, it reaches a broad softening 
temperature range and eventually becomes very fluid. During this fluid state of devolatilization, the pitch is enabled to reorganize the discotic structures (disc-like) or large planar molecules to form coke. Without the fluid state, the material would not be able to reorganize and would devolatilize to a char.

As the thermal treatment approaches $660 \mathrm{~K}$, the discotic structures tend to agglomerate into spherical groups which are known as mesophase (Marsh, 1989). While forming the liquid crystalline state of the mesophase the discotic structures stack into a lamellar arrangement. The large discotic molecules, known as mesogens, may be randomly oriented in the isotropic pitch fluid until the mesophase domain grows to assimilate the mesogens or until carbonization occurs coking the structure solid. This process is shown in Figure 2.8.

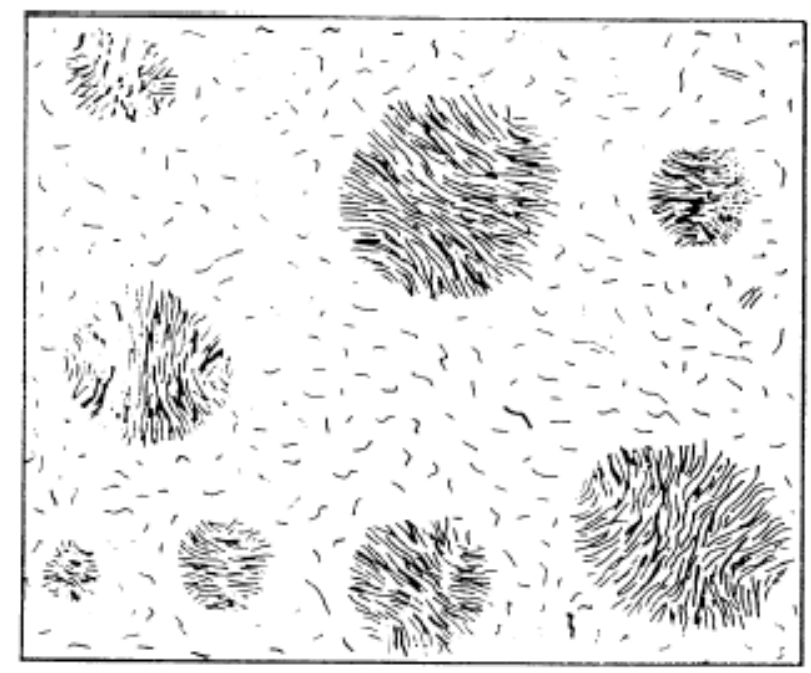

Figure 2.8 Mesogens and Mesophase Domain Formation in a Pitch Matrix while Carbonizing (Marsh, 1989)

The mesophase may coalesce until the entire material is a continuous domain of mesophase. As the heat treatment continues, the mesophase formation and domain growth cause an increase in viscosity. The viscosity will continue to increase until a temperature around $500^{\circ} \mathrm{C}$ is achieved (Marsh, 1989). At around this temperature the 
mesophase will form coke. The actual temperature that yields coke formation is dependant upon the constituents of the pitch.

Often while the mesophase is coalescing, the lamellar orientation does not align much like two ice crystals growing into each other. The molecules attempt to restructure while being drawn back into a spherical structure. The bending and twisting of the lamellar structure can be seen in Figure 2.9.

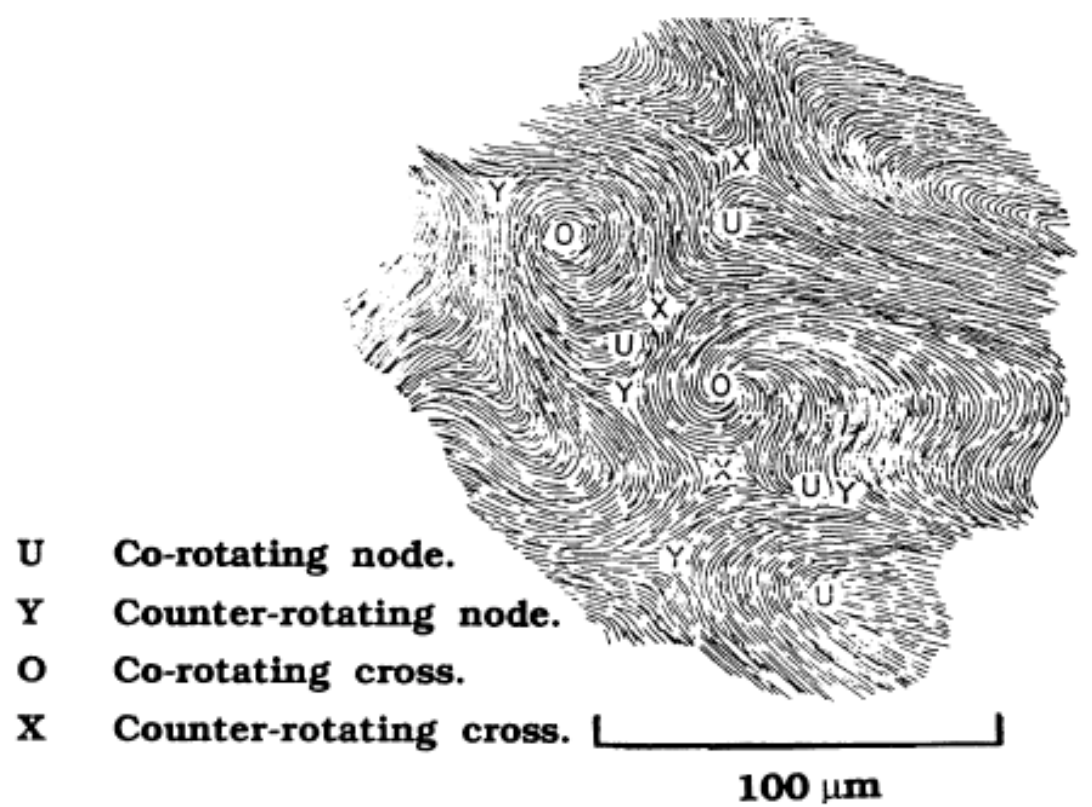

Figure 2.9 Lamellar Form of Coalesced Mesophase Observed by Optical Microscopy (Marsh, 1989) The formation of various lamellar structures is a result of the agglomeration of mesophase. An illustration was made by Brooks and Taylor in Figure 2.10 as two mesophase spherules coalesce. 

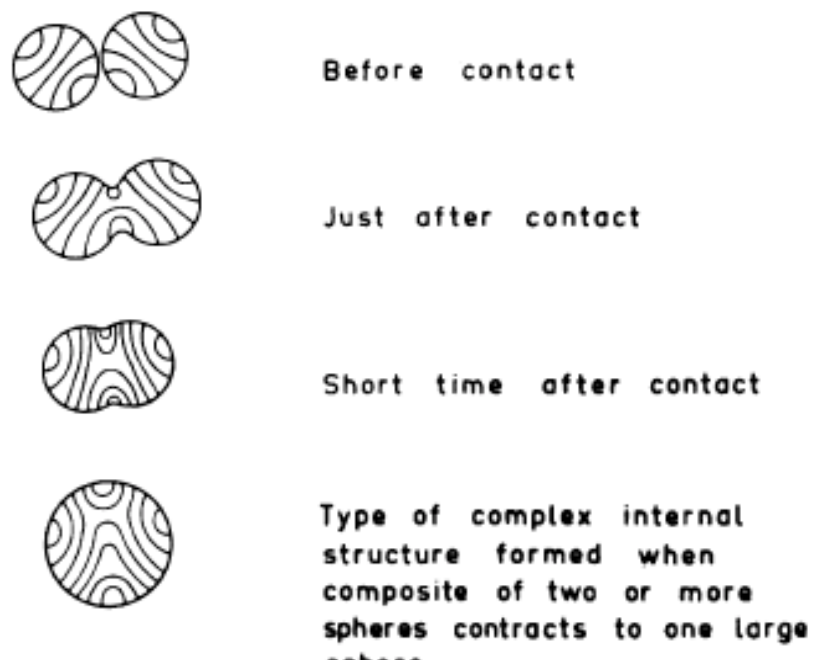

Figure 2.10 Simple Mesophase Coalesces (Brooks and Taylor, 1968)

Increased carbonization temperatures cause crystalline growth, further devolatilization as well as an increase of the pitch viscosity. This viscosity was characterized as seen in Figure 2.11.

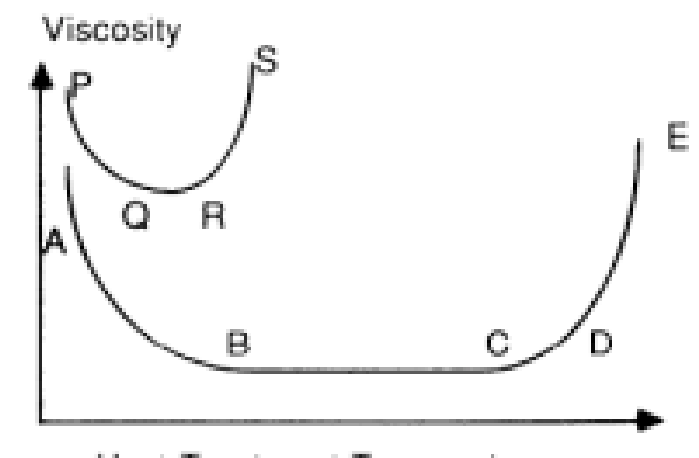

Heat Treatment Temperature

Figure 2.11 Viscosity as a Function of Carbonization Temperature of Pitch (Marsh, 1989)

The top curve represents a typical natural pitch, while the bottom curve represents a synthetic, highly aromatic, relatively homogeneous pitch. Initially, as temperature increases viscosity drops as the pitches become more fluid (PQ and AB). The viscosity then has a minimal value $(\mathrm{QR}$ and $\mathrm{BC})$ until further devolatilization occurs and causes 
crystalline formation (RS and DE). It is during the curve segments of QRS and BCDE that the research of this thesis will be focused. Pitches that follow the PQRS curve tend to form small anisotropic domains oriented in a mosaic, whereas, the ABCDE curve tends to produce large anisotropic domains (Marsh, 1989).

Carbonization can be effected by many factors such as pressure, agitation, temperature, temperature rate, and inert gas sparging. These factors are difficult to study due to the inherent variable interdependence. Sparging, or bubbling an inert gas through the fluid pitch will agitate the pitch as well as increase the rate of devolatilization (Marsh, 1989). Pressure reduces the rate of devolatilization (Marsh, 1989). The rheology is affected by agitation, and promotes coalescence of mesophase (Marsh, 1989).

Mesophase and mesophase domain growth is of primary interest for the development of anisotropic regions in coke. Mesophase growth will be limited if the pitch contains more than $2.5 \%$ quinoline-insoluble material $(\mathrm{QI})$ as the forming spherules are encompassed by particles (Manganaro, 1971). Pitches are identified by their constituents in order to characterize and predict their behavior and ability to produce quality coke.

Mesophase is characterized by optical microscopy using polarized light. Skilled petrographers can identify and measure the amount of mesophase in pitches as well as characterize it. The measurements are based upon the dimensions of the domains or regions. Table 2.2 lists a system for classifying mesophase. 
Table 2.2 Mesophase Classification by Optical Microscopy Properties (Marsh, 1989)

\begin{tabular}{|c|c|c|}
\hline Binder Phase & Width (in Microns) & $\begin{array}{l}\text { Length (L) to Width (W) } \\
\text { Relation }\end{array}$ \\
\hline Isotropic & 0.0 & None \\
\hline Incipient (anisotropic) & 0.5 & $\mathrm{~L}=\mathrm{W}$ \\
\hline \multicolumn{3}{|l|}{ Circular (anisotropic) } \\
\hline Fine circular & $0.5-1.0$ & $\mathrm{~L}=\mathrm{W}$ \\
\hline Medium circular & $1.0-1.5$ & $\mathrm{~L}=\mathrm{W}$ \\
\hline Coarse circular & $1.5-2.0$ & $\mathrm{~L}<2 \mathrm{~W}$ \\
\hline \multicolumn{3}{|l|}{ Lenticular (anisotropic) } \\
\hline Fine lenticular & $1.0-3.0$ & $\mathrm{~L} \geq 2 \mathrm{~W}, \mathrm{~L}<4 \mathrm{~W}$ \\
\hline Medium lenticular & $3.0-8.0$ & $\mathrm{~L}>2 \mathrm{~W}, \mathrm{~L}<4 \mathrm{~W}$ \\
\hline Coarse lenticular & $8.0-12.0$ & $\mathrm{~L}>2 \mathrm{~W}, \mathrm{~L} \leq 4 \mathrm{~W}$ \\
\hline \multicolumn{3}{|l|}{ Ribbon (anisotropic) } \\
\hline Fine ribbon & $2.0=12.0$ & $\mathrm{~L}>4 \mathrm{~W}$ \\
\hline Medium ribbon & $12.0-25.0$ & $\mathrm{~L}>4 \mathrm{~W}$ \\
\hline Coarse ribbon & $25.0+$ & $\mathrm{L}>4 \mathrm{~W}$ \\
\hline
\end{tabular}

\subsection{Coke Processes}

Because this research concerns the process of making coke it is appropriate to review the commercial coking process practiced by the current carbon industry. Coke, as described in this work, is primarily formed through pyrolytic reactions. Pyrolysis is the chemical decomposition of organic material by elevated temperatures in a non-oxidizing environment. Pyrolytic reactions are used industrially to produce coke. Needle coke is commercially produced by delayed coking. Metallurgical coke is produced with coke ovens using coal (Gallaher, 2002). 


\subsubsection{Delayed Coker}

Liquid fuels such as gasoline and diesel are thermally cracked from heavy fractions of petroleum in delayed cokers. Shot, sponge, and needle coke are produced in the large coke drums from pyrolytic distillation of petroleum. The system preheats the petroleum residuum and then pumps it into the coke drums to allow for slow devolatilization and subsequent coking. It is believed that the texture of the needle coke is formed from the stresses induced by volatile gases venting through the coking resids (Ellis, 2000). The economic demand for petroleum fuels is so great, that the primary purpose for delayed coking is to recover the fuel oils despite the 500 USD per ton price of premium needle coke (The Carbon Products Industry Vision for the Future). An illustration of the formation of coke in a delayed coker was presented by Great Lakes Carbon is seen in Figure 2.12. 


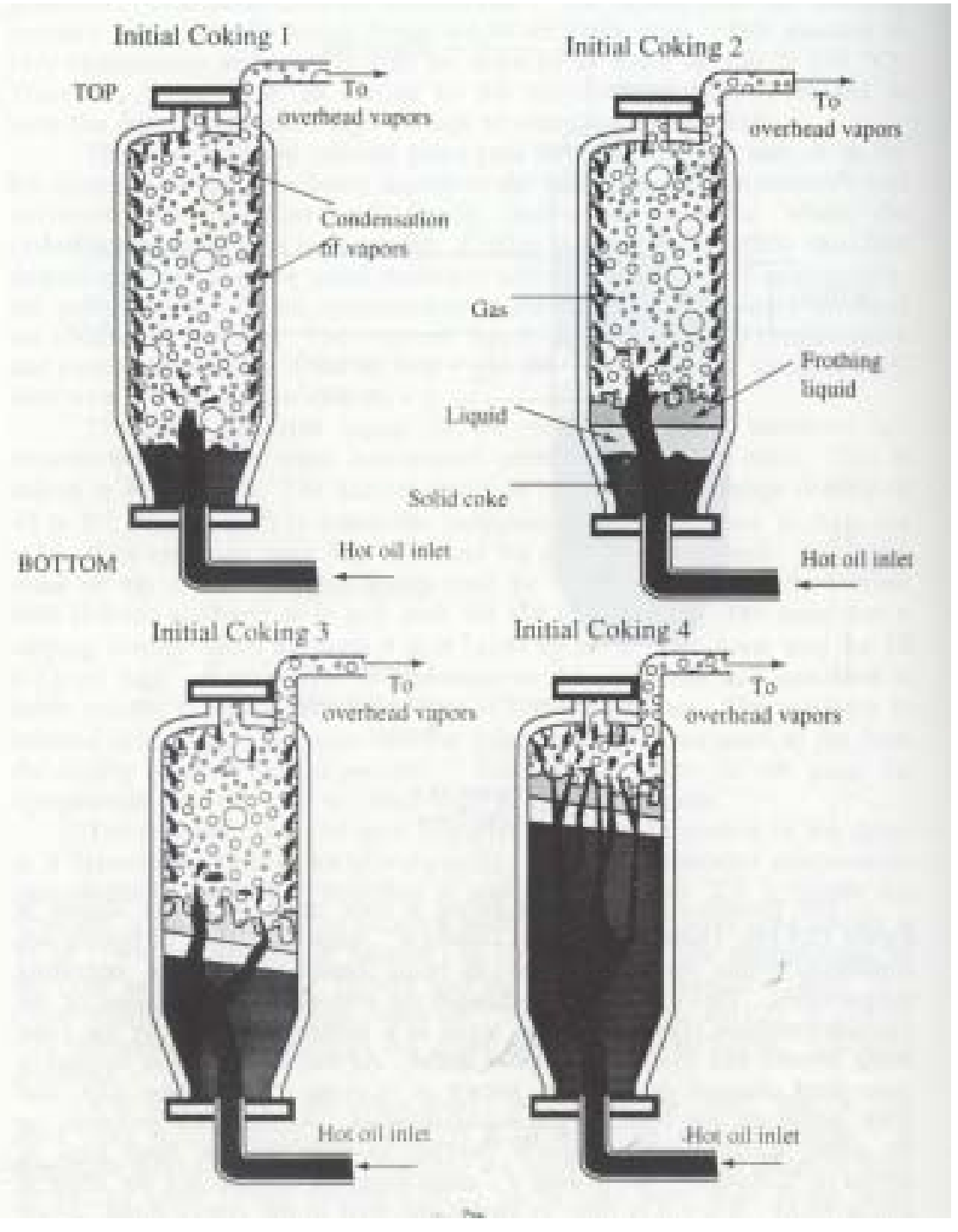

Figure 2.12 Formation of Coke in a Delayed Coking Drum. (Marsh, 1989)

From the illustration in Figure 2.14, in the first drum the initial stage of delayed coking is shown. The liquid petroleum residuum is pumped into the coke drum at carbonizing temperatures. The volatile vapors quickly expand into the drum. The heavier fractions condense in the drum while the lighter vapor fractions are recovered at the top for distillation of fuel oil. The second drum illustration shows the boiling residuum flowing into the drum. The coke forms once sufficient devolatilization occurs. As more solid coke forms the drum begins to contain a slurry of coke, molten petroleum 
resids, and devolatilized gases as seen in the third drum. The gases form channels in the coke as it separated due to density differences. As seen in the fourth and final drum the coke nearly fills the drum with a small head space for the remaining volatile vapors. There have been studies that show that the gas channels in the forming coke produce the anisotropic properties of the coke.

\subsubsection{Coke Oven}

Metallurgical coke, or "met coke", is produce by the pyrolytic devolatilization of coal in coke ovens at temperatures about 1400K (Fitzer, 1995). The coke produced is often used as a filler material for polygranular carbon products such as for electrodes for blast furnaces. Coke ovens operate with a series of long chambers where coal is pyrolytically devolatilized in a bulk mass in a non-oxidizing environment. While the coal is being devolatilized the tars are recovered through condensation. These condensates are distilled to produce coal tar pitch and the gases are combusted to generate heat for the coke ovens. After the coal slowly cokes for a prescribed period of time, it is pushed out of the coking chamber to a quenching car similar to an extrusion process where it is ready for market. A schematic of a general coke oven is shown below in Figure 2.13. 


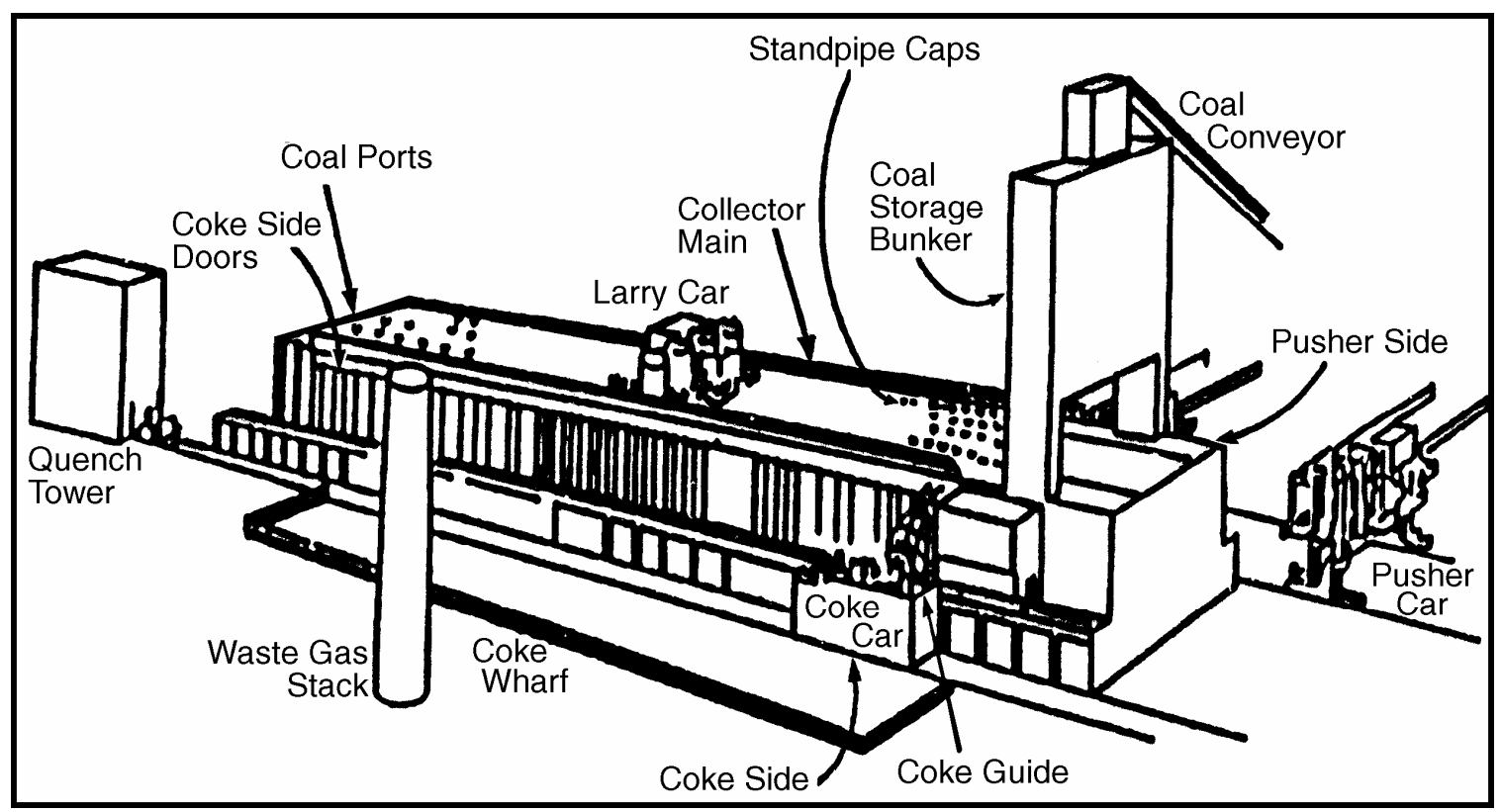

Figure 2.13 By-Product Coke Battery (Gallaher, 2002)

\subsection{Graphitic Carbon Characterization}

Because this research is going to be concerned with the anisotropic nature of cokes produced, it is appropriate to discuss the analytical procedures used to characterize cokes and graphites. The electrical and thermal properties of the coke are largely dependant upon the carbon structure. Efficiency is directly related to the anisotropy of the ordered coke and the density of the coke. These properties can be evaluated optically using polarized light microscopy. Bulk properties are quickly assessed through optical microscopy. The nano-scale properties can be observed using a scanning electron microscope (SEM). The use of electron microscopes allows the user to observe the degree of ordered carbon in dimensions that are below the optical level. Such information helps to determine if change has occurred on a finer level. Since bulk properties are desired industrially, electron microscopes serve best for research. The internal organization of the cokes can be evaluated using X-Ray diffraction techniques. 


\subsubsection{Optical Microscopy}

Optical microscopy reflects polarized light off of the lamellar carbon structure to enable identification of the orientation of the crystalline sheets with respect to the others. Light is emitted from a source and the waves pass through a polarizing plate that orients the light waves. As polarized light reflects from the specimen, the orthogonal waves pass through the retardation plate, which forms a relative phase shift of the reflected image. The image then passes through a second polarized plate, called an analyzer, which orients the light waves into a single plane to be viewed. This is depicted in Figure 2.14.

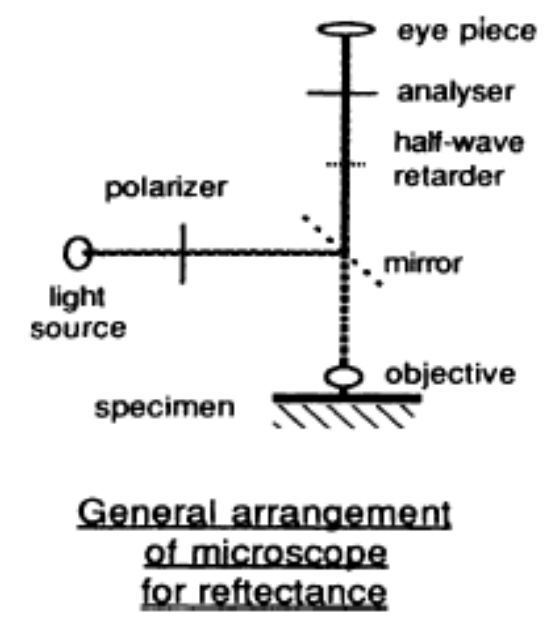

Figure 2.14 Polarized Light Microscopic Optical Arrangement (Marsh, 1989)

Anisotropic and isotropic domains can be identified, characterized, quantified based on size, shape, and color of the isochromatic regions (see Table 2.3 for size and descriptions). The color is related to the orientation of the crystalline planes. Blue and yellow hues are an indication of a plane edge. Purple hues indicate that the planes are parallel to the optical viewing direction. The purple hues do not change color when the specimen is rotated because the angle of the plane does not change with respect to the optical plates. The purple hue can also be an isotropic region though identified by a lighter color than the anisotropic graphene sheets (Marsh, Smith, 1978). The blue and 
yellow hues do change color as the specimen is rotated and completely reverse when the specimen is rotated $180^{\circ}$ or if the half wave retarder plate is reversed (Marsh, 1989). The planar orientation with respective to the birefringent hues can be see in Figure 2.15.
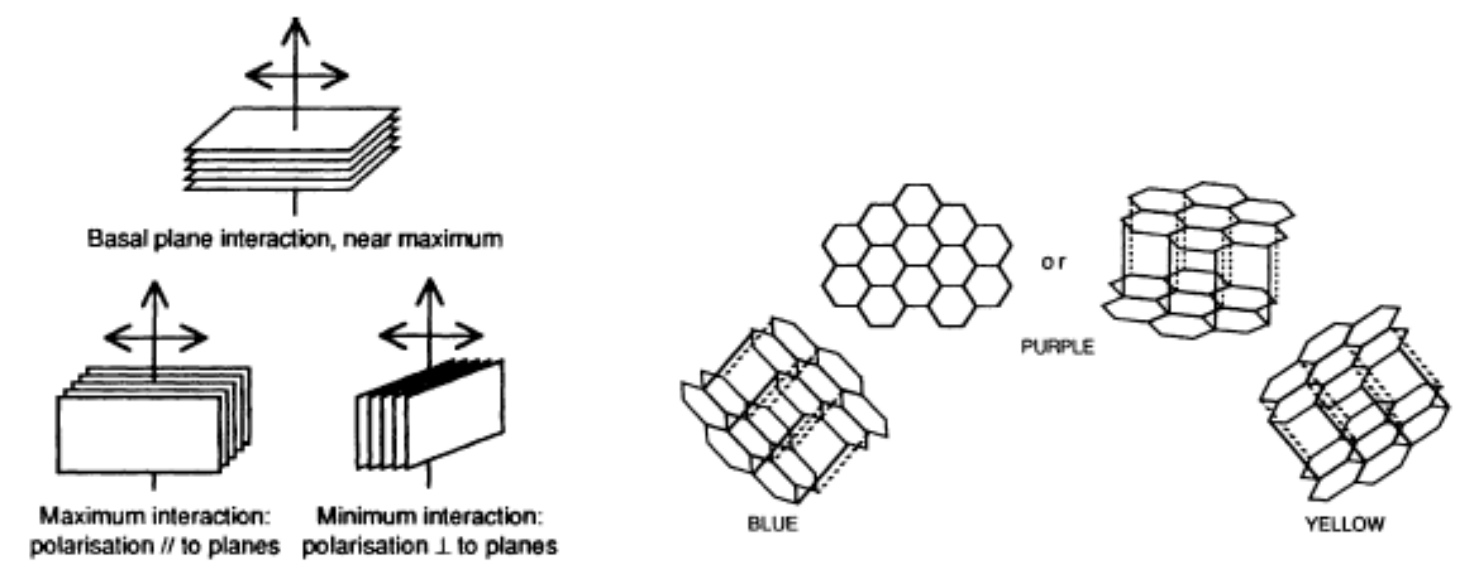

Figure 2.15 Interference Hues from Reflected Light on Graphene Planes (Marsh, 1989) 
Table 2.3 Classification of Optical Texture (Marsh, 1989)

\begin{tabular}{|c|c|c|}
\hline Name & Abbreviation & Description \\
\hline Isotropic & I & No optical activity \\
\hline Very fine-grained mosaics & VMF & $<0.5 \mu \mathrm{m}$ in diameter \\
\hline Fine-grained mosaics & Mf & $<1.5>0.5 \mu \mathrm{m}$ in diameter \\
\hline Medium-grained mosaics & Mc & $<10.0>5.0 \mu \mathrm{m}$ in diameter \\
\hline Supra mosaics & SM & $\begin{array}{l}\text { Mosaics of anisotropic carbon } \\
\text { orientated in the same direction to give a } \\
\text { mosaic area of isochromatic color. }\end{array}$ \\
\hline $\begin{array}{l}\text { Medium-flow anisotropy } \\
\text { elongated }\end{array}$ & MFA & $<30 \mu \mathrm{m}$ in length; $<5 \mu \mathrm{m}$ in width \\
\hline $\begin{array}{l}\text { Coarse-flow anisotropy } \\
\text { elongated }\end{array}$ & CF & $\begin{array}{l}<60>30 \mu \mathrm{m} \text { in length; } \\
<10>5 \mu \mathrm{m} \text { in width }\end{array}$ \\
\hline $\begin{array}{l}\text { Acicular flow domain } \\
\text { anisotropy }\end{array}$ & AFD & $>60 \mu \mathrm{m}$ in length: $<5 \mu \mathrm{m}$ in width \\
\hline $\begin{array}{l}\text { Flow domain anisotropy } \\
\text { elongated }\end{array}$ & FD & $>60 \mu \mathrm{m}$ in length; $>10 \mu \mathrm{m}$ in width \\
\hline Small domains, isochromatic & SD & $<60>10 \mu \mathrm{m}$ in diameter \\
\hline Domains, - isometric & $\mathrm{D}$ & $>60 \mu \mathrm{m}$ in diameter \\
\hline
\end{tabular}

\subsubsection{Scanning Electron Microscopy (SEM)}

"Scanning electron microscopes are used to obtain good resolution, high magnification images of material surface morphology" (Bennet, 2000). There are two forms of electron microscopes, scanning electron microscope (SEM) and transmission electron microscope (TEM). The difference being that the TEM passes an electron beam through a thin sample, whereas the SEM analyses the reflected electron beam from the surface of the sample.

The SEM is essentially the same configuration as an optical microscope in that, it displays the reflective image of the surface based on the crystalline configuration. The 
difference being the medium used to observe the surface morphology. Optical microscopes use radiant light waves, whose wavelength limits optical resolution to 0.2 micron. Electron microscopes use an electron beam which can enable images to be seen of materials less than one angstrom.

\subsubsection{X-Ray Diffraction}

Crystalline materials can be studied using $\mathrm{x}$-ray diffraction (XRD). Refracting an $\mathrm{x}$-ray beam off the 3-dimensional crystalline structure, will project a pattern representative of the average crystalline structure. Material properties such as planar spacing and lattice parameters can be obtained using diffraction techniques.

\subsubsection{X-Ray Diffraction Theory}

Crystalline properties of a material can be identified using x-ray diffraction techniques. The material is subjected to the parallel waves of the x-rays, monochromatic wave XRD schematic shown in Figure 2.16. The x-rays diffract off of the crystalline planes at varying angles. The patterns of the diffracted waves are collected on a diffractogram or a detection unit. 


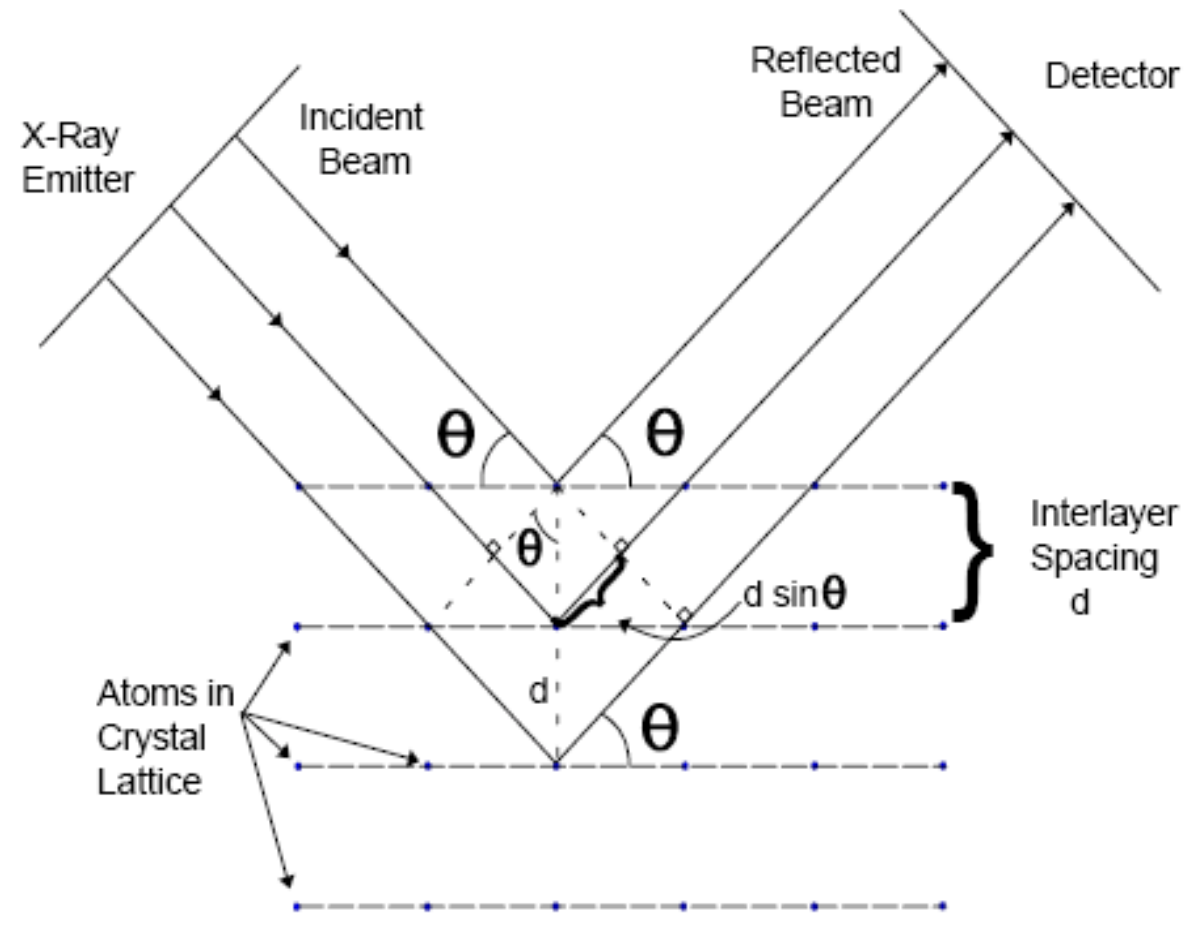

Figure 2.16 Basic X-Ray Diffraction Configuration (Callister, 1994)

The x-ray beams interact with each other after diffracting from the crystal

structure. As the beams pass through the aperture and interact, interference causes the constructive interference for beams in phase and destructive interference for those out of phase. The wave front of x-rays through an aperture is spherical (Bragg, 1975, Bennet, 2000). The interaction of the x-ray waves can be seen in Figure 2.17. 


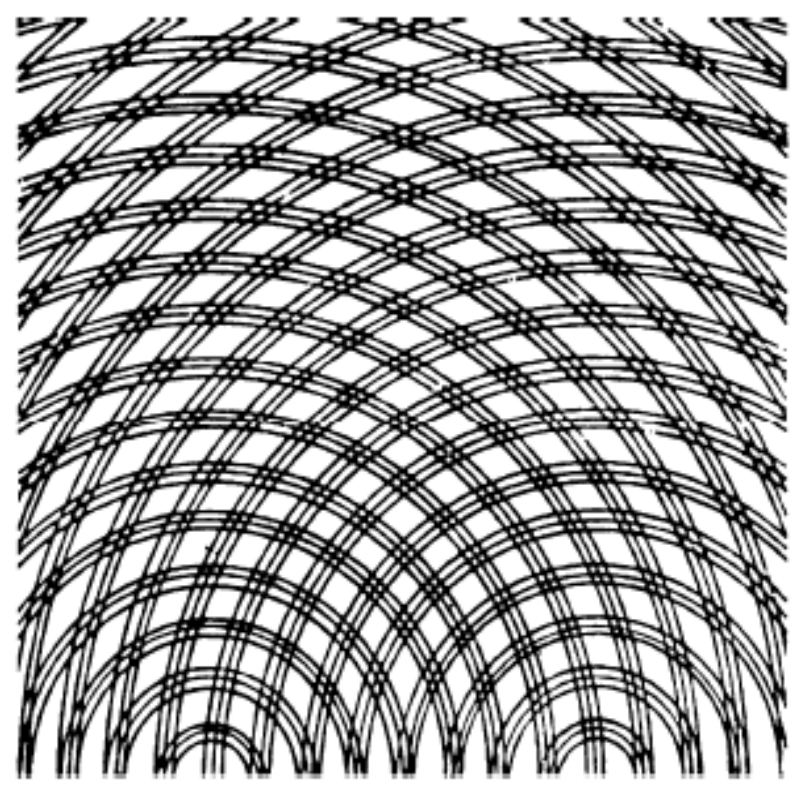

Figure 2.17 Interference of X-Rays Patterns through an Aperture (Bragg, 1975)

The interference patterns will be constructive if the distance between the lattice planes is an integral multiple of wavelength for the x-radiation employed (Bennet,2000). The mathematical representation of the interference patterns is known as Bragg's Law shown as Equation 2.1 (Bragg, 1975).

Equation 2.1 Bragg's Equation

$$
2 d^{*} \sin \theta=n \lambda
$$

Where: $\mathrm{d}=$ interplanar spacing

$\theta=$ angle of incidence of the x-ray beam

$\mathrm{n}=$ order of reflection (integer)

$\lambda=\mathrm{x}$-ray radiation wavelength $\left(1.54056 \mathrm{~A}\right.$ for copper $\left.\mathrm{K}_{\alpha 1}\right)$

\subsection{X-Ray Diffraction Techniques}

There are three common x-ray diffraction techniques - the Laue method rotating crystal, and powder diffraction (Schultz 1982, Bennet, 2000). The Laue method and the rotating crystal method require a single crystal sample. Graphite and graphitic material is 
typically polycrystalline rendering these methods inappropriate. Powder diffraction is commonly used for graphitic materials such as those in this study.

The sample is pulverized to a fine powder, and exposed to $\mathrm{x}$-ray radiation waves. The reflected waves are subsequently analyzed by intensity and diffraction angle (Bennet, 2000). The many crystals formed by the destructive pulverization of the sample cause the powder sample to be randomly oriented. It is the multiple available planes that make all the planes available for diffraction (Azaroff, 1958; Bennet, 2000). Obviously this would not be valid for single crystal methods.

Powder diffraction can be conducted photographically by using film or with an x-ray counter or detector. As the x-ray beam reflect off the randomly oriented plans of the crystalline material the beam forms a conical diffraction surface from the sample to the detector or film as seen in Figure 2.18 (Azaroff 1958, Bennet, 2000).

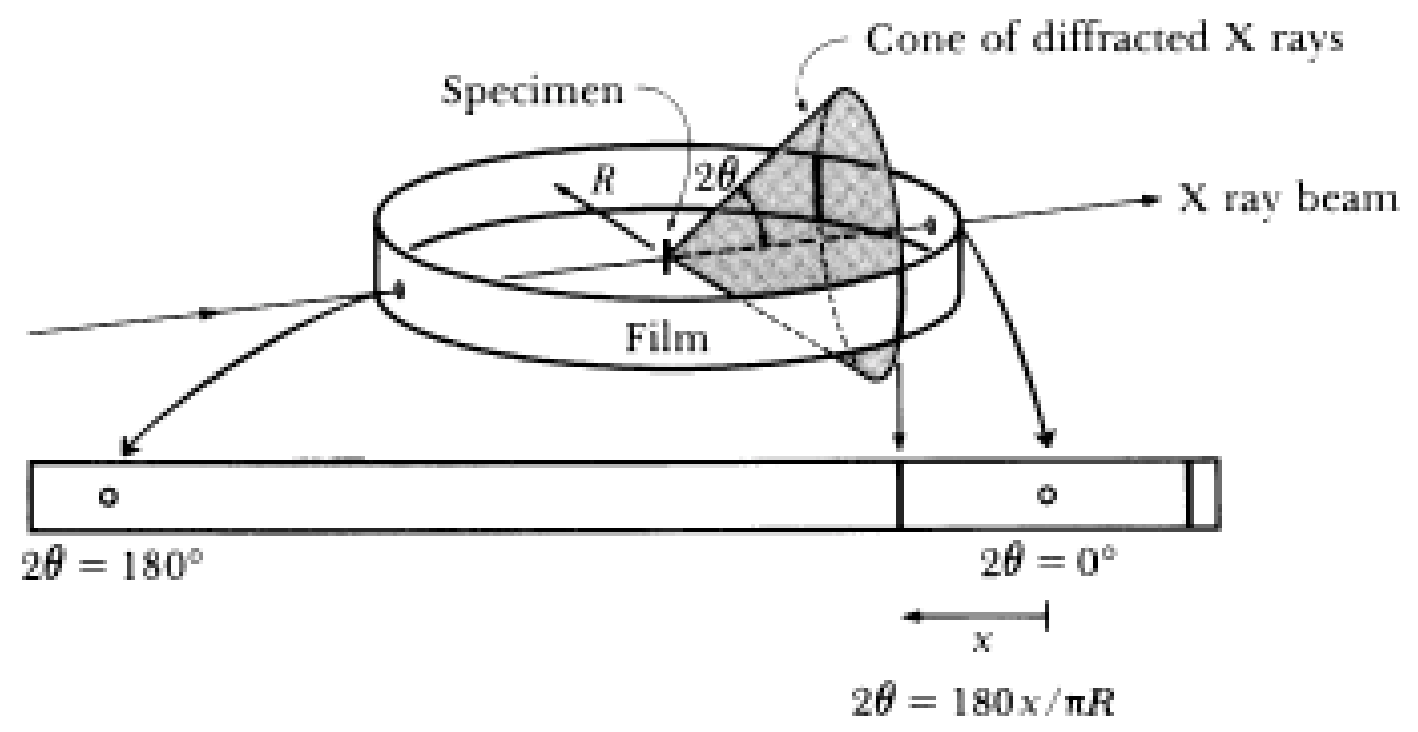

Figure 2.18 Debye-Sherrer X-Ray Diffraction Schematic (Askeland, 1958)

The Debye-Sherrer diffraction technique is the most commonly used (Bennet, 2000). The setup for this technique is shown in Figure 2.19. The $x$-ray detector/counter 
instrumentation is also referred to as the diffractometer, when the intensity of the beam is measured. This particular unit, in practice, is called a goniometer. A typical diffractogram of graphitic material can be seen in Figure 2.20.

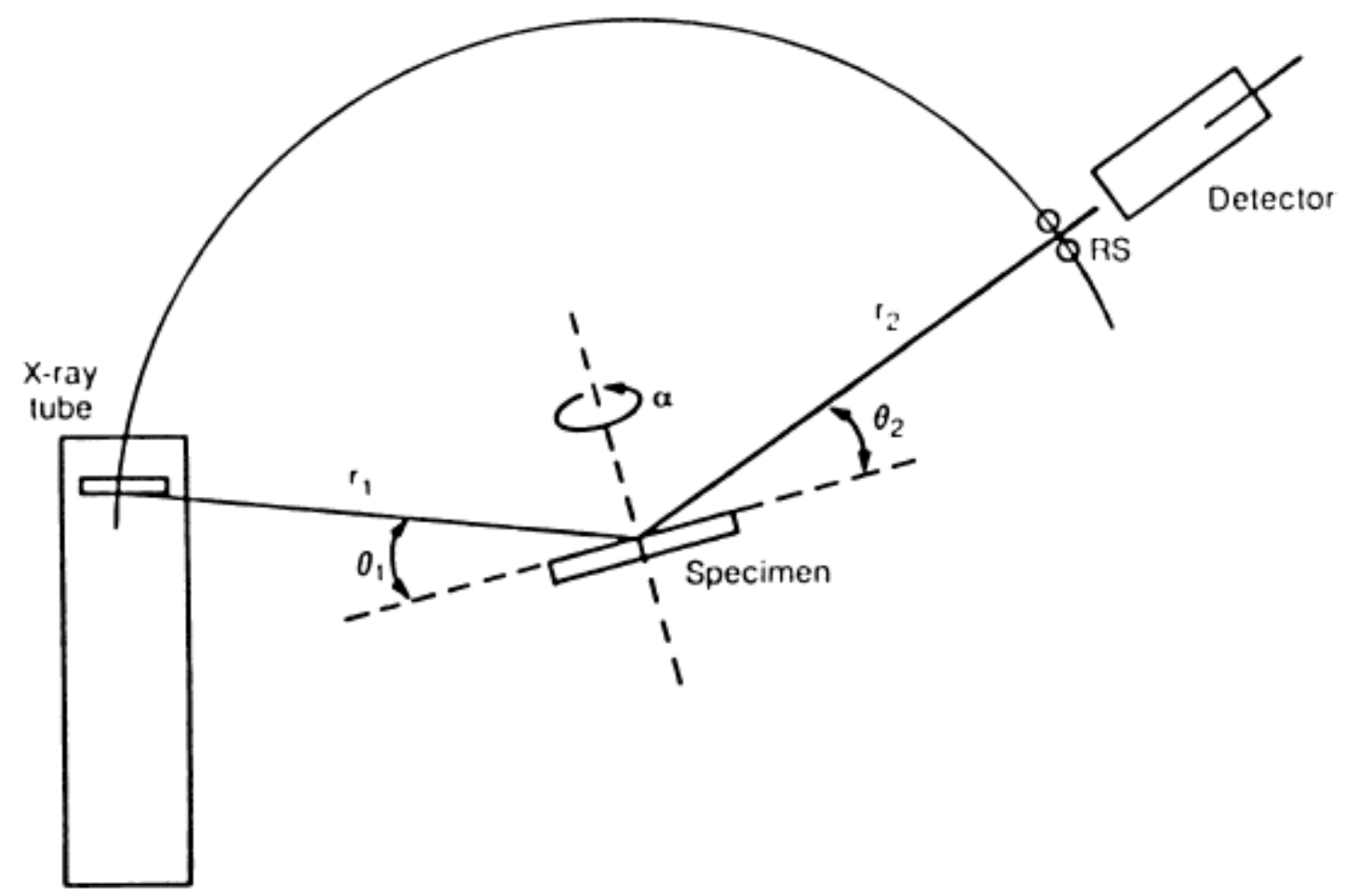

Figure 2.19 Schematic of a Powder X-ray Diffractometer (Jenkins and Snyder, 1996)

Powder diffraction is a useful technique for the characterization of crystalline substances. Much like all analysis techniques, it does have limitations. Powder diffraction is a form of destructive testing. The sample must be pulverized to be analyzed. Also, when analyzing graphite and graphitic material, the interlayer bonding is very weak with respect to the planar bonding. Thus, during the grinding process to obtain the necessary powder, the crystalline structure can be altered (Bennet, 2000). 


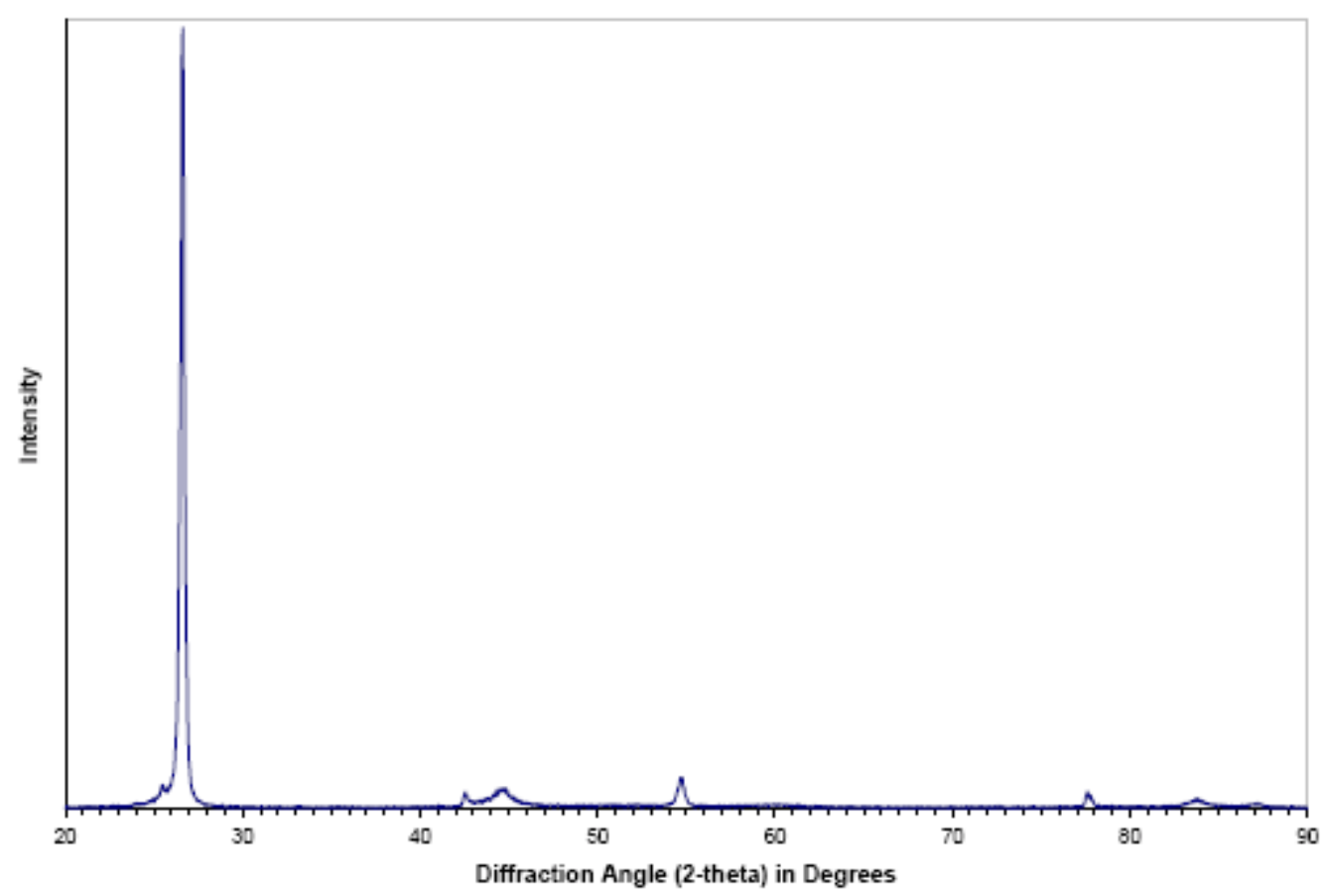

Figure 2.20 Diffractogram of Graphitic Material (Bennet, 2000)

This research involves the degree of crystallization of cokes that are not very crystalline so an analysis of the degree of crystallinity is important. Dr. Rosalind Franklin, using x-ray diffraction (XRD), discovered a relationship of interlayer spacing of carbon structure and the degree of order for the carbon material. The measure of order can be related to the d-spacing using XRD techniques. Rosalind Franklin discovered a relationship of the spacing between the graphene planes of graphite. The least ordered graphite would have a spacing of 3.44A and the most ordered graphite would show the ideal 3.354A (Franklin, 1951). Figure 2.21 shows Franklin's function of spacing as a measure of proportional disordered planes, $\mathrm{p}$, using the 002 peak of XRD analysis of graphite. The d-spacing between the layers is a function of the randomness of the alignment of the layers, as seen in Equation 1. 
Equation 2.2 Graphene Plane Spacing as a Function Proportional Disorder (Franklin, 1951)

$$
d_{(002)}=3.440-0.086\left(1-p^{2}\right)
$$

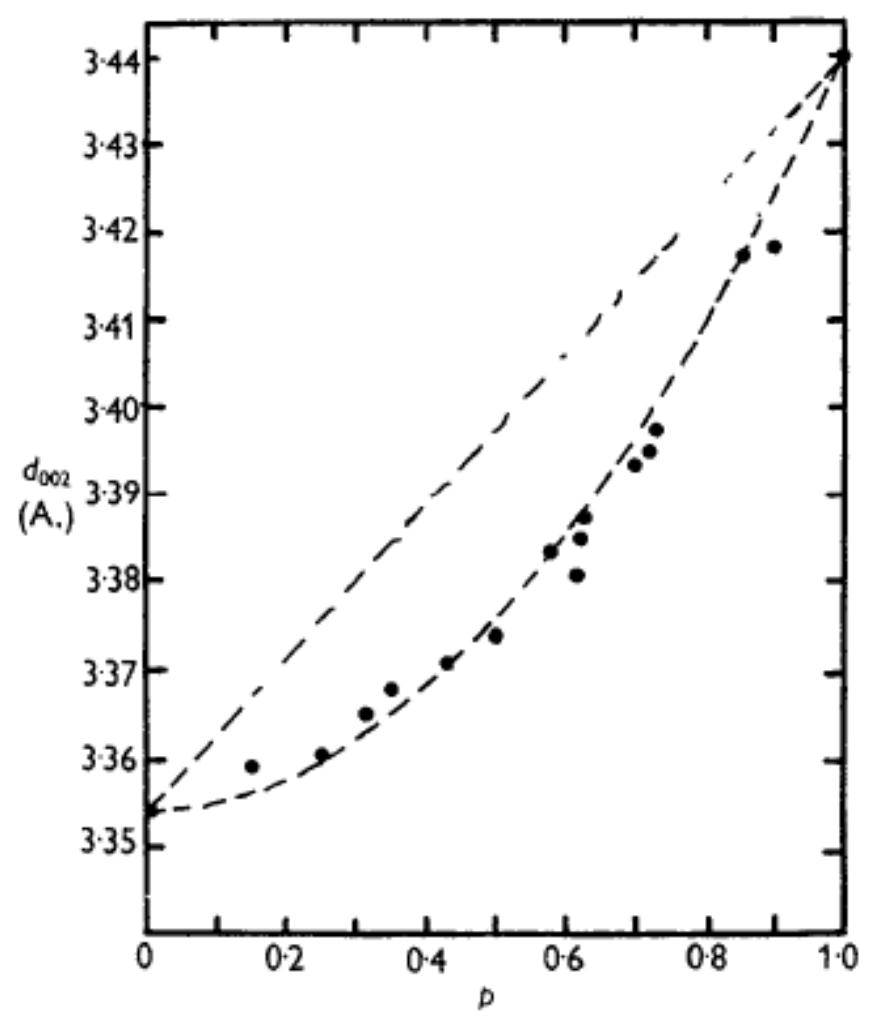

Figure 2.21 Spacing of $\mathbf{d}_{002}$ Planes as a Function of Proportional Disorder Using XRD Analysis (Franklin, 1951) 


\section{Theory}

Over the years innovation in the coke industry has been progressive and is driven by market demands. Much research has been conducted with regard to coker feedstock and thermal heat treatment, though much less publicized investigations have been made toward the mechanics of the coke development. The patent to produce needle coke by delayed coking by Shea (1956), describes the process and procedure still used today (Ellis, 2000). Hot desulfurized oil is pumped into the coking drums. During this process the thermal cracking temperature is reached but coking is "delayed" until the feedstock reaches the coke drums. In the drums hot volatile gases are emitted from the decant oil. The gases form bubbles which rise through the coking feedstock thereby stretching the coke as it begins to form. The temperature gradients as well as the internal stresses caused by the hot gases causes the coke to form oriented crystalline structures known as needle coke.

It has been proposed by Dr. Stansberry and Dr. Stiller that these mechanisms of coking can be simulated using a mechanically induced shear stress on the feedstock while coking. A preliminary experiment was conducted by Dr. Stansberry using a heated tube reactor and a hand drill. The material produced had visible indication that the stirring affected the crystalline structure. Further investigation was desired. Stansberry and Stiller desired a linear texture to the coke. So a piston cylinder mechanism was then conceived and built to rapidly coke the coal tar pitch feedstock in a one inch tube. This was done while pressing a piston and a coal tar pitch through the hot zone with a hydraulic cylinder. The use of hydraulics was chosen to overcome the adhesion of the coke to the stainless steel tube walls. This mechanism produced several samples. It was 
found that a longer coking time was required to devolatilize the material to the state of a green coke. Figure 3.1 shows an SEM image of the semicoke produced using the piston induced shear stress. It can be seen that there are oriented layers that formed parallel to one another. This differs from the leaf-like structures seen in Figure 3.2. The amorphous shape and random dispersion are indicative of an isotropic material.

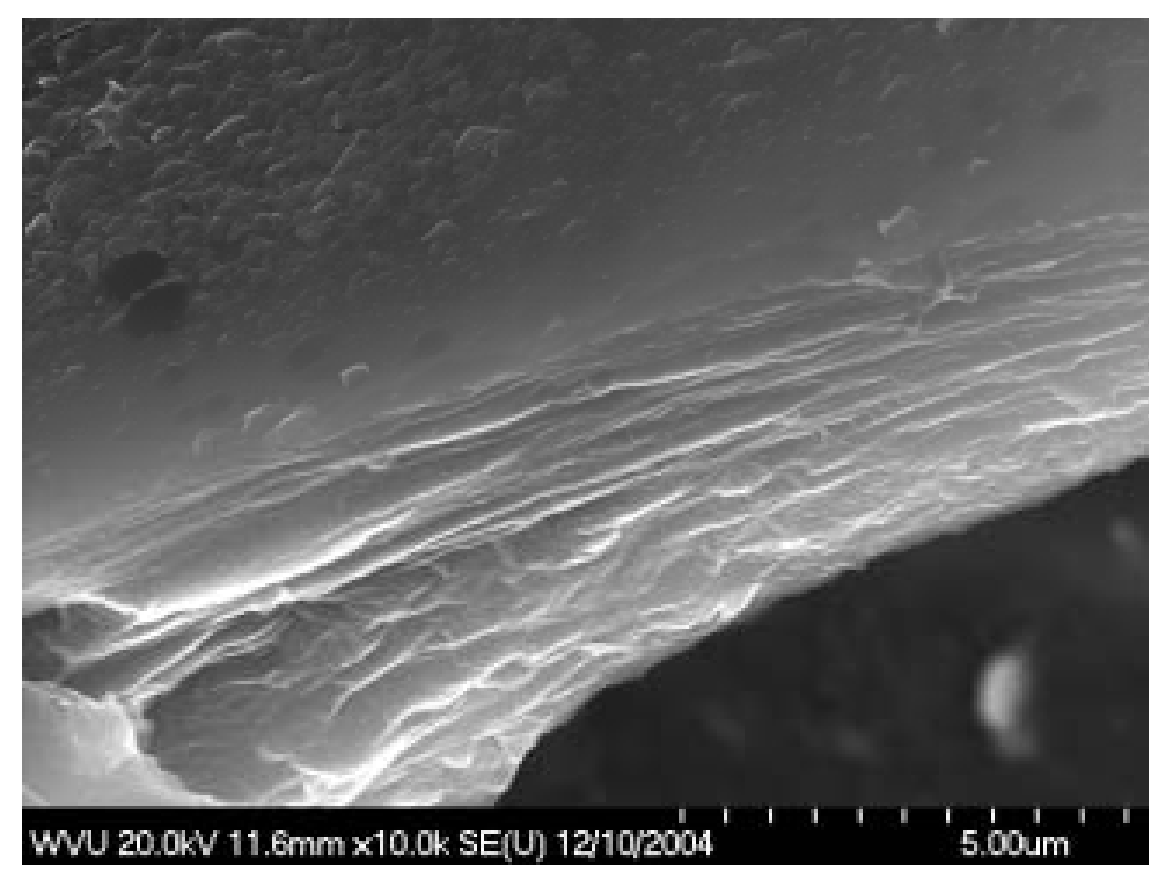

Figure 3.1 SEM Image of Oriented Coke Layers 


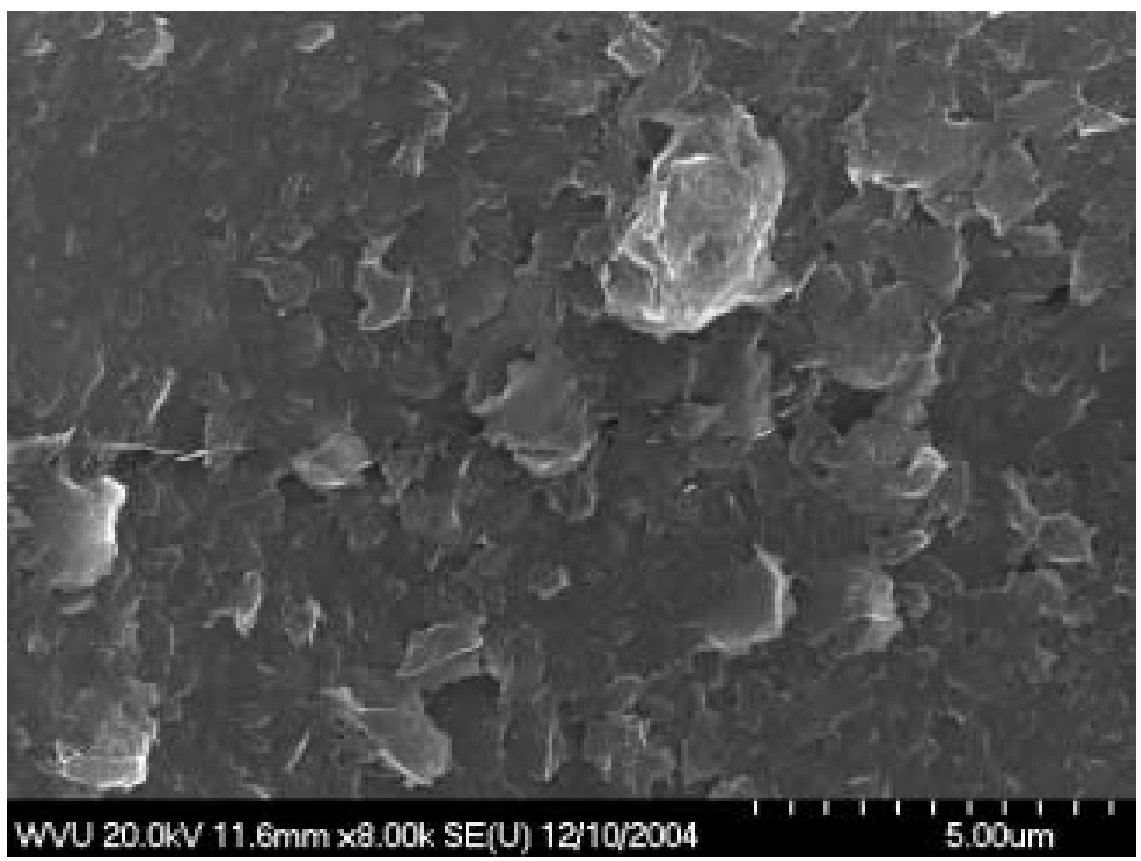

Figure 3.2 SEM Image of an Amorphous Coke Structure

The character of the structure shown in Figure 3.1 showed that the process was promoting a texture to the layers of the crystalline formation. It was obvious that a longer coking time was required, since some of the pitch was not devolatilized. A new mechanism was constructed. It consisted of a metal drum screwed onto a stirring shaft. The shaft was turned while the tube reactor was heated. This allowed for a longer coking time but did not induce a more desirable texture in the coke. Thus a mechanism was desired to continually induce a shear stress on the surface of coke formation. This lead to the design of a reactor and wiping blade described in the following chapter. 


\section{Reactor Design and Instrumentation}

Carbon is undeniably a useful material. It can be manipulated to produce a vast array of carbon products. Carbon fiber, synthetic graphite, carbon black, coal tar enamel, medication, and synthetic fuel are but a few products made from carbonaceous materials. Controlling the mechanisms that aids the formation of carbon materials is important for the production of superior carbon materials. In order to investigate induced stress on the crystallinity of pregraphitic material, a specialized reactor was desired. The small diameter of the tube reactor, used in the prior experiments, was too small for a wiping blade. Thus, a larger reactor was required.

There are many commercially available reactors that are capable of mixing at temperatures less than $600^{\circ} \mathrm{C}$, though it was decided to build a reactor specifically to meet the needs of this research. The reasons for these decisions were to add a thermocouple in the bottom of the reactor, chrome plating was desired, and removable ends allow for less destruction to coke samples during removal. In order to measure the process temperature, a thermocouple port needed to be installed in the bottom of the reactor. This would permanently change an expensive reactor. Also, a thermocouple well from the top was not a possibility since the wiper blade would rotate into it. Finally, it was found that chrome plating reduces the adhesion of coke to steel. It also limits and possibly stops the precipitation of iron from stainless steel reactor.

In an effort to reduce costs, the heater for a one liter autoclave was used. The inner diameter of the heater was 4.375 inches and the length was 8 inches. It was realized that 4 inch schedule 40 pipe $(O D=4.5 \mathrm{inch})$ would work if the outer diameter were turned down 0.125 inch. This pipe has an inner diameter of 4.026 inches. In order 
to keep construction simple, standard low pressure (150 class) slip flanges were welded on each end. The bottom was closed with a low pressure blind flange. Another blind flange was used to house a graphite bearing, nitrogen line, and a volatile line out at the top. The flange system seemed to be a good idea by incorporating standard parts. It also made possible the use of standard graphite gaskets. Figure 4.1 shows the constructed reactor. The gas lines are 0.25 inch tube compression fittings.

The shaft sized was decided to be 0.75 inch. There were two reasons for this selection. As torque sensors were compared, the $200 \mathrm{~N}-\mathrm{m}$ (148 ft-lb) capacity rotary torque sensor required a 0.75 inch shaft. This shaft size was sufficiently wide to bolt a wiper blade. It was estimated that $40 \mathrm{ft}-\mathrm{lb}$ would fracture the green coke. The estimate was based on green sponge coke initial fracture strength of $10 \mathrm{MPa}(1.45 \mathrm{ksi})$. If the wiper blade was to fracture half an inch of coke along the entire length of the 4 inch blade, approximately $40 \mathrm{ft}-\mathrm{lbs}$ would be required. The larger sensor was selected as a precaution.

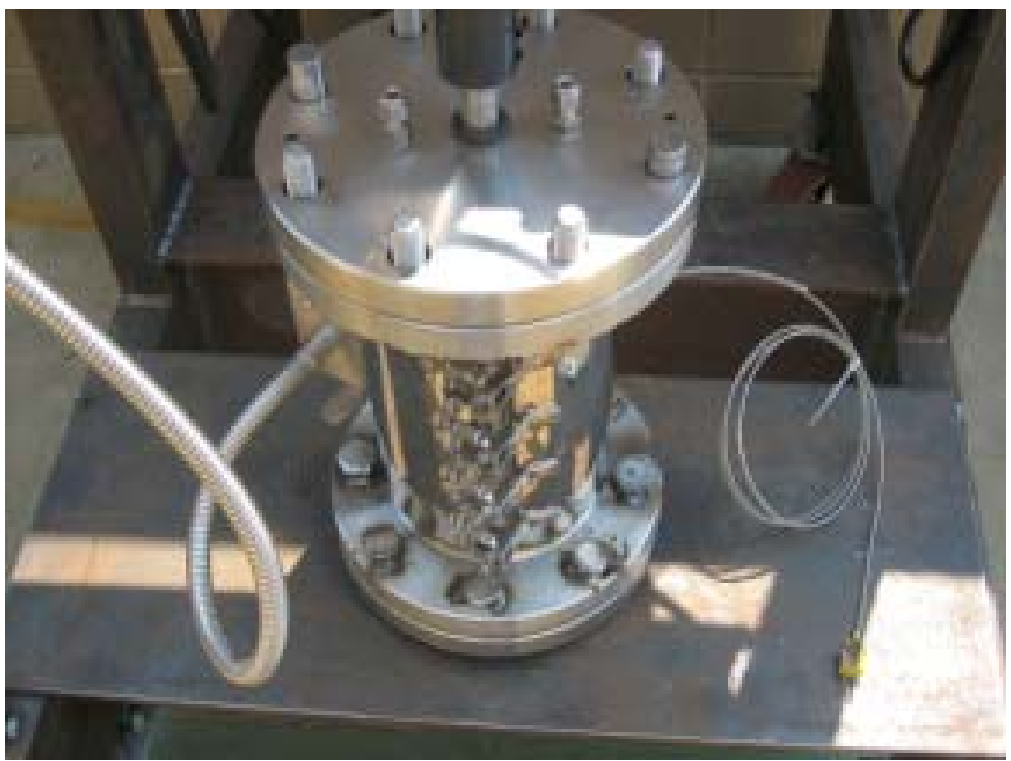

Figure 4.1 Flange Shear Coke Reactor 
It was estimated that a motor capable of variable speed and significant working torque would be required. A direct current (DC) motor was in order. For a 4 inch inner diameter reactor, and at $100 \mathrm{rpm}$, the wiper blade would travel almost 21 inches per second. There was a compromise of the motor speed and available torque. The motor found to meet the needs of the system was a Baldor DC motor. The standard equipment can be seen in Table 4.1. The motor operated at $83 \mathrm{rpm}$ and produced about $30 \mathrm{ft}-1 \mathrm{bs}$.

Table 4.1 Standard Equipment for the Shear Coker Reactor

\begin{tabular}{|c|c|c|}
\hline Instrument & Company & Part Number \\
\hline Tachometer & Monarch Instruments & ACT-3 \\
\hline Temperature Controller & Omega & Cni-844 \\
\hline Torque Sensor & Magna-Lastic Devices Inc. & A90-217502-B \\
\hline Data Aquistion & Omega & OMB-DAQ-55 \\
\hline Motor & Baldor & GPP3340 \\
\hline Heater & Industrial Heater Corp. & B-25808 \\
\hline
\end{tabular}

During the trial experiments, it was found that the flanges were a significant heat sink. This was anticipated, although not to the observed extent. The rate of heat transfer was so great that the hot zone of the reactor, at the location of the reaction, would not exceed $250^{\circ} \mathrm{C}$. After several attempts to insulate the reactor and compensate for the heat loss, it was decided that the flanges would be removed. A new reactor bottom plug was fabricated. The plug included the thermocouple compression fitting and a slotted restraining bar. The new reactor can be seen in Figure 4.2 with the process thermocouple installed. The inside of the reactor is shown in Figure 4.3. The inside reactor walls were chrome plated, but the lower plug was made of 304 stainless steel. It is obvious from the red coloring of the bottom of the reactor, that the iron was precipitating out of the solid solution during thermal treatment. This observation was most apparent after the 8 hour 
$600^{\circ} \mathrm{C}$ oxidizing pyrolysis reaction used to remove residual carbon deposits. There was no observed iron oxide on chrome surfaces.

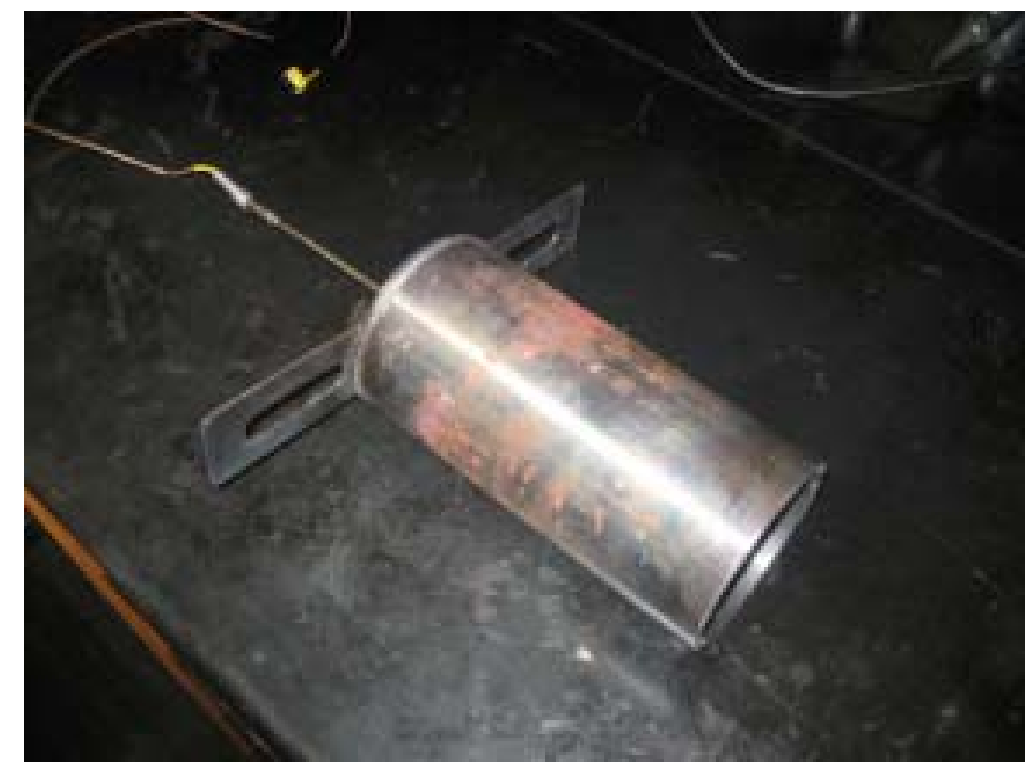

Figure 4.2 Shear Coke Reactor after Final Modifications

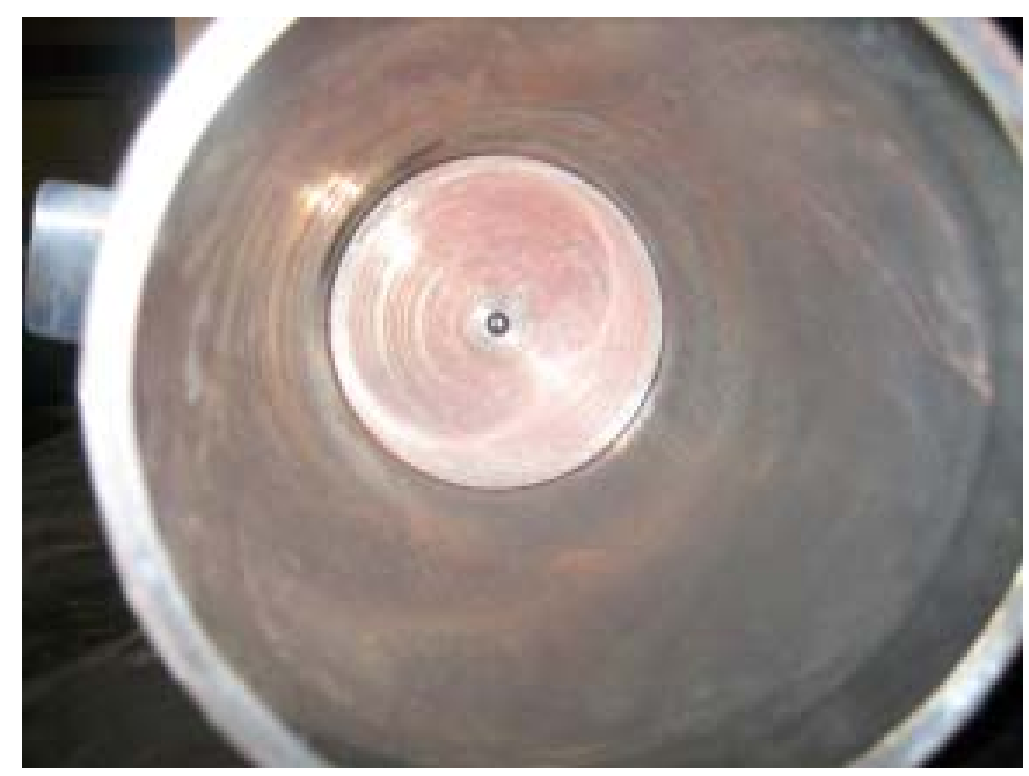

Figure 4.3 Inner View of the Shear Coking Reactor Thermocouple Probe at the Base

The design of a suitable wiper blade posed several challenges. A non-corrosive, elastic material that functions up to $600^{\circ} \mathrm{C}$ was required. Grade 5 titanium has a liquidus 
temperature $\sim 1600^{\circ} \mathrm{C}$. This means that at the operating temperature of the reactor, the titanium will not form titanium carbide. It was suggested that slots be cut into the wiper blade so that the molten pitch would not be moved around the vessel as a vortex. A preliminary configuration was sketched. Without extensive literature of the mechanical behavior of pitch, an educated guess was the only practical course of action. Since the electric motor could only produce around $30 \mathrm{ft}-\mathrm{lbs}$ of torque, and the inner diameter of the reactor was about 4 inches, it was found that at $75 \%$ of the yield strength of the titanium a blade thickness of up to 0.1875 inch would be acceptable. A more flexible blade was desired. To put less than $10 \mathrm{lbs}$ of force on the reactor wall it would require a blade thickness around 0.02 inch. Fortunately there were vendors that stock 15 and 20 thousandth inch sheets of grade 5 titanium. In practice it is excessively difficult to drill and cut precise slots into waif thin metal. Spiral drill flutes tend to pull the flimsy metal up the longitudinal drill axis until the sheet of metal is ruined. Water-jet technology solved these problems. A computer aided drawing of the blade was made and sent to a local machine shop, Wilson Works in Morgantown, WV, where the template was programmed into the machine and cut out of the supplied titanium sheet. The quoted water-jet hourly rate was $120 \mathrm{USD} / \mathrm{hr}$.

During the experimental trials it was found that the titanium was being plastically deformed, see Figure 4.4. A similar blade composed of 301 stainless steel was implemented in an effort to determine if a less costly blade could be used to produce similar results. It was found that the stainless steel blades could be produced and made to be disposable and less costly than the titanium counter parts. The deformations of the blades were very comparable - nearly exact. This is likely due to the metallic strengths 
being reduced by the elevated temperatures, and the hot working of the blades against the forming solid coke on the reactor wall. The disposable stainless steel blades were used for all further experiments.

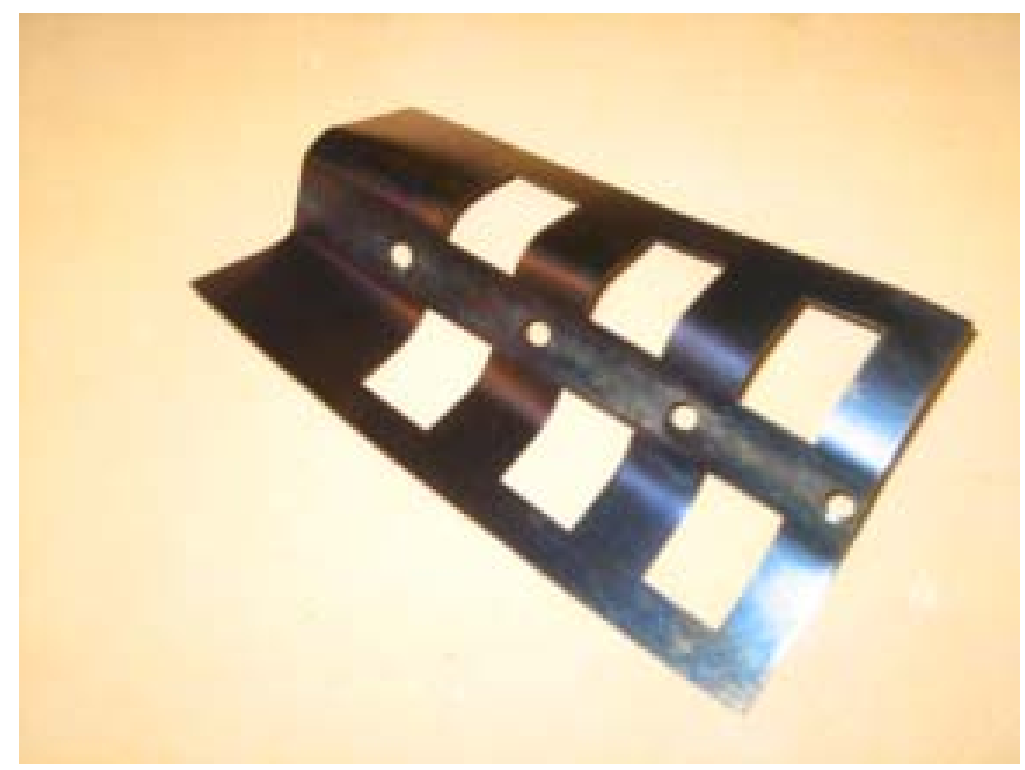

Figure 4.4 Original Wiper Blade Design (used)

In an effort to reduce the volatile gas emission from the shear coker, a series of traps were installed. From Figure 4.5 it can be seen that three traps are assembled in series. The first trap rests in a solution of water and ice. The second trap is chilled with a solution of solid carbon dioxide (dry ice), and acetone. In the third trap, activated carbon is used for its adsorption properties. The activated carbon typically adsorbs compounds that remain gaseous at or near room temperature. This unit is also referred to as a scrubber. Each of the traps were made of 3 inch copper tubing. The bottom of each trap was capped. The top had a threaded pipe fitting and a threaded cap on top. In the pipe cap, two holes were drilled and tapped $3 / 8^{\text {th }}$ NPT. Yellow brass pipe to tube compression fittings were installed to facilitate the assembly of the gas ventilation lines. Copper was 
the material of choice due to the lower temperatures and the desire for efficient heat transfer. To date there is no evidence of corrosion from coal tar distillates.

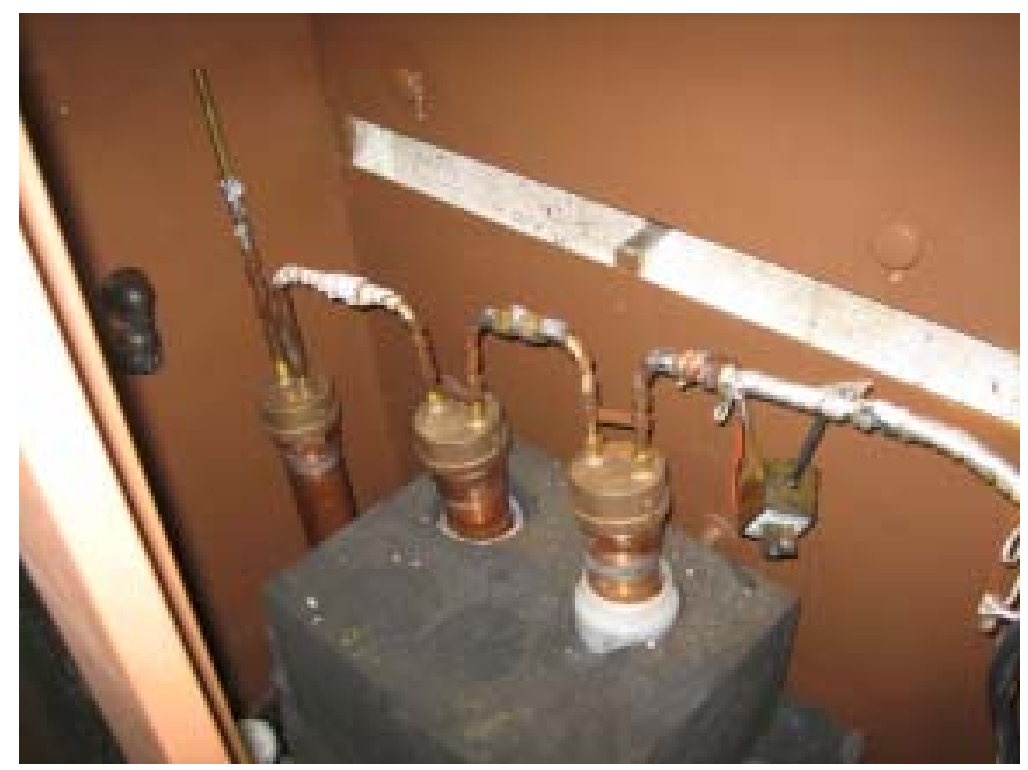

Figure 4.5 Cold Traps and Activated Charcoal Filter

The lid of the reactor was made of 304 stainless steel. The machinability of 304ss is greater than that of $316 \mathrm{ss}$, but has slightly decreased corrosive resistance. From experience with coal tar distillates, it is known that volatile vapors will condense and clog lines rather quickly. To reduce the risk of these clogs, the line was heated and constructed of 0.5 inch tubing. The larger diameter decreases the surface area to volume ratio. This aids in controlling the condensation of vapors on the ventilation walls. Now a $1 / 2$ inch compression fitting for the vent line, a 0.25 inch pipe fitting for the nitrogen purge line, and a graphite bearing for the 0.75 inch stirring shaft needed to be arranged on the reactor lid. Graphite bearings operate at elevated temperatures with low friction, and low thermal expansion. A graphalloy bearing was found with an outside diameter of 1.125 inches, inner diameter of 0.75 inch, a height of 1.25 inches, that could operate at $398^{\circ} \mathrm{C}$. The bearing and the fittings were arranged on the lid and machined to specifications. The 
lid can be seen in Figure 4.6. The nitrogen purge line incorporates a quick connect fitting for ease of usability.

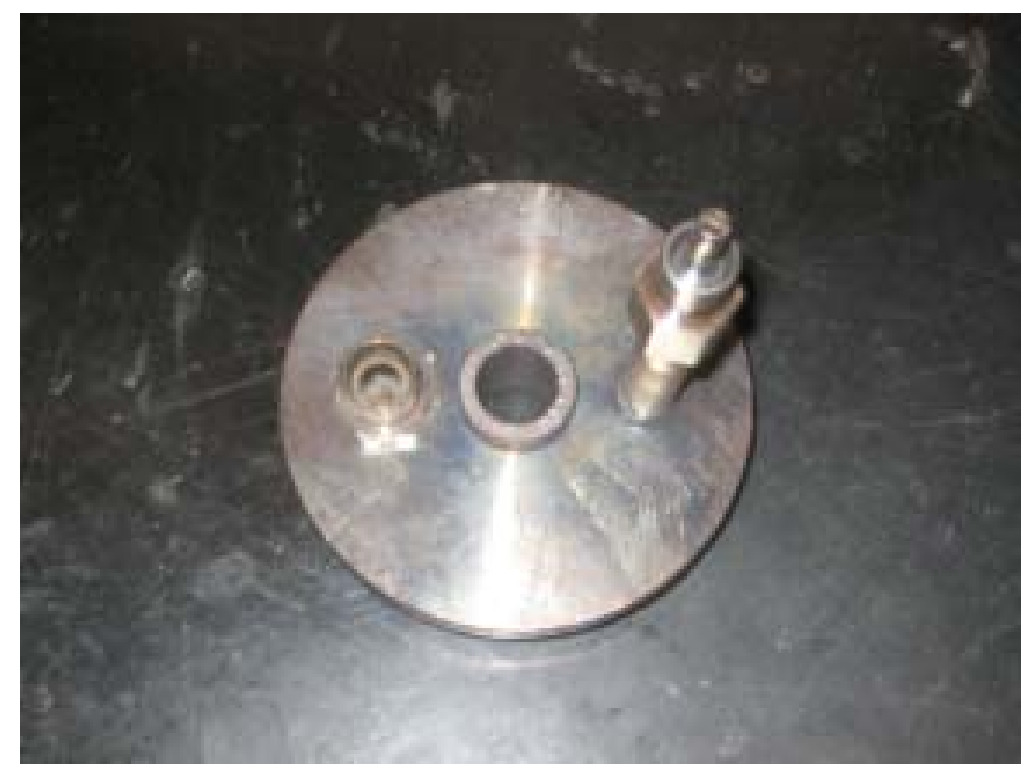

Figure 4.6 Reactor Lid with Volatile Port, Stirring Shaft Bearing, and Nitrogen Gas Coupling (from left to right)

The stirring shaft was made of 0.75 inch 304 stainless steel. Machinable stainless steel was needed to produce a shaft with through holes with which to fasten the wiper blade. The bolts used were $1 / 4$ inch NC stainless steel. A backing strip was made to better clamp, and secure the blade to the shaft. The shaft assembly is shown in Figure 4.7. The wiper blade/shaft assembly was placed in the reactor. There is approximately 0.0625 inch between the inner diameter of the reactor and the width of the blade, seen in Figure 4.8. There were some variances between blades, but only a few thousandths of an inch. 


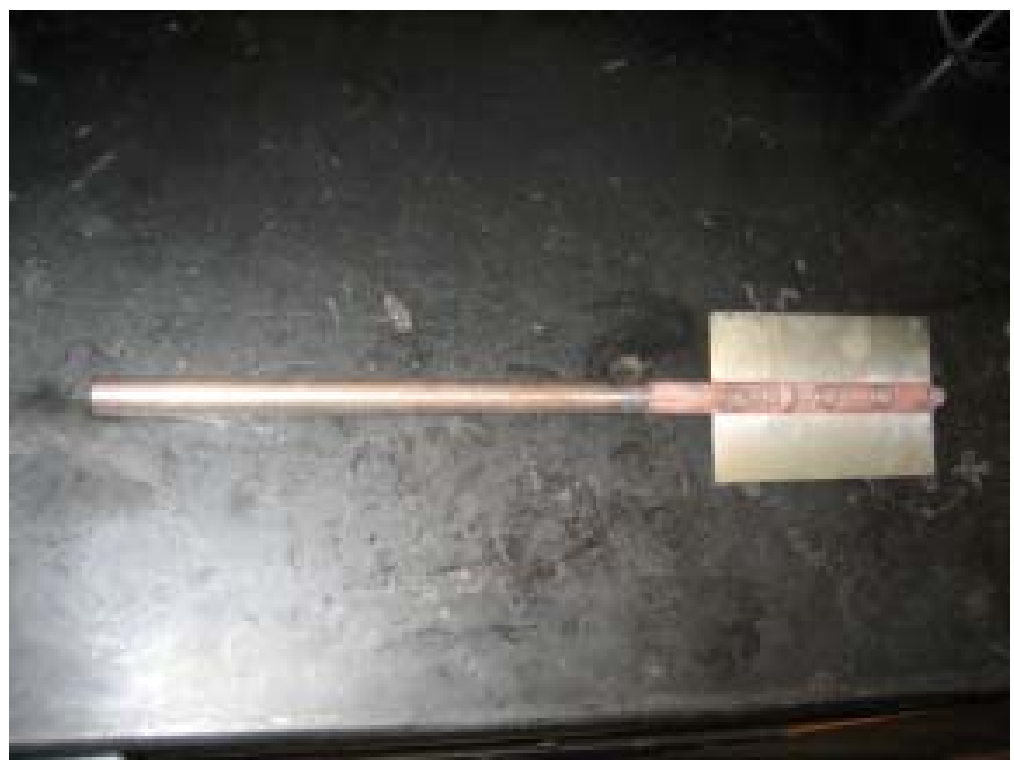

Figure 4.7 Stirring Shaft with Stainless Steel Wiper Blade

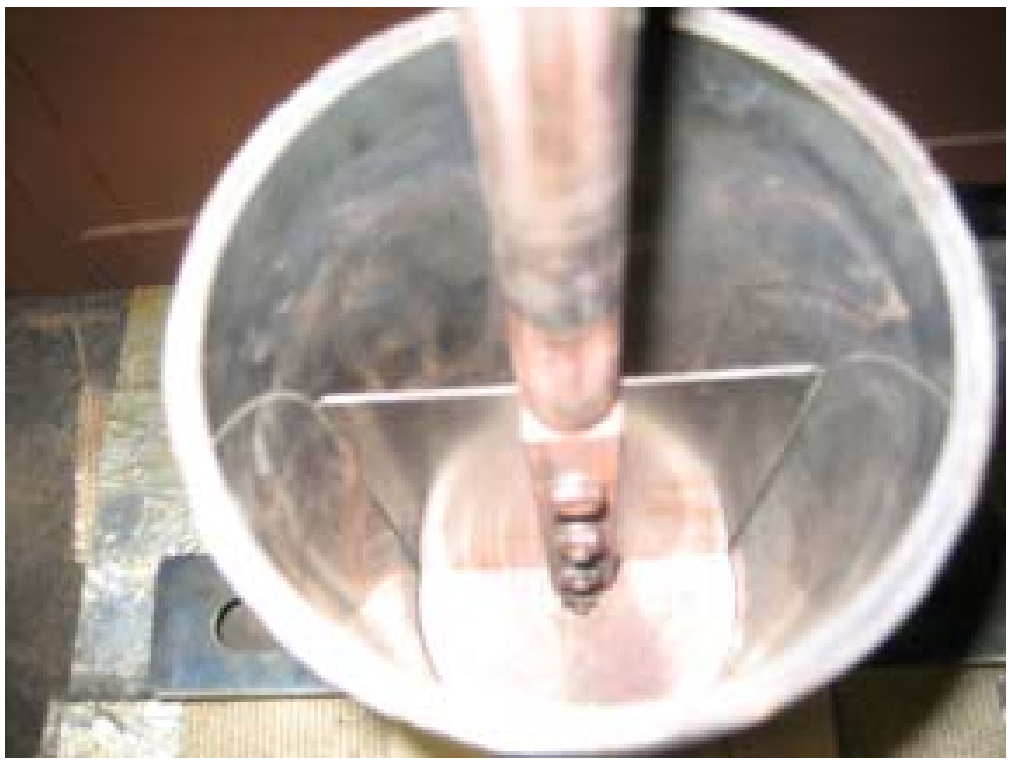

Figure 4.8 Wiper Blade Fixed to the Stirring Shaft inside the Reactor

The reactor was then assembled as described in Chapter 5. At this point the reactor appeared as in Figure 4.9. An intermediate shaft was installed with keyed shaft couples. The intermediate shaft was a necessary element. When the intermediate shaft was removed, it provided vertical clearance so that the reactor could be elevated above the torque restraining pins shown in Figure 4.10. The complete test apparatus is 
presented in Figure 4.11. It shows the instrumentation panel, computer interface, data acquisition system, and appropriate location within a fume hood.

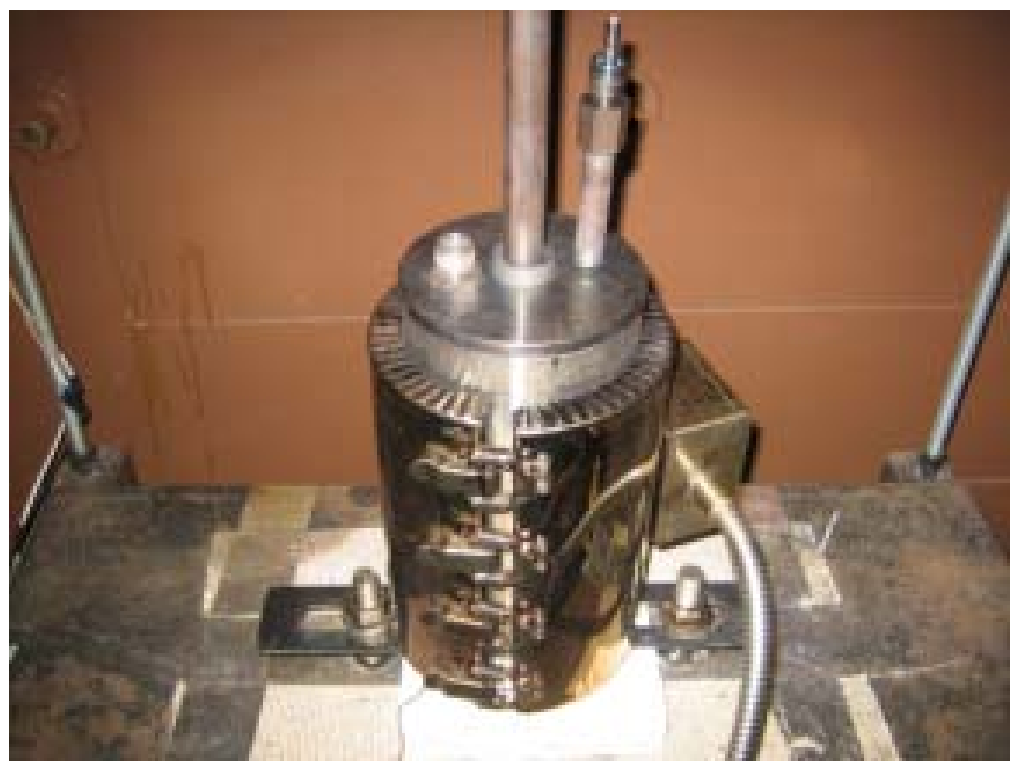

Figure 4.9 Assembled Reactor (Nitrogen Purge Line and Volatile Vent Line not Attached)

The final elements to the test apparatus were the instruments. The list of components can be found in Table 4.1 as previously mentioned. An Omega temperature controller was installed. To control the temperature from the process temperature of the molten pitch. The reason the process temperature was used as the control reference temperature was to rapidly heat the reactor to the desired temperature of the reaction without excessive temperature profile experiments. The overshoot was deemed acceptable since it remained below the solidification temperatures. It is common to control reaction temperatures from the skin temperature, but this added complexity for reduced overshoot at the cost of response time. The controller output was DC voltage to a solid state relay. The relay acted as an on/off switch for the heater.

The Baldor motor was controlled using a variable motor controller. The motor controller converted alternating current (AC) to direct current. The direct current was 
controlled linearly using a variac or variable voltage transformer. The speed of the electric motor was proportional to the voltage applied. This made calibration user friendly.

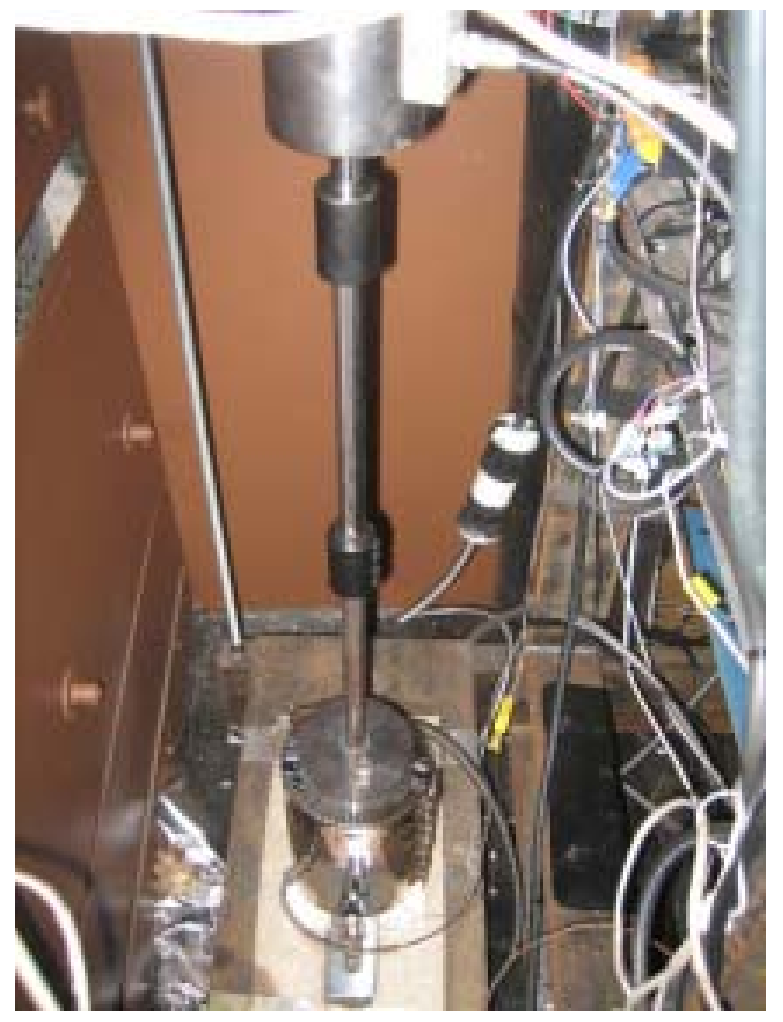

Figure 4.10 Shear Coking Reactor Secured in the Test Apparatus

A tachometer was required to determine the angular speed of the motor. The Monarch optical tachometer was selected for its data output terminals, and the operating range met the needs for this research.

The Omega data acquisition is easily interfaced with a personal computer through a USB port. The system allowed for multiple data collection rates, frequency pulse, differential digital signals, as well as analog signals. The system could be expanded for further studies, thus making it ideal for the screening experiments for this research. 
The torque sensor greatly increased the knowledge of the behavior of these reactions. A Magna-Lastic rotary torque sensor was used. The sensor worked by detecting shifts in a magnetic field from the stress induced by torque in the shaft. This noncontact torque sensor was ideal for this application. The $200 \mathrm{~N}-\mathrm{m}$ model was selected since the torque could be detected from 0 to $5000 \mathrm{rpm}$. Since the sensor could detect $<1$ to $200 \mathrm{~N}-\mathrm{m}$ it seemed a safe decision to select a sensor that was unlikely to be overloaded and could be used in further experiments of larger demand.

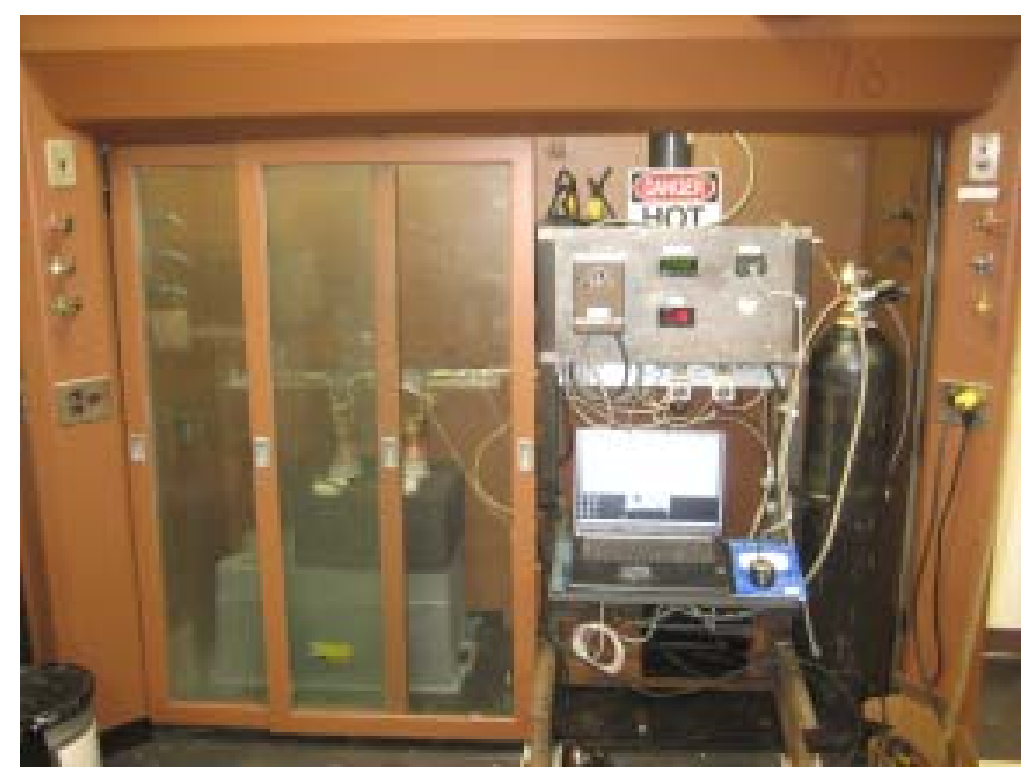

Figure 4.11 Complete Test Apparatus 


\section{Experimental Procedure}

\subsection{Statistical Design and Analysis}

A $2 \mathrm{k}$ factorial statistical design was selected to screen the effects of temperature and rate of induced stress on the forming coke. This experimental design and analysis assumed that the effects are linear (Montgomery, 2001). Even though this may not be correct, it provided an indication as to which variables had the more significant effect on the mechanically arranged order of the pregraphitic carbon. The factorial design used two variables: temperature, and angular velocity. Mesophase domain growth occurs around $400^{\circ} \mathrm{C}$, so the heat treatment temperatures of $375^{\circ} \mathrm{C}$ and $425^{\circ} \mathrm{C}$ were selected. The stirring rate of 35 and $75 \mathrm{rpm}$ was selected. These values were approximately 50 and 100 percent of the operational speed of the motor, respectively. The high $(+)$ and low (-) configurations of the factorial design are shown in Table 5.1 The table shows a complete series of system configurations for a $2^{\mathrm{k}}$ factorial design (runs 1-4) and a series of control experiments (runs $1 \& 2$ ). The axis, $\mathrm{X} 1$, relates to the angular velocity, and $\mathrm{X} 2$ is the heat treatment. The main effects as described by Equations 5.1, 5.2, and 5.3 governed the effectiveness of each parameter.

Table 5.1 2k Factorial Experimental Test Sequence (a) Experimental Values (b)

\begin{tabular}{|c|c|c|}
\hline Run & $\mathbf{X 1}$ & $\mathbf{X 2}$ \\
\hline 1 & -1 & 1 \\
\hline 2 & -1 & -1 \\
\hline 3 & 0 & 1 \\
\hline 4 & 0 & -1 \\
\hline 5 & 1 & 1 \\
\hline 6 & 1 & -1 \\
\hline
\end{tabular}

\begin{tabular}{|c|c|c|}
\hline Run & X1 (rpm) & X2 ('C) \\
\hline 1 & 0 & 425 \\
\hline 2 & 0 & 375 \\
\hline 3 & 35 & 425 \\
\hline 4 & 35 & 375 \\
\hline 5 & 75 & 425 \\
\hline 6 & 75 & 375 \\
\hline
\end{tabular}


The main effect of parameter $\mathrm{A}, \mathrm{B}$, and the interaction of $\mathrm{A}$ and $\mathrm{B}(\mathrm{AB})$ is defined as:

5.1 Main Effect of Parameter A

$$
A=\frac{1}{2 n}[a b+a-b-(1)]
$$

5.2 Main Effect of Parameter B

$$
B=\frac{1}{2 n}[a b+b-a-(1)]
$$

\subsection{Interaction Effect of Parameters A and B}

$$
A B=\frac{1}{2 n}[a b+(1)-a-b]
$$

(Montgomery, 2001)

The effects of the mechanically induced stress were evaluated over a temperature range of mesophase domain growth. Effectiveness of the temperature and the stirring rate was quantified using the main effects (Equation 5.1, 5.2, \& 5.3). This provided direction to further research of greater depth.

\subsection{Preparation of Pitch}

The pitch obtained for the experiments was a coal tar pitch from Koppers Inc. The pitch was processed using a vibration separation (VSEP) technique to remove nearly all solvent insoluble material or ash. Using proximate analysis the pitch was tested for moisture, volatile matter, and ash material by weight. The results are shown in Table 5.2 It should be noted that a negative ash value is not possible. This is likely due to convective gas currents in the testing apparatus that cause a buoyant effect on the scale. The ash value is assumed to be zero. 
Table 5.2 Proximate analysis of the Coal Tar Pitch Material

\begin{tabular}{|c|c|c|c|}
\hline Sample & \% Moisture & \% Volatile Matter & \% Ash \\
\hline Coal Tar Pitch B1 ave & 0.28 & 35.37 & -0.065 \\
\hline Coal Tar Pitch B2 ave & 0.27 & 37.865 & -0.025 \\
\hline Coal Tar Pitch B3 ave & 0.745 & 52.18 & -0.27 \\
\hline
\end{tabular}

The pitch was then processed using a elemental analyzer to determine the composition of carbon, hydrogen and heteroatoms, sulphur and nitrogen by weight. The results are shown in Table 5.3. Since pitch does not have a defined melting point, it is characterized by the softening point as test by ASTM D-3104. The results can be seen in Table 5.4

Table 5.3 Elemental Analysis of Coal Tar Pitch Material

\begin{tabular}{|c|c|c|c|c|}
\hline Sample & Nitrogen \% & Carbon \% & Hydrogen \% & Sulphur \% \\
\hline Coal Tar Pitch B1 & 1.13 & 91.27 & 4.50 & 0.22 \\
\hline Coal Tar Pitch B2 & 1.09 & 90.66 & 4.35 & 0.18 \\
\hline Coal Tar Pitch B3 & 1.06 & 90.02 & 4.56 & 0.24 \\
\hline
\end{tabular}

Table 5.4 Mettler Softening Point of the Pitch Material by ASTM-3104

\begin{tabular}{|c|c|}
\hline Sample & Softening Point 'C \\
\hline Coal Tar Pitch B1 ave & 154.2 \\
\hline Coal Tar Pitch B2 ave & 147.7 \\
\hline Coal Tar Pitch B3 ave & 104.2 \\
\hline
\end{tabular}

From Table 5.4 it can be seen that sample B1 and B2 have similar softening points. As a result material sample B2 was selected for the experiments. If further testing was required material B1 could supplement the material B2 which would have similar material behavior.

The samples of pitch arrived in 5 gallon cans as a solid. Each sample of pitch was crush to a granular powder. The void space varied, but approximately $500 \mathrm{ml}$ of pitch was weighed and poured into the reactor. 


\subsection{Preparation of Reactor}

The reactor, between experiments, was heated in an oxidizing environment to remove the remaining carbon. Once the reactor was clean, the thermocouple was installed in the bottom. The reactor was then placed on the test stand. The stirring shaft with the attached wiper blade was then placed in the reactor. The reactor lid was placed over the shaft prior to securing the shaft with collars. The reactor was then filled with pitch and the lid firmly secured. A nitrogen line was connected to provide an oxygen free environment. The vent line was secured using a compression fitting. Once this was complete, the heater band was secured with the appropriate thermocouples.

\subsection{Cold Trap Instillation}

After the reactor was prepared to operate, the cold volatile trap was prepared. The first trap in series was cooled at $0^{\circ} \mathrm{C}$ using water and ice. The second trap sat in a bath of acetone and dry ice. The third trap contained activated charcoal. The lines of the cold traps were heated so as to keep the volatile matter from condensing within and clogging the lines. The lines were heated to approximately $400^{\circ} \mathrm{C}$. It should be noted that the experiments were conducted within a fume hood for added protection.

\subsection{Reaction}

Once the reactor had been prepared and the cold traps installed, the reaction could safely occur. A slow flow of nitrogen was applied to the system as the temperature controller was set to the desired devolatilization temperature. The computer and the data acquisition system was initiated and began recording the torque of the wiper shaft, the angular speed of the shaft, the skin temperature at the bottom of the reactor, and the middle. It was found to be advantageous to control the temperature using the process 
temperature probe in the bottom of the reactor. This caused some oscillating temperature but enabled better temperature control. The electric motor was not initiated until a process temperature of $200^{\circ} \mathrm{C}$ was established. Since the softening point of the pitch was $147^{\circ} \mathrm{C}$, this ensured the pitch was fluid. The pyrolytic devolatilization of the pitch continued for 5 hours at $375^{\circ} \mathrm{C}$ and 3 hours at $425^{\circ} \mathrm{C}$. The time difference was selected as a result the slower devolatilization of pitch at lower temperatures. As the pitch devolatilized, it was whipped against the reactor wall at angular speeds between 0 and 75 revolutions per minute (rpm). Once the molten pitch devolatilized for the prescribed time, the temperature was ramped to approximately $475^{\circ} \mathrm{C}$. The coke seemed to form near this temperature. The wiping continued until a torque spike was observed. Once the torque reached a peak value and returned to the mixing value, the experiment was declared complete. The data acquisition was discontinued, the heater turned off, and the stir motor turned off. Once the reactor cooled to $200^{\circ} \mathrm{C}$ the nitrogen valve was closed. The reactor was then allowed to cool to ambient temperature before obtaining the product.

\subsection{Coke Sampling}

The lid of the reactor was removed once it reached ambient temperature. The stirring shaft and wiper blade were removed. Radial cuts were made in the coke before driving a chisel down the side of the reactor to dislodge the coke. This method seemed to produce nuggets of coke with less destruction to the product. 


\subsection{XRD Sample Preparation}

Coke samples were pulverized to perform $\mathrm{x}$-ray diffraction. The samples were initially crushed with a mortar and pestle. Each sample was placed in a ball mill with ceramic balls. The ball mill was operated until $10 \mathrm{ml}$ of coke was produced in a powder of 160 mesh ( $<98$ microns). The standard test method, ASTM D-5187, calls for 200 mesh ( $<75$ microns) pulverized coke to be scanned. The 200 mesh sieve was not available. Since this study is comparative evaluation of the parameters, the use of the 160 mesh sieve was deemed accebtable.

\subsection{SEM Sample Preparation}

Representative samples of coke that had been affected by the wiper blade during devolatilization were selected for SEM micrographs. The samples were cut to an appropriate size, placed on the sample holder with double sided adhesive, and observed with the SEM. The samples did not require a conductive metallic coating.

\subsection{Optical Microscopy}

Graf Tech International performed the petrography of the green coke and the pitch. The optical texture of coke is observed by the optical interference patterns by using cross polarized light (Gray, 2007). By adding quartz or gypsum tint plate the interference pattern and optical domains appear with color (Gray, 1986). As mentioned in Section 2.17.1 the orientation of the crystalline planes dictate the color of the interference patterns when a tint plate is used. Color change occurs for anisotropic materials when the stage or the analyzer is rotated. Isotropic domains remain unchanged regardless of observed orientation.

Petrographers use these tools and techniques to characterize coal, pitch, cokes, graphite, etc. Petrography focuses on the identification and volume approximation of 
carbon entities or macerals (Marsh, 1989). This enables the characterization of feed materials and products. The properties of a material can be estimated and even approximated based upon the percent of constituents. A similar method of optical texture identification is used to evaluate the material properties based upon the surface texture. In this method the texture of a carbonaceous material is identified by the domain type and size. Each domain type and size is referenced to a number, called the optical texture index factor, or OTI factor (Marsh, 1989). The OTI can be observed in Table 5.5. The OTI is determined for each domain and multiplied by the point count. This value can be used, comparatively, to define the relative anisotropic properties.

Table 5.5 Optical Texture Index (Marsh, 1989)

\begin{tabular}{|c|c|c|c|}
\hline Domain Type & Symbol & Size Range & OTI Factor \\
\hline Isotropic & Is and Ip & No Optical Activity & 0 \\
\hline Fine Mosaics & F & diameter $<0.8 \mu \mathrm{m}$ & 1 \\
\hline Medium Mosaics & M & $>0.8 \mu \mathrm{m}$ diameter $<2.0 \mu \mathrm{m}$ & 3 \\
\hline Coarse Mosaics & C & $>2.0 \mu \mathrm{m}$ diameter $10.0 \mu \mathrm{m}$ & 7 \\
\hline Granular Flow & GF & $>2 \mu \mathrm{m}$ length; $>1 \mu \mathrm{m}$ width & 7 \\
\hline Coarse Flow & CF & $>10 \mu \mathrm{m}$ length; $>2 \mu \mathrm{m}$ width & 20 \\
\hline Lamellar & L & $>20 \mu \mathrm{m}$ length; $>10 \mu \mathrm{m}$ width & 30 \\
\hline
\end{tabular}




\section{Results and Discussion}

Carbonaceous materials can be processed into many forms. The multiple bonding mechanisms of carbon enable a wide array of artifacts to be produced. But the diverse bonding of carbon can complicate production of bulk carbon artifacts. Often carbon bonds to other elements that complicate and/or contaminate the production of coke and synthetic graphite. For this reason, the quality of carbon product production depends heavily upon the feed material. This effect was reduced or even eliminated by using a single batch of coal tar pitch as a feed material.

There are other factors that contribute to the degree of graphitization. Temperature and temperature ramp rates are very important. Pyrolytic decomposition of carbonaceous material for the production of quality coke requires controlled devolatilization rates. This is controlled with temperature. Although it can be seen that temperature can increase the graphitic characteristics of carbon, it is not the only mechanism to do so.

\subsection{SEM Micrograph Image Analysis of Coke Structure}

The coke was produced by pyrolysis at temperatures of $375^{\circ} \mathrm{C}$ and $425^{\circ} \mathrm{C}$, low and high respectively. The temperature was increased to $475^{\circ} \mathrm{C}$ to ensure that coke had completely formed. As the coke was being wiped by the stirring blade, the torque was monitored. It was noticed during trial runs that the torque would spike once the coke formed. After the torque spike the value would return to a normal operating value. This marked the end of the green coking cycle. Since the conventional method of coke production uses only thermal treatment, the time interval of the torque spike of the stirred reaction was observed. The control experiment was performed with this time constraint. 
The coke produced was typical of sponge coke manufactured at atmospheric pressure. The pores were round, varied in size, and were randomly distributed. Coke samples T375_0 and T424_0 were observed with an SEM with optical multiplicative factor of 50. In Figure 6.1, the textured induced by the volatile gases can be seen in the low temperature sample. This is not as apparent in Figure 6.2 which is the high temperature sample. The clarity of the micrograph is a function of the heat treatment temperature. The low temperature samples have more volatile matter that reduced the conductivity of the sample. In both Figure 6.1 and 6.2 the coke exhibited large pore wall size and large pore diameters. This would be a result of agglomeration of the liquid phase carbon matrix during devolatilization. The devolatilized gases caused an open pore coke structure to form.

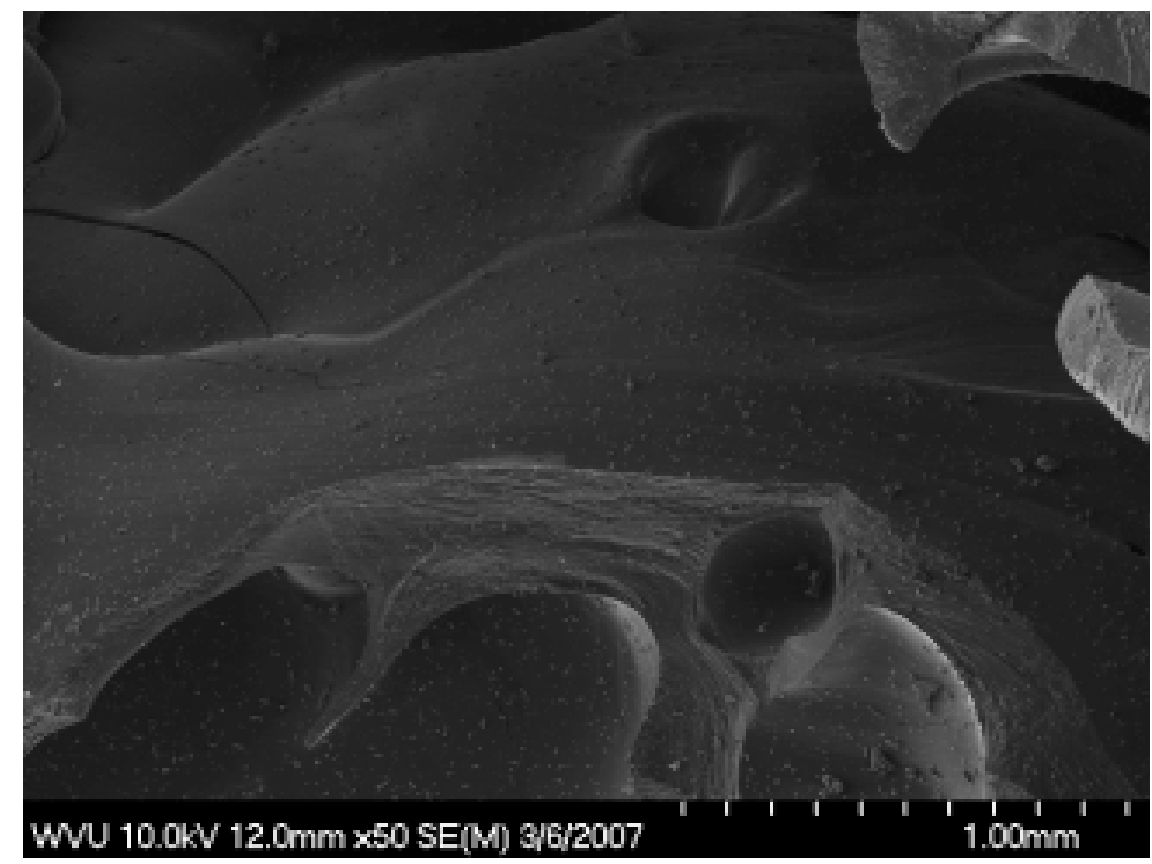

Figure 6.1 Green Coke Sample T375_0 


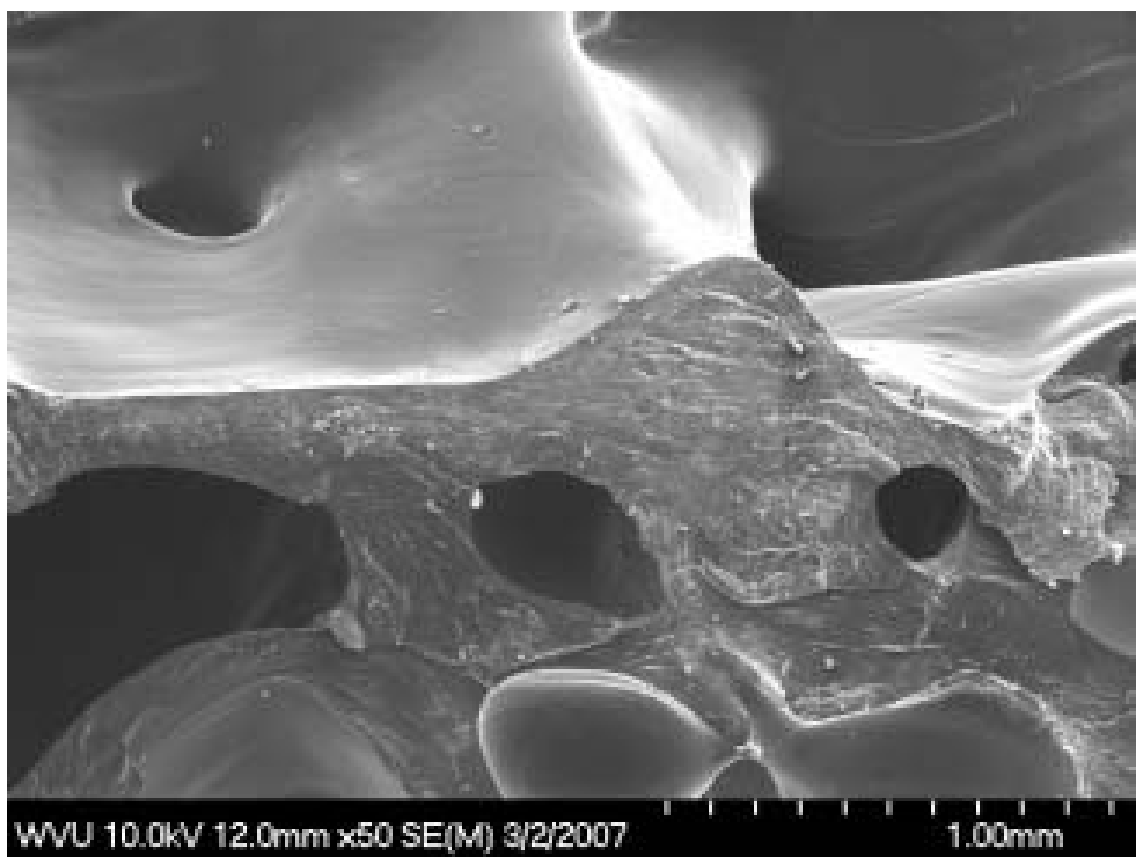

Figure 6.2 Green Coke Sample T425_0

There seemed to be more texture in the samples T375_50, T375_100, T425_50, and T425_100. The SEM micrographs of these samples at 50x optical magnification can be seen in Figures 6.3, 6.4, 6.5, and 6.6 respectively. This seemed very evident in Figure 6.3 where the heat treatment was conducted at $375^{\circ} \mathrm{C}$ and agitation with the wiper blade was performed at 35 revolutions per minute. The pore size appears to be smaller. Also there seemed to be evidence of oriented gas channels. Figure 6.4 shows some lamellar structure formation. It can be seen that there were some pores created by devolatilized gas expulsion. Do note that there was a different morphology of Figure 6.4. The mechanism(s) that caused the differences have not been identified. It may be possible that there was excess nitrogen flow. Sample T375_100 did have the lowest coke yield which may be indicative of the cause. The best surface texture was sample T425_50 seen in Figure 6.5. A combination of reaction temperature as well as a stirring rate that promoted reorganization of the carbon molecules likely promoted the highly oriented 
carbon structure. Whereas the structural orientation of sample T425_100 was good, it appeared slightly less ordered than sample T425_50.

The proposed theory was that induced shear stress would promote oriented carbon structures to reorganize during pyrolytic carbonization. This appeared to be true for the micrographs shown, although another phenomenon may exist. The rapid stirring rate of $75 \mathrm{rpm}$ may cause turbulence during the liquid phase of the carbonization. Turbulence would likely cause a more uniform heating of the pitch. By reducing the temperature gradient, the means of coking at the site of induced stress would be reduced. This would cause sample to coke in a near isothermal manner causing the wiper blade to push the sample around the vessel. It is more ideal to have the blade induce stress on a controlled region of the sample as it is carbonized. The reason being, that it established a cause and effect that can be measured and quantified. Once the mechanisms of induced orientation are identified turbulence may be used to commercialize the process. 


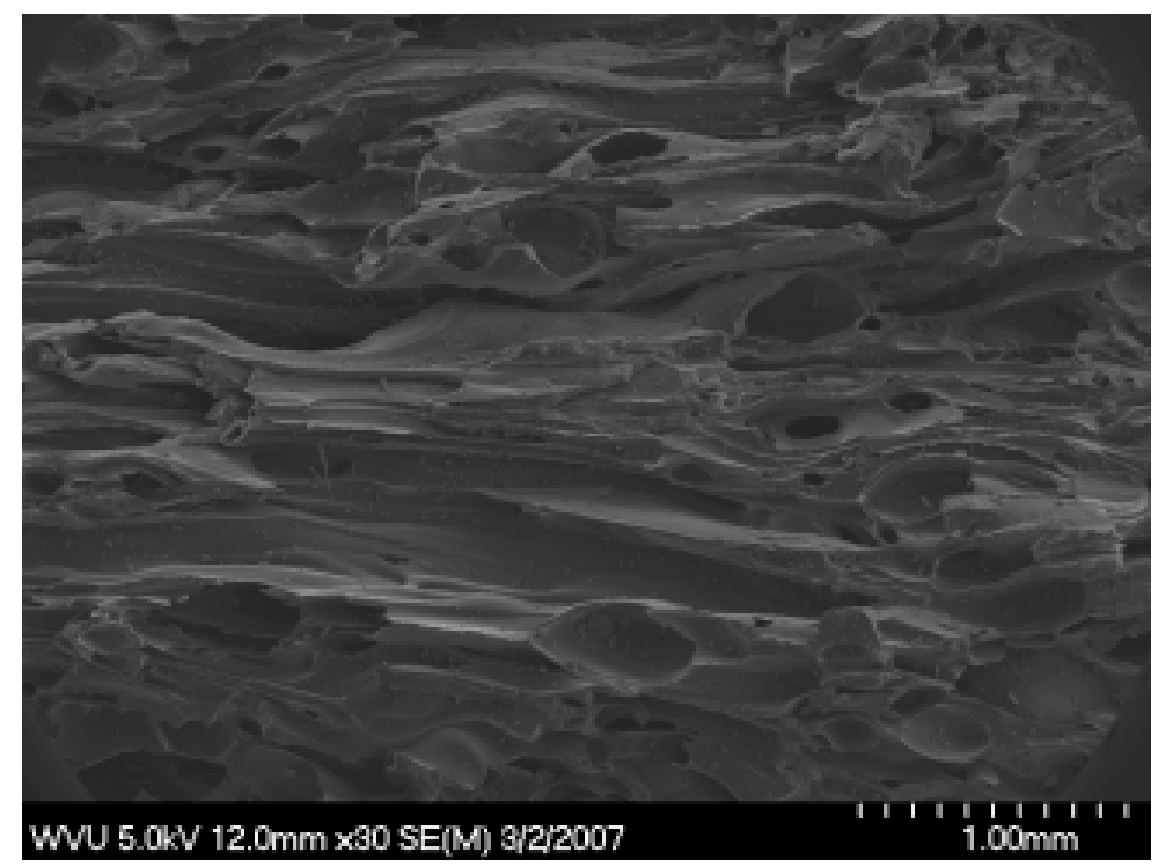

Figure 6.3 Green Coke from Alternative Process Sample T375_50

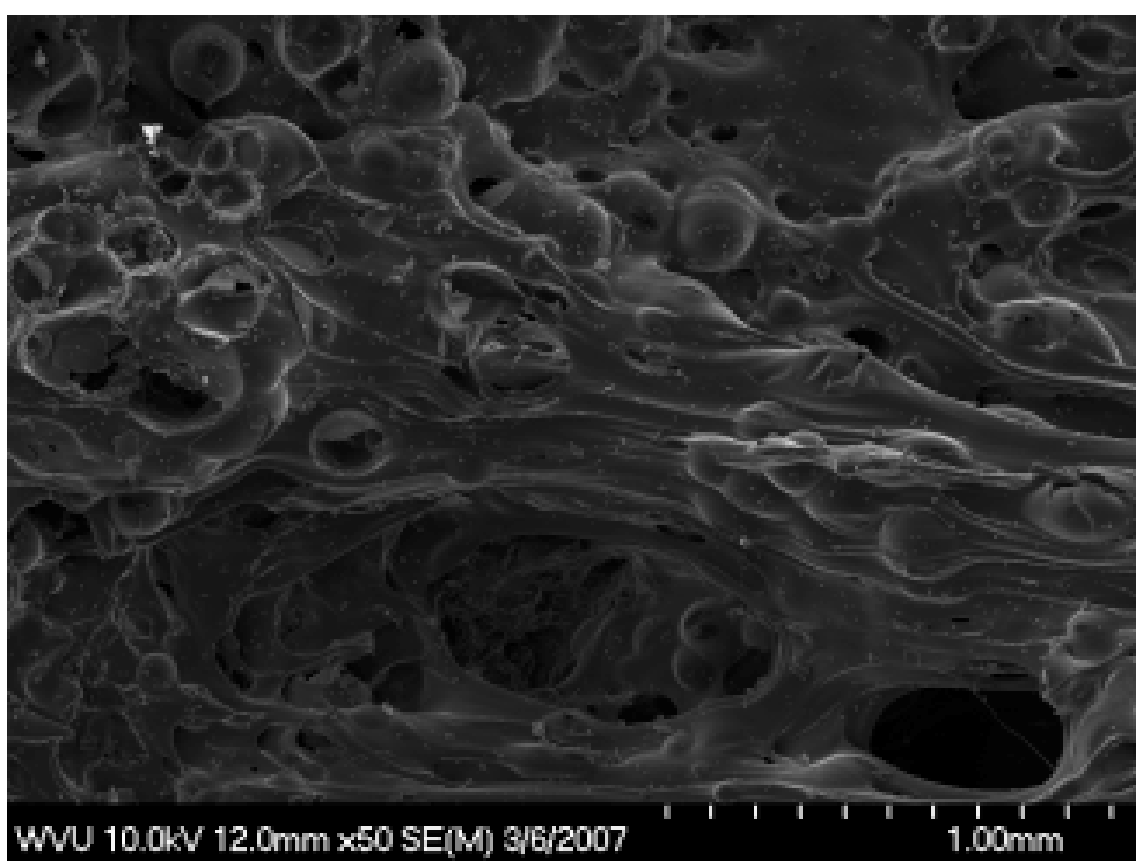

Figure 6.4 Green Coke from Alternative Process Sample T375_100 


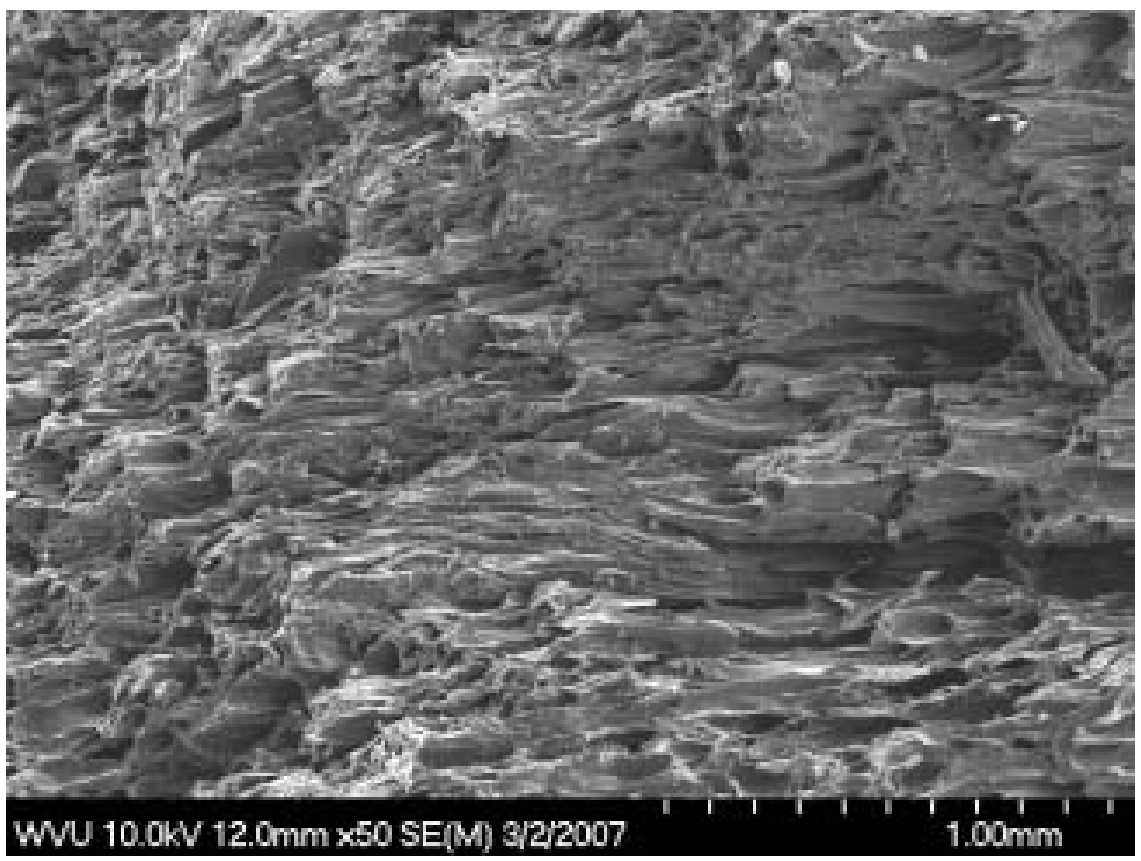

Figure 6.5 Green Coke from Alternative Process Sample T425_50

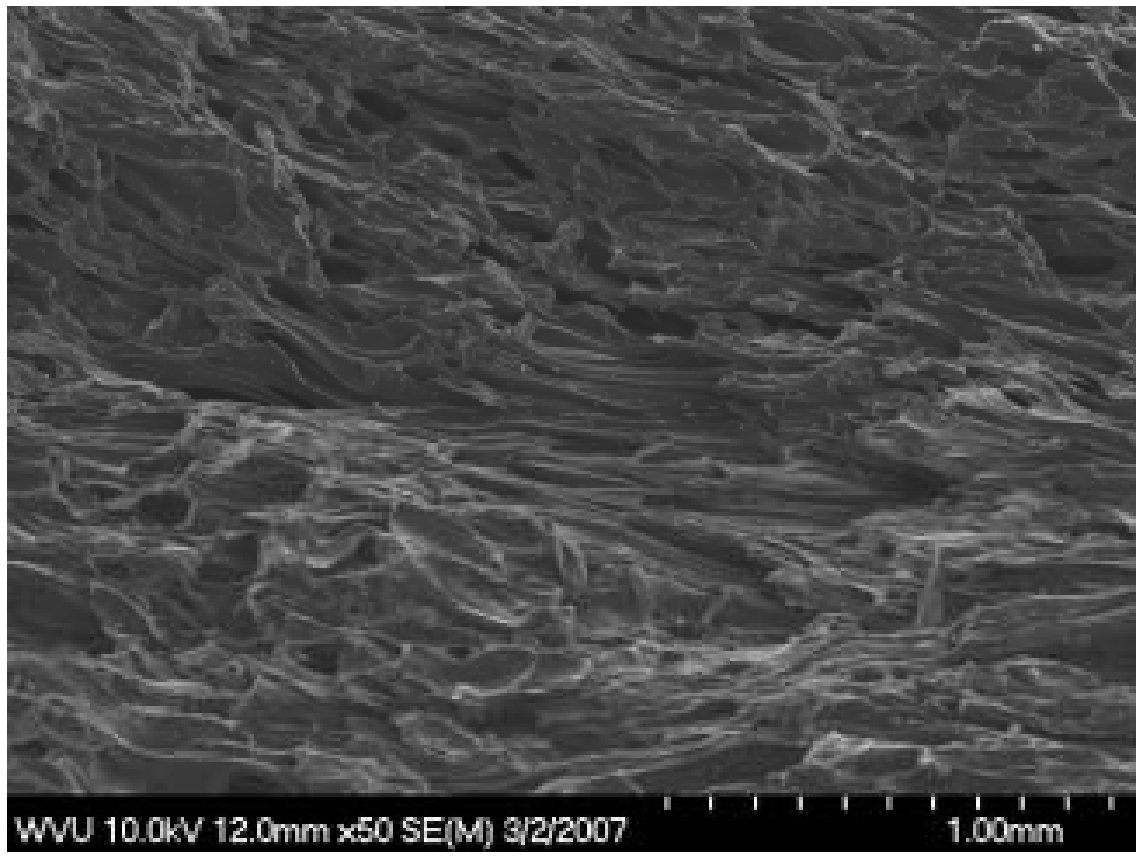

Figure 6.6 Green Coke from Alternative Process Sample T425_100 


\subsection{XRD Analysis of Crystalline Structure}

The coke was analyzed over the range of $2 \theta$ for 14 to 34 degrees to observe the 002 peak of the pregraphitic carbon structure. The low angle diffraction of the samples caused intensity peak variances. As the sample was scanned over an angular range, the area of the sample exposed to the x-rays varied (Bennet, 2000). This is displayed in Figure 6.7, where a is the length or area of the sample, $w$ is the width of the x-ray beam, and $\theta$ is the angle of inflection.

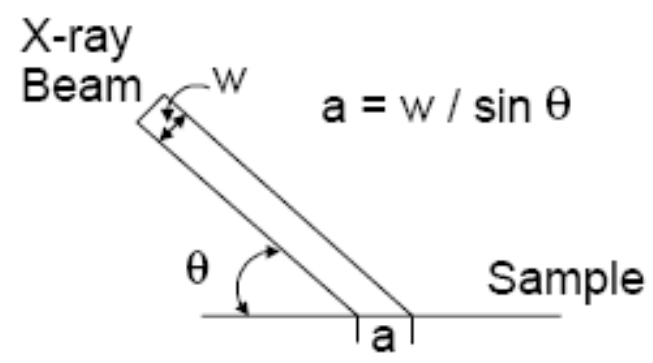

Figure 6.7 Irradiation as a Function of Angle (Bennet, 2000)

The other geometrical factor is that the diameter of the conical diffraction pattern increases with diffraction angle. Figure 6.8 shows that as the angle of diffraction increases the circumference of the diffraction cone increases. Since only a portion of the cone can be observed by the analyzer, the amount observed decreases inversely proportional to $\sin \theta$. When these factors are combined, it is known as the Lorentz factor (Klug \& Alexander, 1974). 


\section{Goniometer}

\section{Radius}

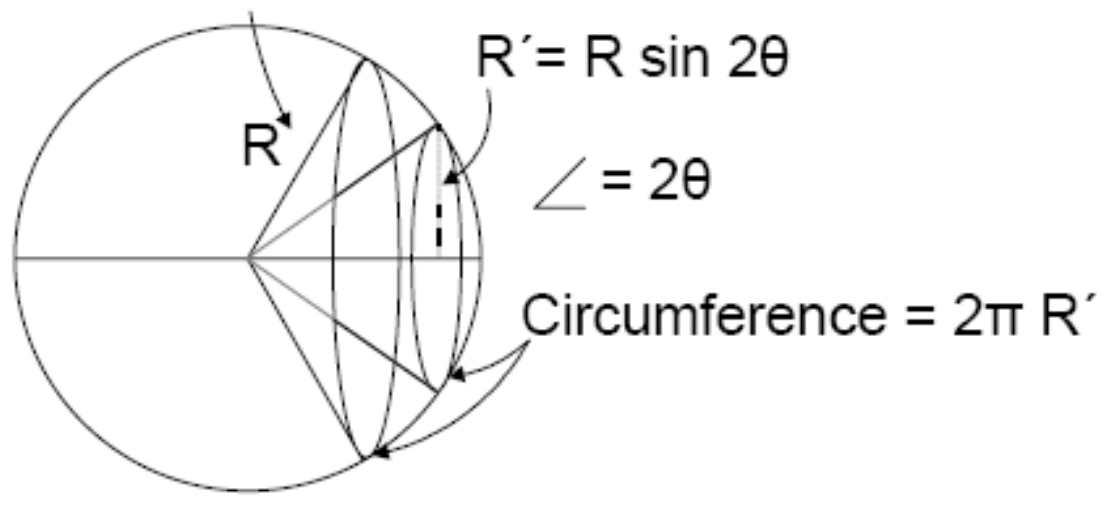

Figure 6.8 Cones of Reflection as a Function of Diffraction Angle (Bennet, 2000)

The x-ray radiation emitted from the source is generally unpolarized. But since the diffracted beam is polarized, the intensity must be compensated. The exception to this is when the $\mathrm{x}$-ray beam is monochromaticized to the crystal (Bennet, 2000). The intensity of the polarizing effect is a function of the diffraction angle. It has been described by Equation 6.1 (Klug \& Alexander, 1977).

Equation 6.1 Intensity Relationship to the Amplitude as a Function of Angle

$$
I \propto \frac{1+\cos ^{2} 2 \theta}{2}
$$

The fore mentioned effects are usually collected into one term. This term is shown in Equation 6.2 and is known as Lorentz-Polarization, $\mathrm{L}_{\mathrm{p}}$. The raw diffraction data was corrected by dividing the raw data by $\mathrm{L}_{\mathrm{p}}$. All XRD data was corrected in this manner.

Equation 6.2 Lorentz Polarization Equation (Cullity, 1978)

$$
L_{p}=\frac{1+\cos ^{2} 2 \theta}{\sin ^{2} \theta \cos \theta}
$$


The data was corrected for the geometric and polarization effects. The XRD corrected intensity was then plotted in Figure 6.9. From the corrected data, the peak angle was determined along with the full width at half peak height. This is described by ASTM 5187. The peak values were determined. With this information the crystallite length, $\mathrm{L}_{\mathrm{c}}$ was determined using Equation 6.3. Bragg's equation, seen as Equation 2.1, was used to determine the $\mathrm{d}_{002}$-spacing between the graphene sheets. The as processed sample data was compiled in Table 6.1 along with the calculated proportion of disorder from Equation 2.2. Recall that Franklin found the d-spacing as a function of graphene plane disorder for graphite. It was calculated in these experiments in an attempt to relate graphitic precursor properties to those of graphite. The observations of the peaks showed that the residual crystalline strain caused a peak shift of the XRD intensity curve (Philips, 2007). Until the green coke is heat treated to form graphite, thereby relieving the strains, the peak shift will remain.

\section{Equation 6.3 Debeye-Scherrer Equation}

$$
L_{c}=\frac{k \lambda}{\beta \cos \theta}
$$

Where: $\mathrm{k}$ is a constant $\left(0.89\right.$ for $\left.\mathrm{L}_{\mathrm{c}}\right)$

$\lambda$ is the wavelength of the $\mathrm{x}$-ray radiation $\left(1.54056 \AA\right.$ for copper $\left.\mathrm{K}_{\alpha} 1\right)$

$\beta$ is the half height peak width in radians

$\theta$ is the Bragg angle at maximum peak intensity 
Table 6.1 Crystallite Dimensions of XRD 002 Peak (Samples were Tested as Processed)

\begin{tabular}{|c|c|c|c|c|c|}
\hline Sample & $\begin{array}{c}\text { FWHM } \\
\text { (theta) rad }\end{array}$ & $\begin{array}{c}\text { Peak } \\
\text { Location }\end{array}$ & $\begin{array}{c}\text { Crystallite Length, } \\
\text { Lc }(\mathbf{\AA})\end{array}$ & $\begin{array}{c}\mathbf{d}(\mathbf{0 0 2}) \\
\text { spacing (̊) }\end{array}$ & $\begin{array}{c}\text { Proportional } \\
\text { Disorder }\end{array}$ \\
\hline T375_0 & 0.0436 & 26.15 & 15.7 & 3.4044 & 0.77 \\
\hline T375_50 & 0.0698 & 25.95 & 16.6 & 3.4302 & 0.94 \\
\hline T375_100 & 0.0375 & 25.96 & 18.3 & 3.4296 & 0.94 \\
\hline T425_0 & 0.0428 & 26.07 & 16.0 & 3.4146 & 0.84 \\
\hline T425_50 & 0.0442 & 25.91 & 15.5 & 3.4359 & 0.98 \\
\hline T425_100 & 0.0485 & 25.90 & 14.1 & 3.4369 & 0.98 \\
\hline
\end{tabular}

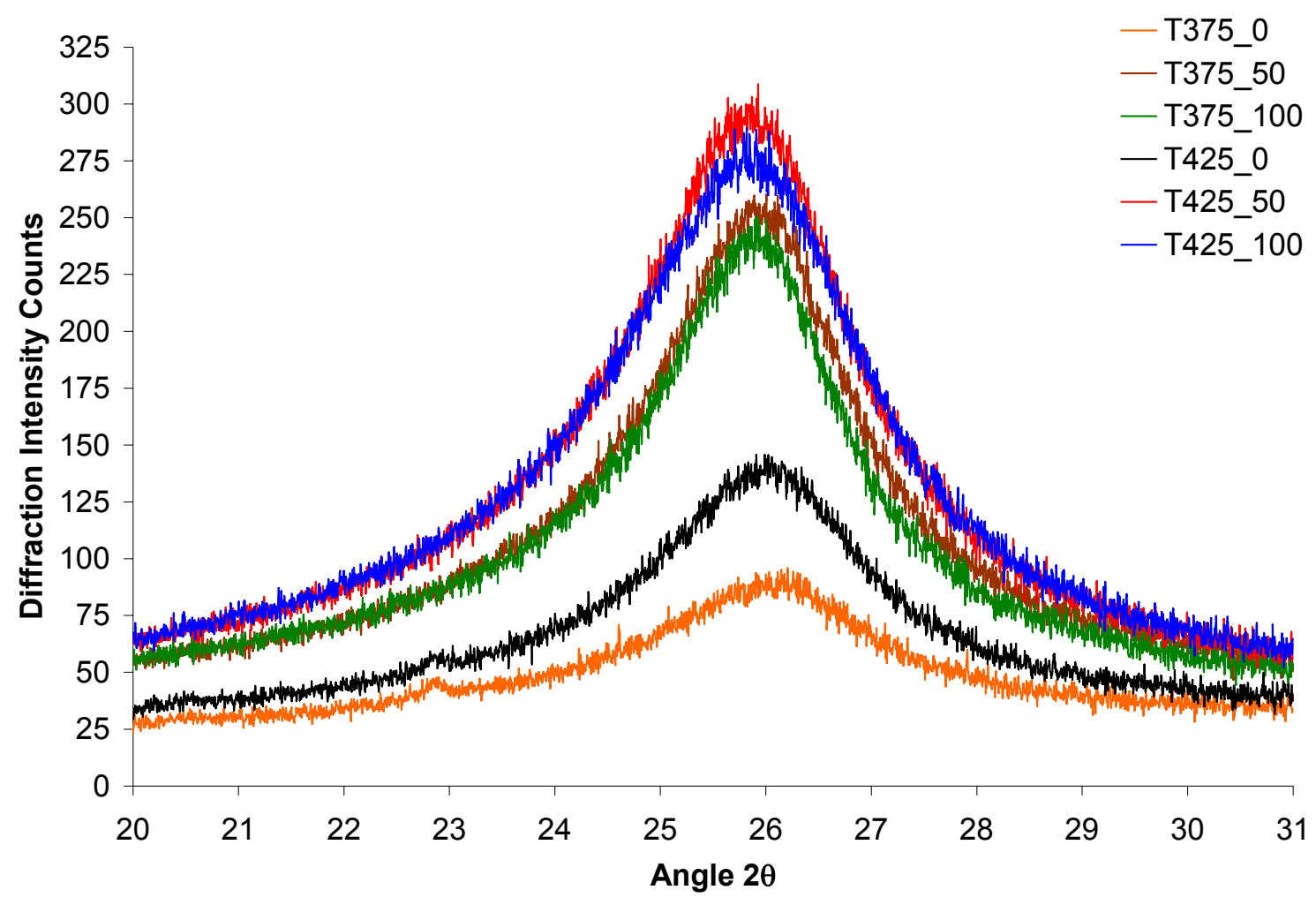

Figure 6.9 X-Ray Diffraction of Green Coke Samples as Processed (shown from 20 to 31 20)

A second series of data was produced using the same material and conditions then labeled as $\mathrm{U}$ series. The XRD was preformed at a slower rate in an attempt to better observe the crystalline differences of the green amorphous material. The slower rate increased the number of intensity counts and reduced the noise in the data. The U-series XRD curve can be seen in Figure 6.10. The diffraction curves showed that there was 
little difference between the samples as tested. Since the duplicate data series did not match the patterns of the initial T-series, the samples were tested again to eliminate the possibility of an error during sample preparation. The XRD scan conditions remained the same. The XRD patterns can be seen in Figure 6.11 of the T-series data. For Figure 6.10 and 6.11 the color schemes are identical and correspond to the reaction conditions for which the samples were obtained. It is obvious that there is little difference between the diffractions curve patterns. Furthermore it can be seen that the maximum intensity sample order changes from Figure 6.9 to Figure 6.10 and also in Figure 6.11. The differences could be the result of varying samples and or surface morphology. The diffraction curve values can be seen in Table 6.2 along with the calculated values of the crystallite width, d-spacing of the 002 plane, and proportion of disordered, turbostratic carbon layers.

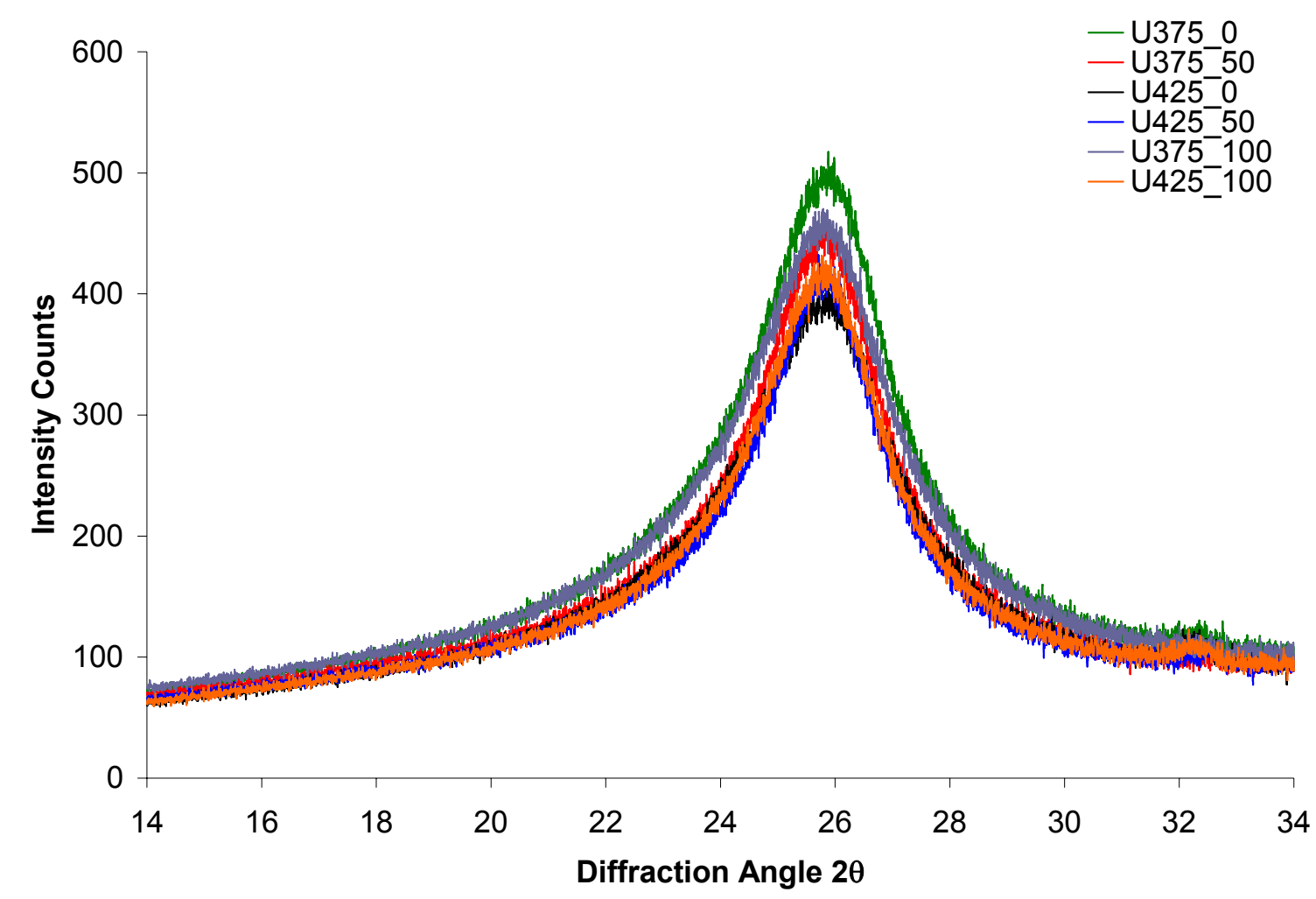


Figure 6.10 U Series XRD Data as Tested

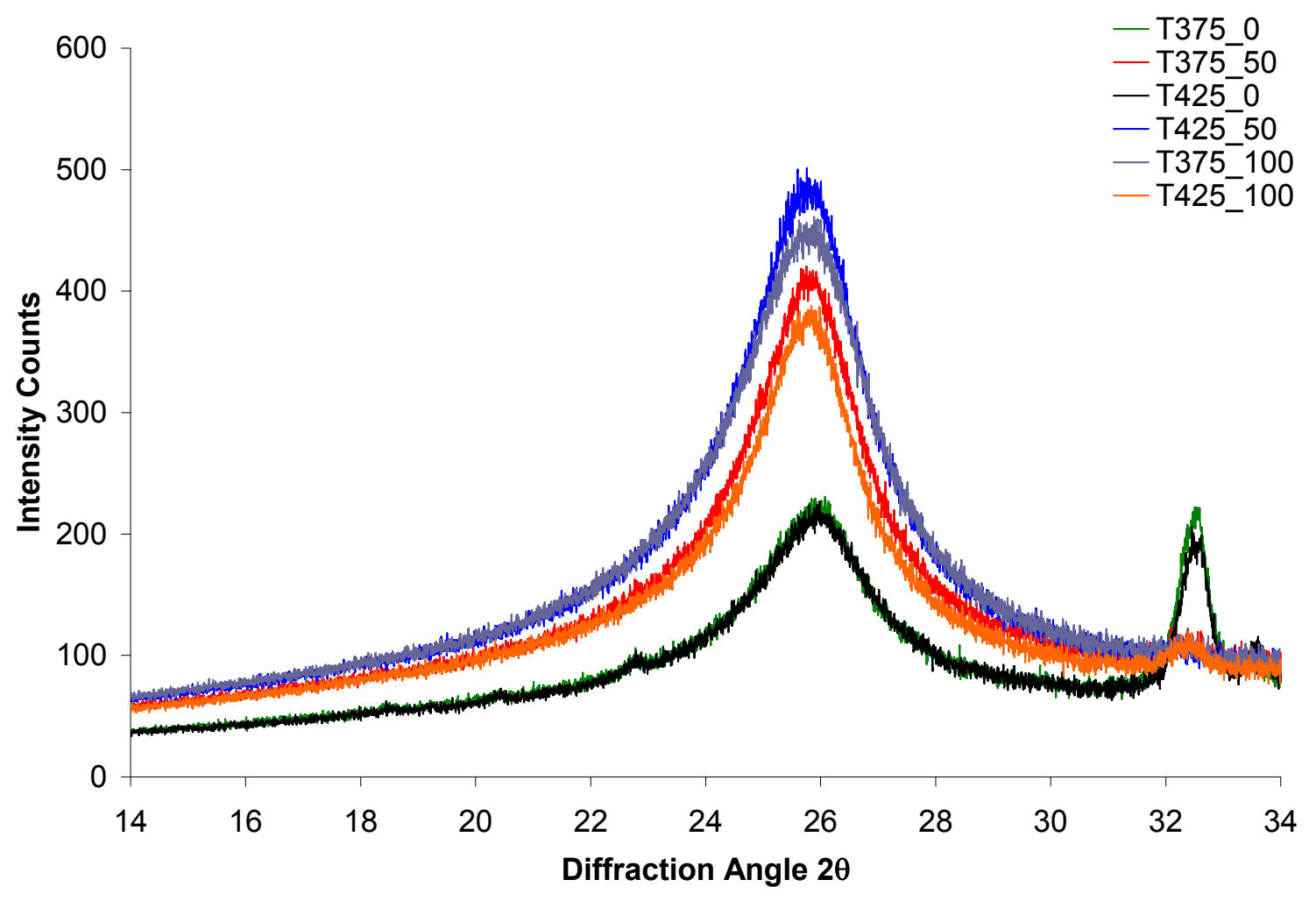

Figure 6.11 T-Series XRD Data as Tested. There is a peak at $32.5^{\circ}$ due to contamination.

Table 6.2 Crystallite Dimensions of XRD 002 Peak (Samples were as Tested)

\begin{tabular}{|c|c|c|c|c|c|}
\hline Sample & $\begin{array}{c}\text { FWHM } \\
(\boldsymbol{\theta})\end{array}$ & $\begin{array}{c}\text { Peak } \\
\text { Location }\end{array}$ & $\begin{array}{c}\text { Crystallite } \\
\text { Length, Lc }(\mathbf{\AA})\end{array}$ & $\begin{array}{c}\mathbf{d}_{\mathbf{0 0 2}} \\
\text { Spacing } \\
(\mathbf{\AA})\end{array}$ & $\begin{array}{c}\text { Proportion of } \\
\text { Disorder }\end{array}$ \\
\hline T375_0 & 2.4 & 26.1 & 16.1 & 3.42 & 0.84 \\
\hline T375_50 & 2.4 & 25.9 & 16.1 & 3.44 & 0.98 \\
\hline T375_100 & 2.1 & 25.9 & 18.6 & 3.44 & 0.98 \\
\hline T425_0 & 2.3 & 26.1 & 17.0 & 3.42 & 0.86 \\
\hline T425_50 & 2.8 & 25.9 & 14.1 & 3.44 & 1.01 \\
\hline T425_100 & 2.4 & 25.9 & 16.7 & 3.44 & 1.01 \\
\hline U375_0 & 3.2 & 25.9 & 12.4 & 3.44 & 0.98 \\
\hline U375_50 & 2.9 & 25.8 & 13.7 & 3.45 & 1.06 \\
\hline U375_100 & 3.3 & 25.9 & 12.0 & 3.44 & 0.98 \\
\hline U425_0 & 3.2 & 25.9 & 12.5 & 3.44 & 0.99 \\
\hline U425_50 & 2.8 & 25.9 & 14.1 & 3.44 & 0.98 \\
\hline U425_100 & 2.8 & 25.9 & 13.9 & 3.44 & 1.01 \\
\hline
\end{tabular}

Once the intensity XRD intensity curves were corrected an attempt to reduce the background intensity was made. The background diffraction intensity is a result of 
scattered x-rays. This is caused by vibration of molecules (temperature), air molecules, as well as amorphous material (Klug, 1974). The effects will be grouped together as background scatter. In order to compare the differences caused by the parameter change, the background intensity was determined. This can be done by establishing a straight line from at the base of the intensity curves. This is illustrated in Figure 6.12, which shows that the background line averages the fluctuations of the intensity curve. The crystalline intensity is a measure of the area below the sample intensity curve and above the background intensity line (Klug, 1974). If the degree of crystallinity is desired, reference materials of amorphous and crystalline structures can be used to establish a proportion of crystallinity. Rather a comparison of integrated crystalline intensity was established for the parameters, wiper blade stirring rate, and heat treatment temperature, listed in Section 5.1 .

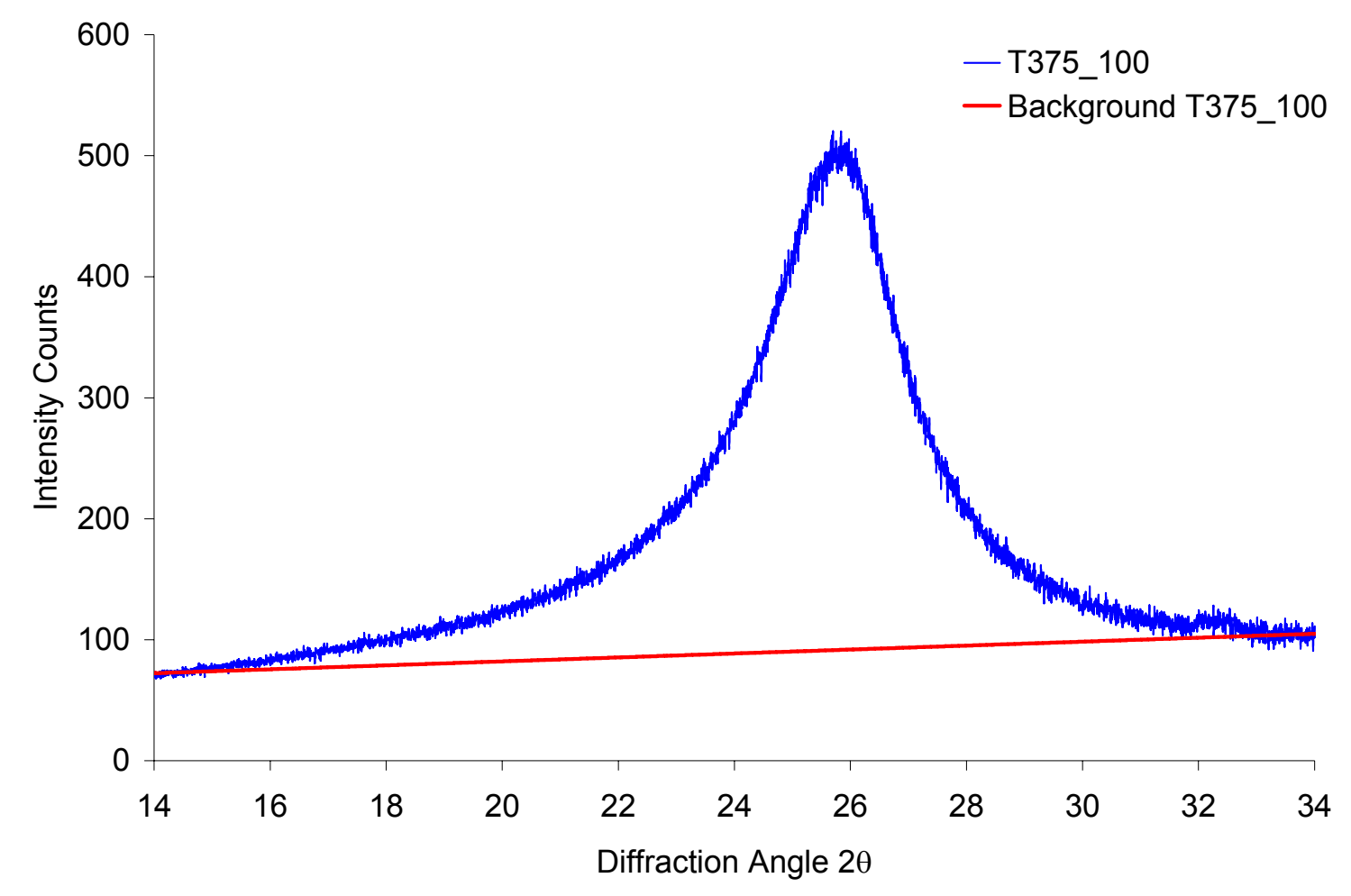

Figure 6.12 XRD Intensity Curve with Separated Crystalline and Background Region 
The main parameter effects defined by Equations 5.1, Equation 5.2, and Equation 5.3 were used with the crystalline intensity of each sample to compare parameters. After integrating the region under the intensity curves, the background value was subtracted from the total. This is the crystalline intensity value, which is used as the effect obtained from each parameter (Klug \& Alexander, 1974). The main effects due to parameter changes were calculated using the statistical analysis described in Chapter 5. The results can be seen in Table 6.3 for the as processed samples and Table 6.4 for the as tested samples. Since there are 3 stirring rate parameters and 2 temperature parameters, the data was split into two blocks for comparison shown in Figure 6.13. Block I is a comparison of the stirred reaction with the non-stirred reaction at different heat treatment temperatures whereas, Block II investigates the effects of increased stirring rate under the same heat treatments.

The value of Block I was calculated to determine the effects of stirred reactions to a control reaction with no stirring of temperatures at high and low values. The stirring had a significant effect $(B)$ relative to the temperature effect (A). There was no combined effect $(\mathrm{AB})$ observed. Block II was determined, and showed the effect of increased stirring rate. This data set was to determine the effect of shear rate on the crystallinity. It can be seen, for the as processed samples, that there was a slight negative effect from increasing the angular velocity (Effect B of Block II). There was a noticeable increase of crystallinity from parameter A (temperature). This is consistent with conventional manufacturing techniques used to produce pregraphitic carbon materials. It was noticed 
that there was a significant effect from the interaction of parameters within Block II.

This may be due to the increased viscosity at the operating temperature.

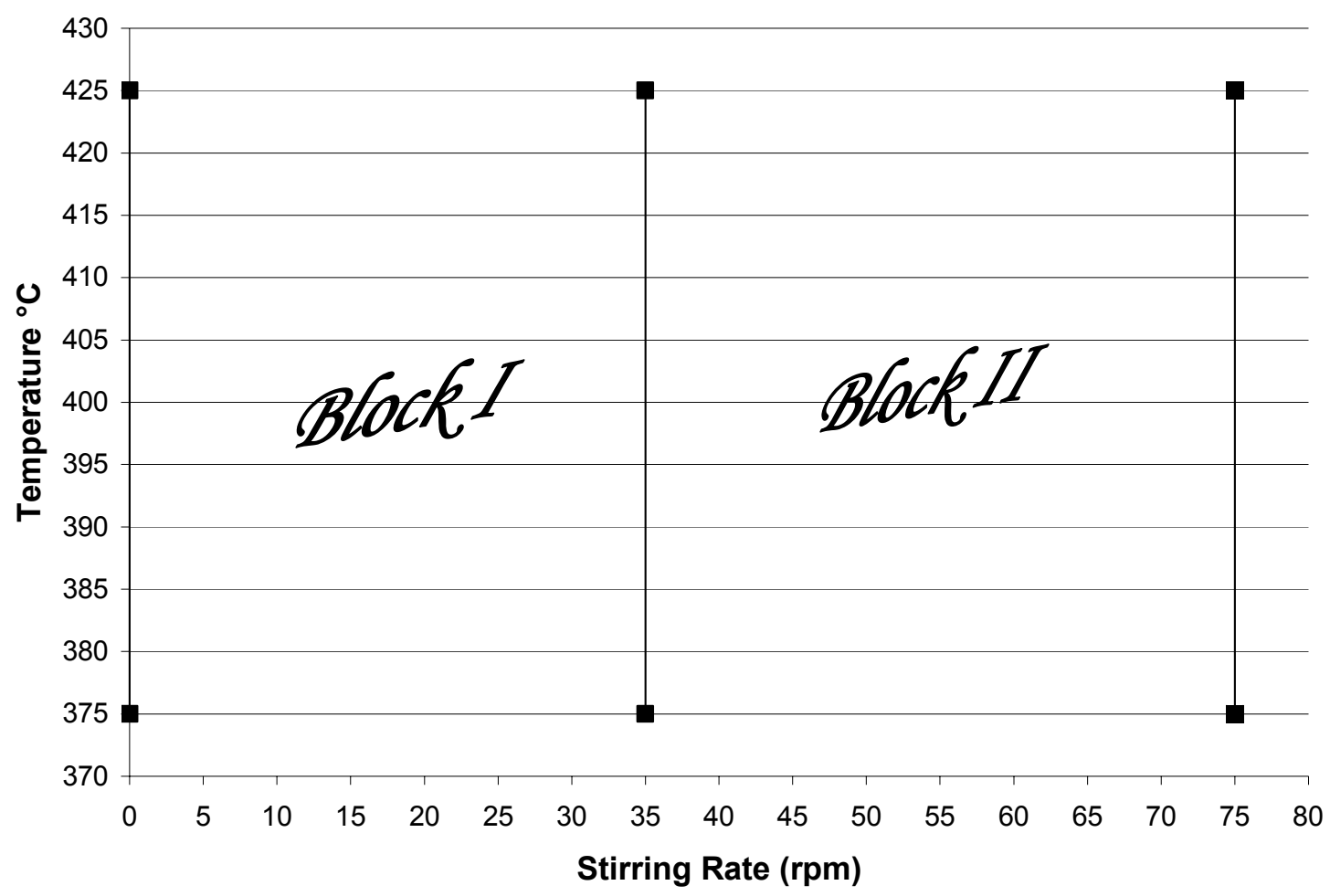

Figure 6.13 Parameter Set Points and Block Comparison Configuration

Table 6.3 Effects of Parameter Change as a Function of Crystallinity (Samples as Processed)

\begin{tabular}{|c|c|c|}
\hline Main Effect & Block I & Block II \\
\hline A (Temperature) & 137 & 155 \\
\hline B (Stirring Rate) & 420 & -50 \\
\hline AB (Combined) & -7 & 232 \\
\hline
\end{tabular}

Table 6.4 Effects of Parameter Change as a Function of Crystallinity (Samples as Tested)

\begin{tabular}{|c|c|c|c|c|c|c|}
\cline { 2 - 7 } \multicolumn{1}{c|}{} & \multicolumn{3}{c|}{ Block I } & \multicolumn{3}{c|}{ Block II } \\
\hline Main Effect & T series $^{*}$ & U series & Average & T series & U series & Average \\
\hline A (Temperature) & 3 & -11 & -4 & -10 & -3 & -6 \\
\hline B (Stirring Rate) & 34 & -48 & -7 & 5 & -30 & -12 \\
\hline AB (Combined) & 3 & 4 & 3 & -15 & 4 & -5 \\
\hline
\end{tabular}

* Contamination in $\mathrm{T}$ series samples without stirring reduced the crystallinity 
The effects of temperature and wiper blade angular velocity were determined by a measure of crystallinity. Figure 6.14 shows the increase of crystalline intensity as a function of temperature change. The temperature has a rather consistent effect on the crystallinity of the carbon. Figure 6.15 shows the nonlinear effect of shear rate on the crystallinity. From 0 to $50 \%$ stirring speed, 0 and $35 \mathrm{rpm}$ respectively, it can be seen that the crystallinity increased at a similar rate for the two temperature effects. During the increment of 35 and $75 \mathrm{rpm}$, the values decreased slightly. The other notable difference is that the lines are no longer parallel to each other. These are believed to be a result of the fluid mechanics. It is possible that the higher stirring rate caused turbulence in the liquid which disrupted the reorganization of carbon.

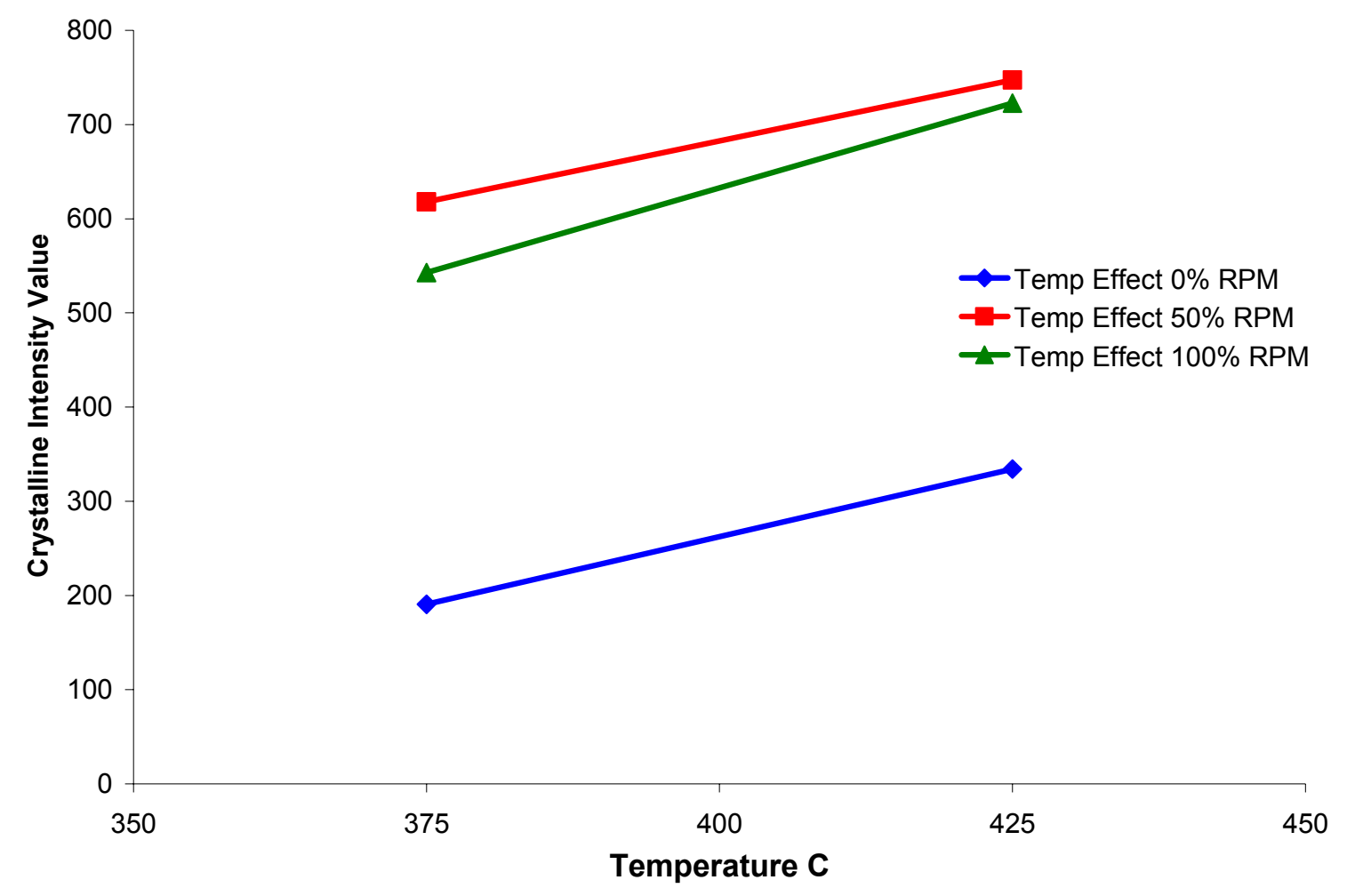

Figure 6.14 Crystalline Intensity Value as a Function of Temperature (T-Series as Processed) 


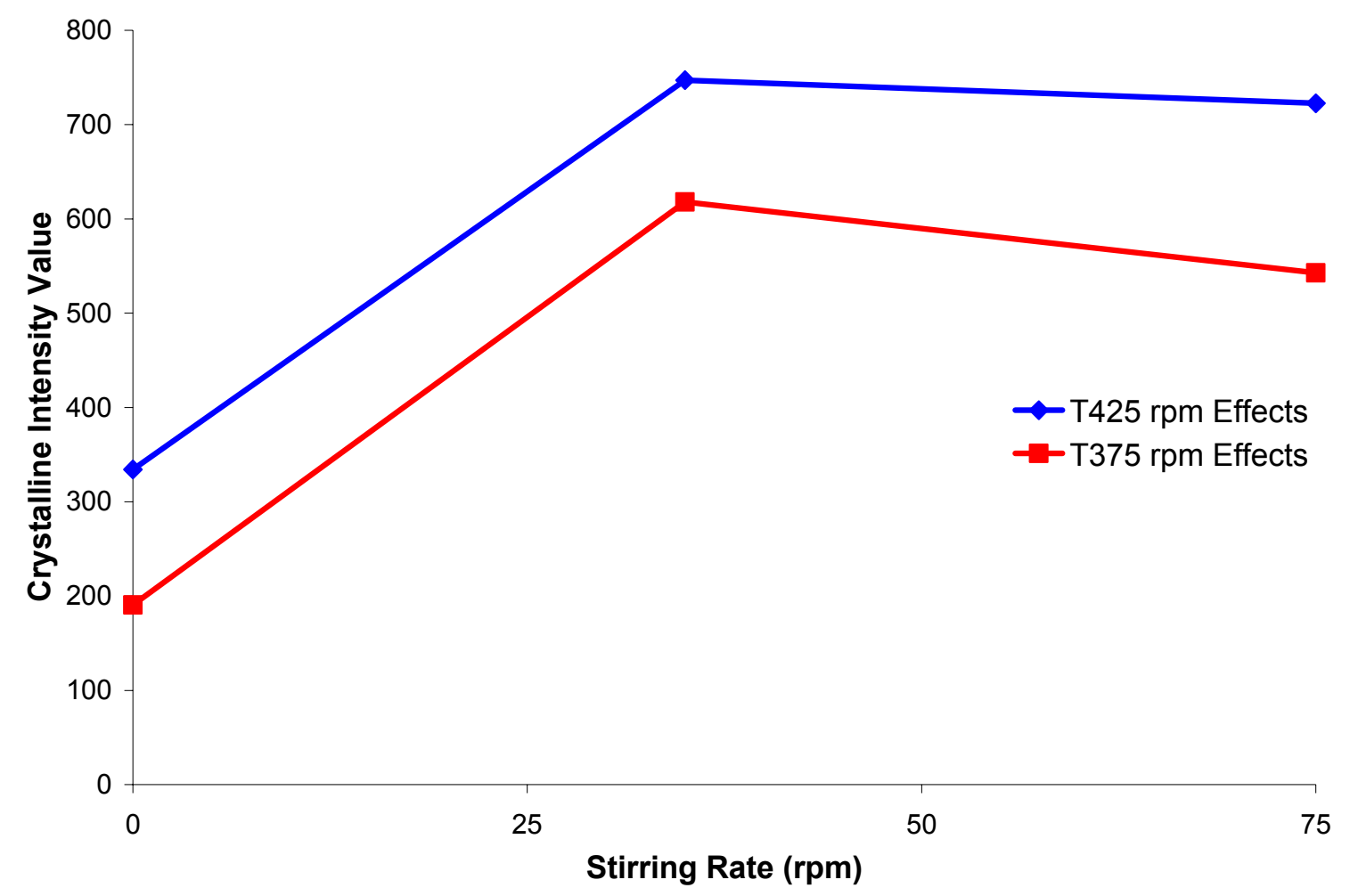

Figure 6.15 Crystalline Intensity Value as a Function of Wiper Speed (T-Series as Processed)

The crystalline diffraction patterns observed in Figure 6.10 and Figure 6.11 of $\mathrm{U}$ series and $\mathrm{T}$ series respectively, were analyzed. The main effects were determined as shown in Table 6.4. The effect on the comparative crystalline value due to the changes of temperature can be seen in Figure 6.16. The figure showed that there was very little difference between the temperature effects. The final coking temperature of $450^{\circ} \mathrm{C}$ was reached for all samples. Heat treatment of the samples to a uniform temperature was performed in order to eliminate the differences due to final temperature. Recall that there was high ash values that would have reduced the mesophase domain growth for the samples T375_0 and T425_0. The ash explains why the crystalline formation was low for the $\mathrm{T}$ series $0 \mathrm{rpm}$ show in Figure 6.16 in black. 


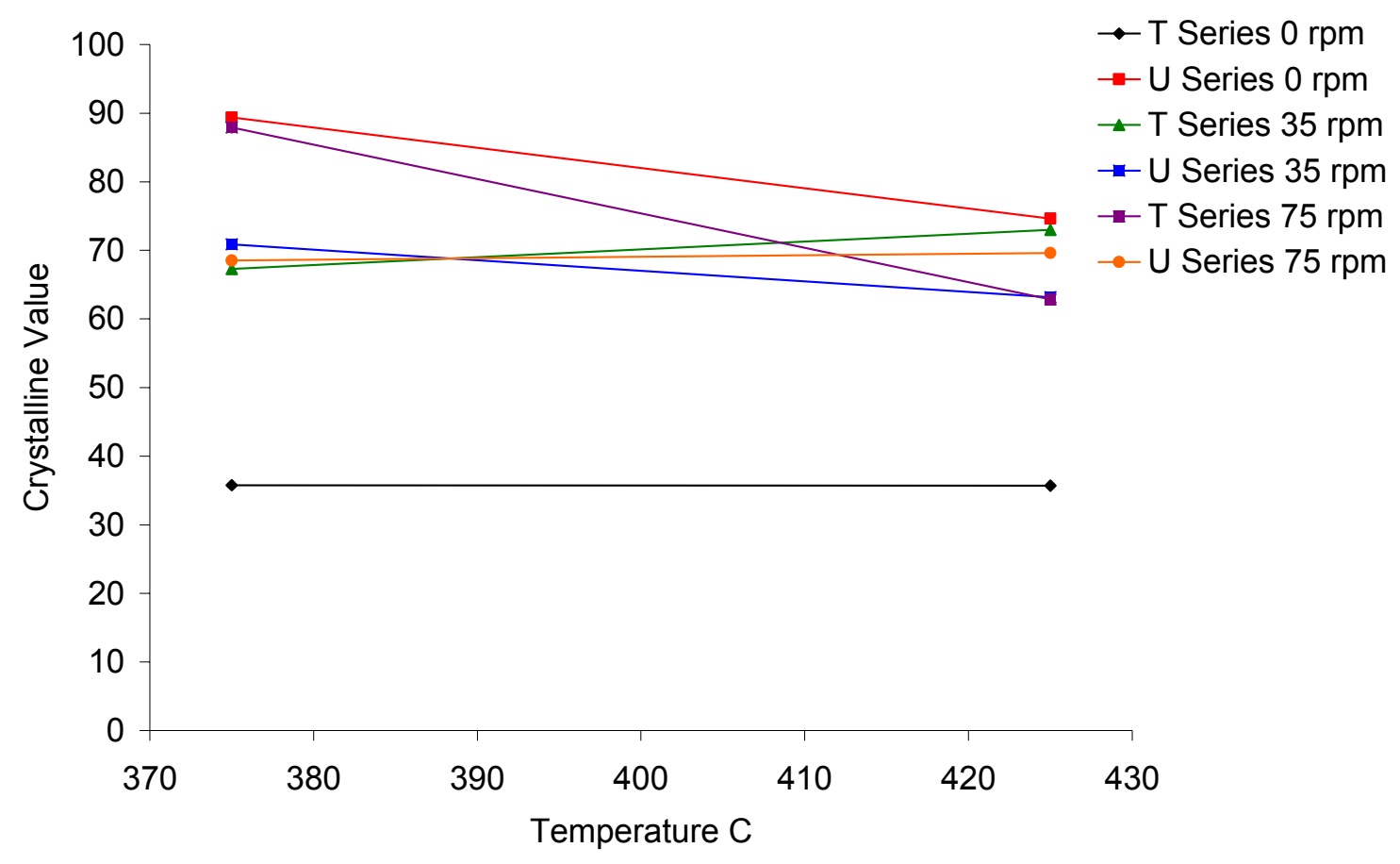

Figure 6.16 Temperature Effects on Crystallinity of Green Coke

The effect on the crystallinity of the green coke due to the stirring rates was determined and is displayed in Figure 6.17. The blue and orange data series are for the $\mathrm{T}$ series coke samples. At $0 \mathrm{rpm}$ the samples, again, were contaminated and the data points should not be considered. It can be seen using the $\mathrm{U}$ series data that a slight reduction of crystallinity occured from 0 to $35 \mathrm{rpm}$. This could be a result of more rapid heating, as the entire sample was heated uniformly due to stirring. Between the $35 \mathrm{rpm}$ and $75 \mathrm{rpm}$ stirring rates in Figure 6.17, two of the samples increase crystallinity and two decrease. Sample selection, and sample preparation for XRD may have caused the differences seen in crystalline values. 


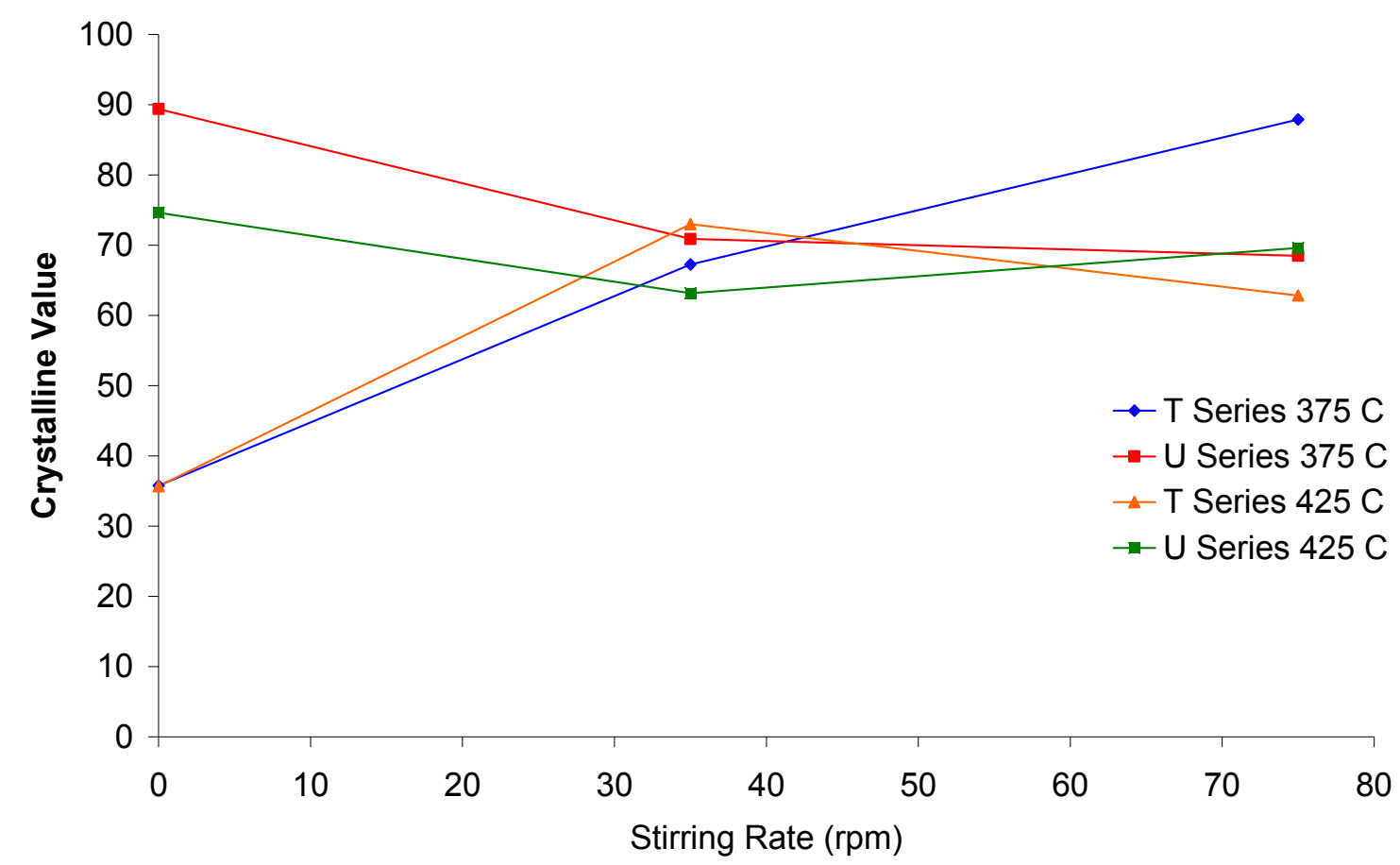

Figure 6.17 Effect of Stirring Rate on Crystallinity of Green Coke

\subsection{Polarized Light Optical Microscopy}

Representative samples of the pitch feed material, and subsequent coke was sent to Graf Tech International (GTI) where polarized light microgaphs were obtained. Each figure contains two images, a back field (left) and polarized light (right). The pitch contained very few quinoline insolubles $(\mathrm{QI})$. The very low QI $(<2.5 \%)$ enables the crystalline domain growth. In Figure 6.18 a larger circular structure with sections within can be observed in the upper left region of the figure. That particular structure is known as carryover QI. It is a char that was carried over from the coke oven to the tar distillation process. The carryover QI here is known as a cenosphere from the spherical shape and porous center. Figure 6.19 shows the cenosphere at 500x magnification. The 
cenosphere is about $63 \mu \mathrm{m}$ in diameter. The smaller spherical structures are mesophase suspended in the coal tar matrix. These mesophase structures are best seen in Figure 6.20. In the polarized light micrograph on the right of the figure the mesophase spherules appear to be darker in some regions of the circular area shown. This is due to the lamellar structure within the liquid crystalline mesophase.
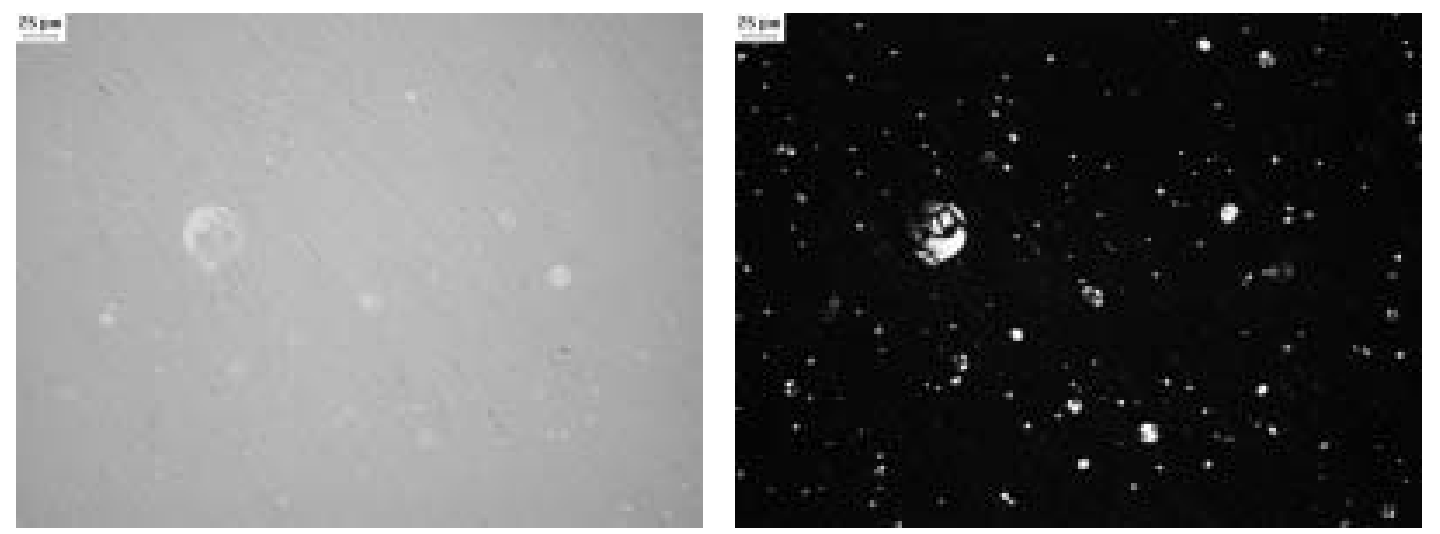

Figure 6.18 Coal Tar Pitch from Koppers Inc. Magnification 200X Note: Carryover QI in Glassy Coal Tar Pitch Matrix and Fine Mesophase Spherules
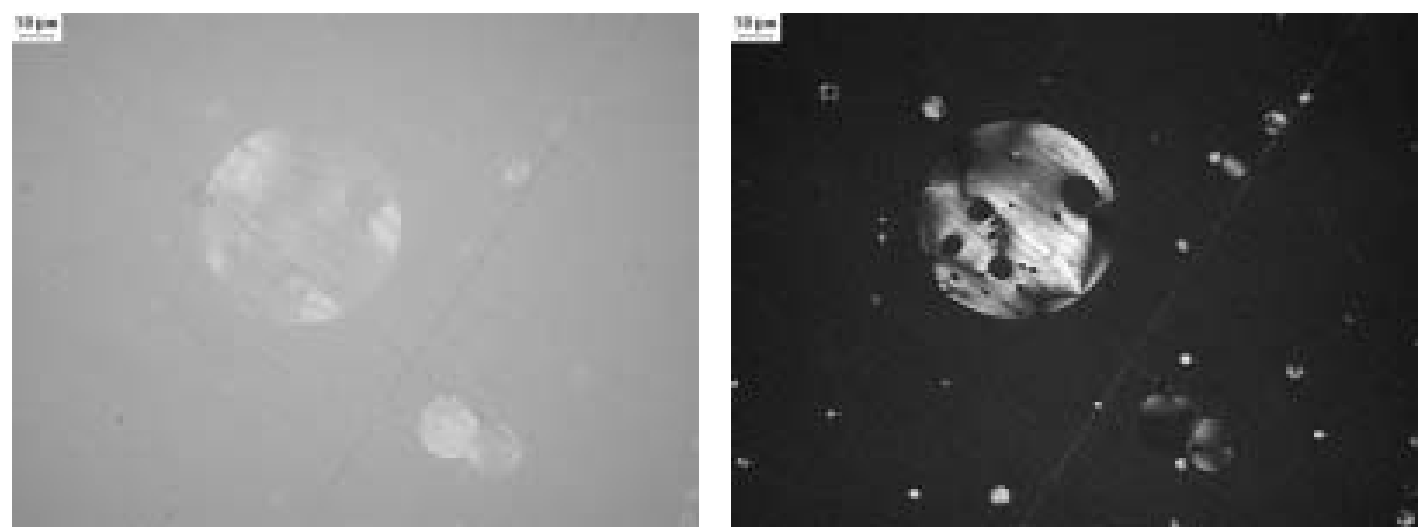

Figure 6.19 Coal Tar Pitch from Koppers Inc. Magnification 500X Note: Large Carryover QI in Glassy Coal Tar Pitch Matrix 

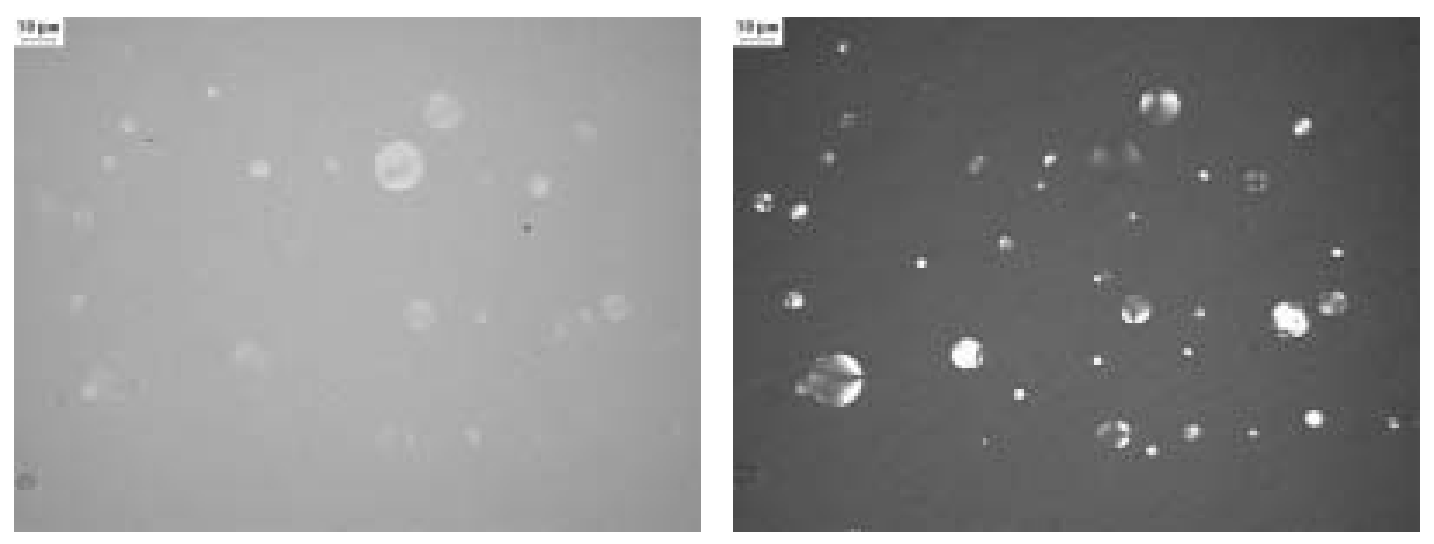

Figure 6.20 Coal Tar Pitch from Koppers Inc. Magnification 500X Note: Mesophase Spherule Structures

Varying degrees of sponge coke were produced. The green coke had many domains that were anisotropic. The anisotropic domain textures varied from fine lenticular to fine ribbon. There were enclosed void regions, known as vesicles, where gases escaped the mass during devolatilization. Coke micrographs in Figure 6.21 to Figure 6.25 were formed by devolatilizing coal tar pitch for several hours at the prescribed rate until coking was complete. These images showed the structural formation of coke from thermal treatment at $375^{\circ} \mathrm{C}$. During visual inspection the sponge coke produced without the applied shear stress appeared to have larger and fewer vesicles or pores. In Figure 6.21 large vesicles can be seen as well as a mosaic of anisotropic structures. Figure 6.22 show medium lenticular structures and fine ribbon structures at the middle to the lower left corner of the image. Higher magnifications of Figure 6.21 and 6.22 were observed. Figure 6.23 has medium to coarse lenticular structures and large vesicles that appear black in the polarized light image. Further magnification of Figure 6.22 is shown in Figure 6.24 and 6.25. These figures display the medium to coarse lenticular structure. In Figure 6.25 the domain boundary can be clearly observed between the lenticular and the ribbon structures. There is a fissure along the boundary layers of 
the domains. The internal stresses induced by shrinkage upon cooling caused the fissure.

The fissure is seen best in the backfield image on the left of Figure 6.25 .
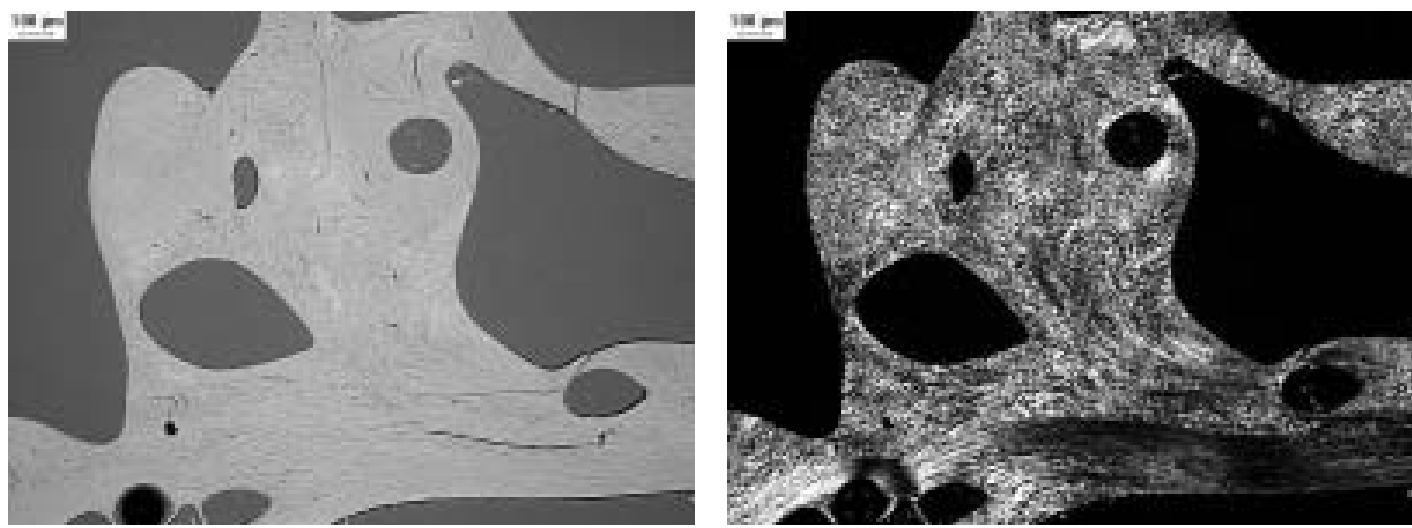

Figure 6.21 Green Coke Texture Induced by Heat Treatment. Magnification 50X
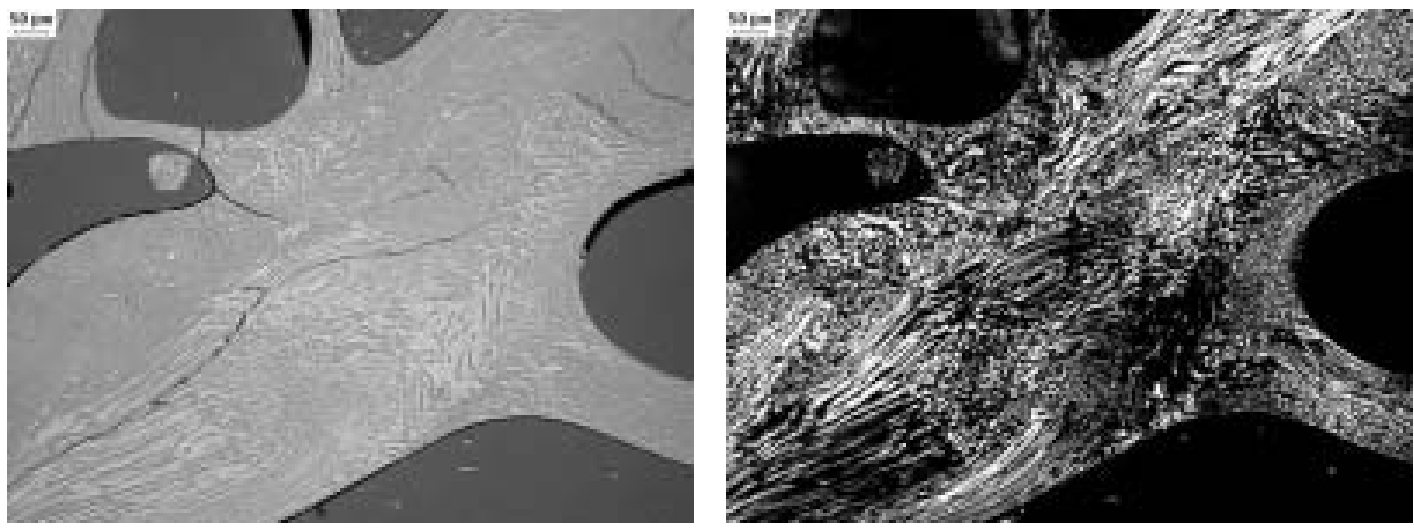

Figure 6.22 Green Coke Texture Induced by Heat Treatment. Magnification 100X
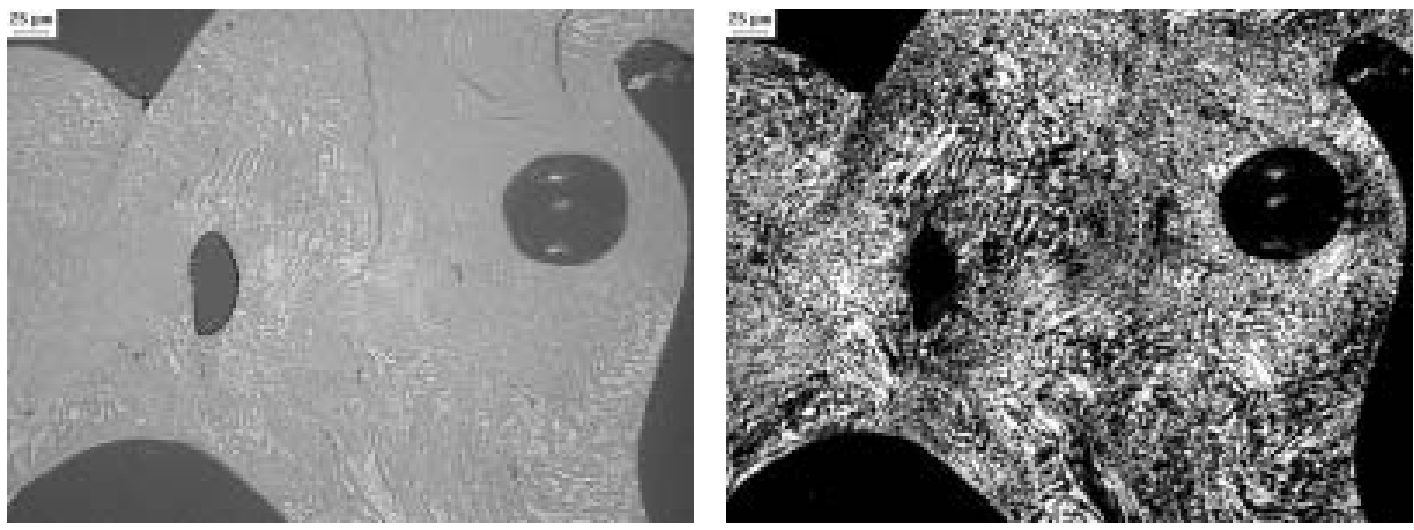

Figure 6.23 Green Coke Texture Induced by Heat Treatment. Magnification 200X 

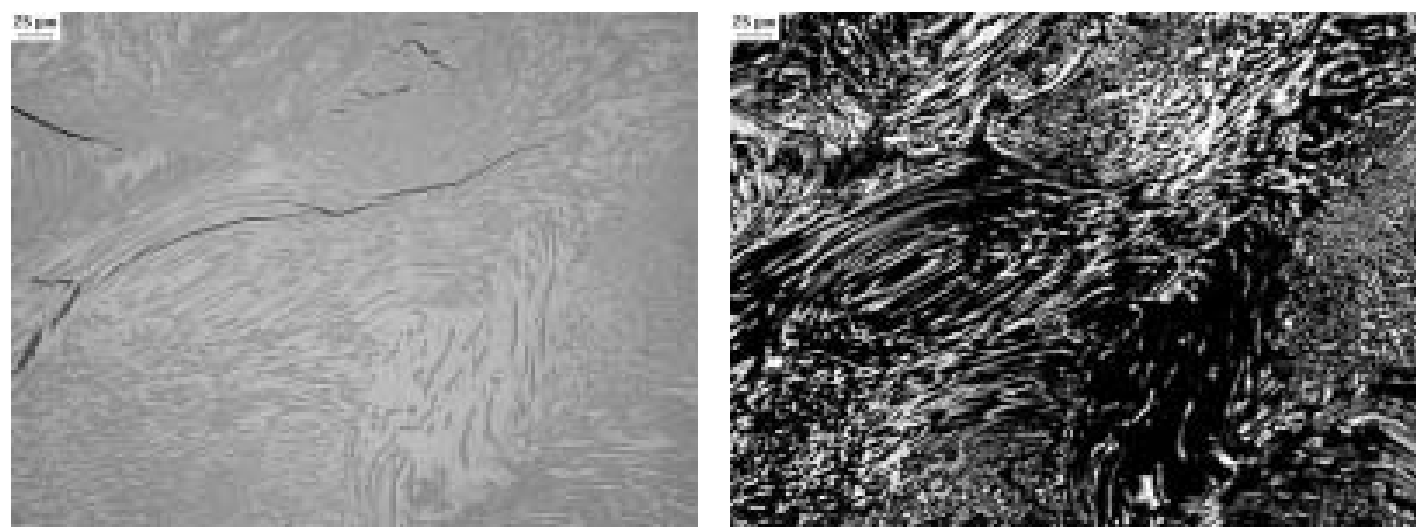

Figure 6.24 Green Coke Texture Induced by Heat Treatment. Magnification 200X
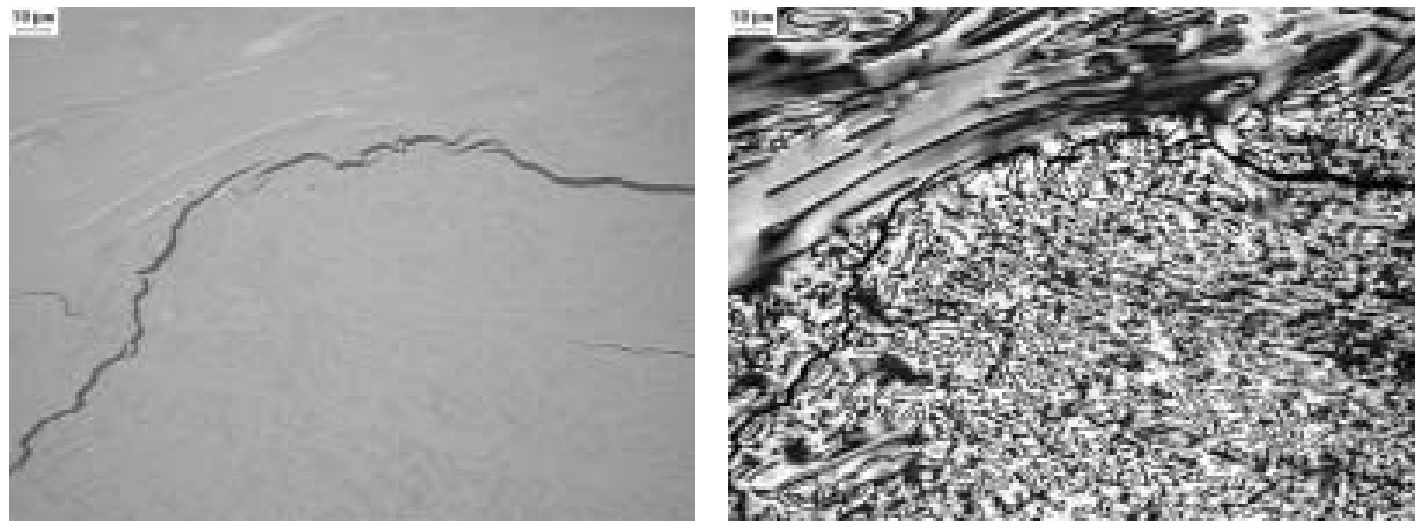

Figure 6.25 Green Coke Texture Induced by Heat Treatment. Magnification 500X

Coke samples obtained from heat treatment at $425^{\circ} \mathrm{C}$ are shown in Figure 6.26 to 6.29. The sample in Figure 6.26 has medium to coarse lenticular structures. Left of center is a region of incipient fine circular coke. In Figure 6.28 the incipient circular coke was observed at $500 \mathrm{X}$ magnification. The circular structures are less than $3 \mu \mathrm{m}$ in diameter. Medium to coarse lenticular domains dominate the image in Figure 6.27 and also at 500X magnification in Figure 6.29. There are no observed flow domains in the images of the sample T425_0 shown in Figure 6.26 through Figure 6.29. 

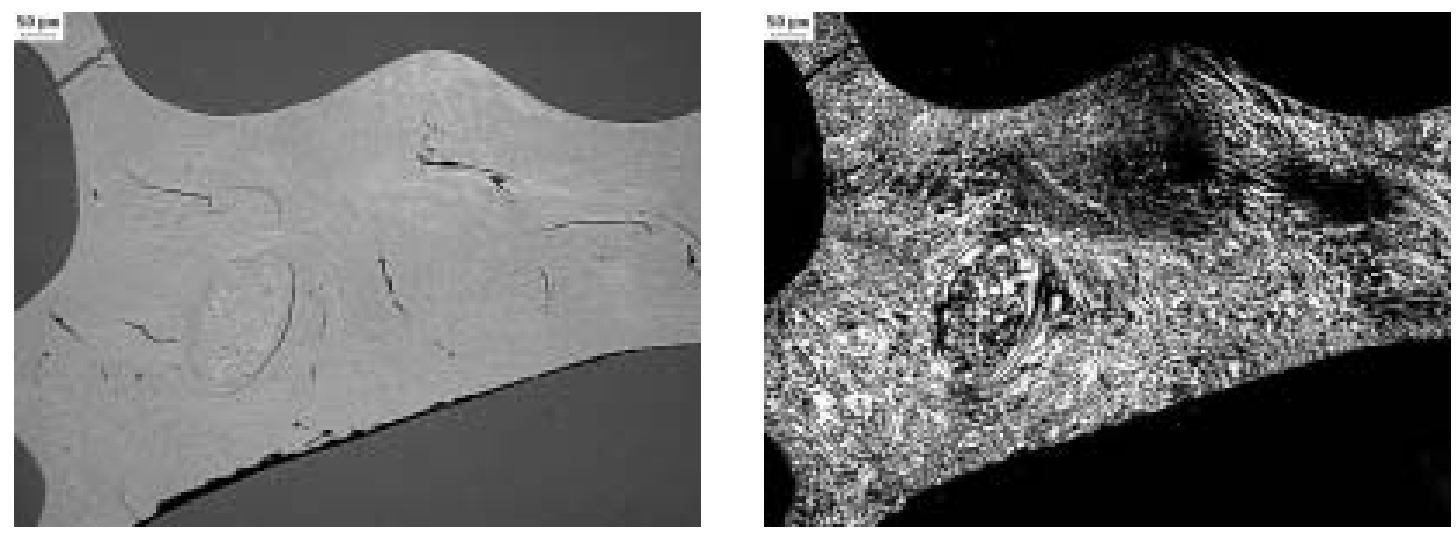

Figure 6.26 Green Coke Texture Induced by Heat Treatment. Magnification 50X
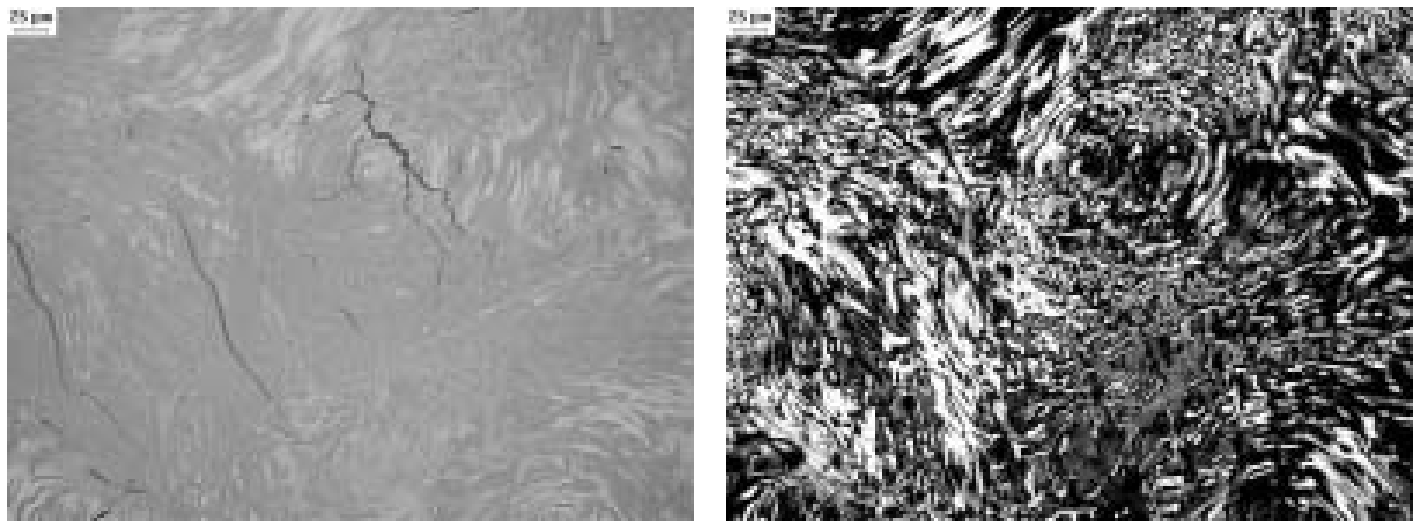

Figure 6.27 Green Coke Texture Induced by Heat Treatment. Magnification 200X
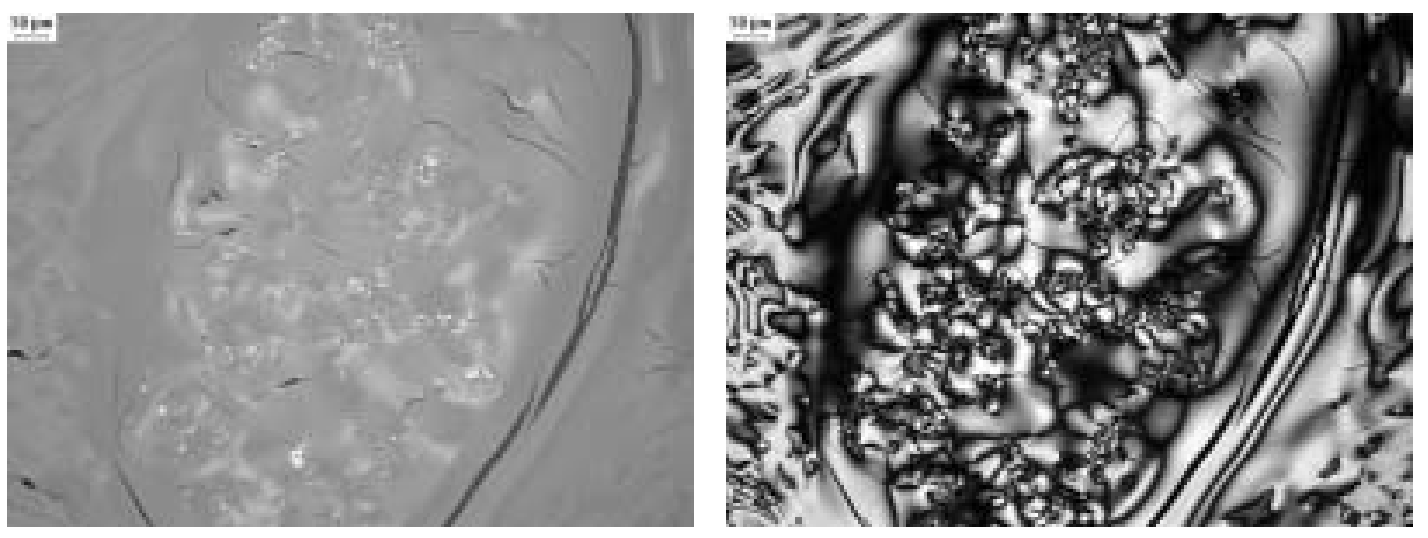

Figure 6.28 Green Coke Texture Induced by Heat Treatment. Magnification 500X 

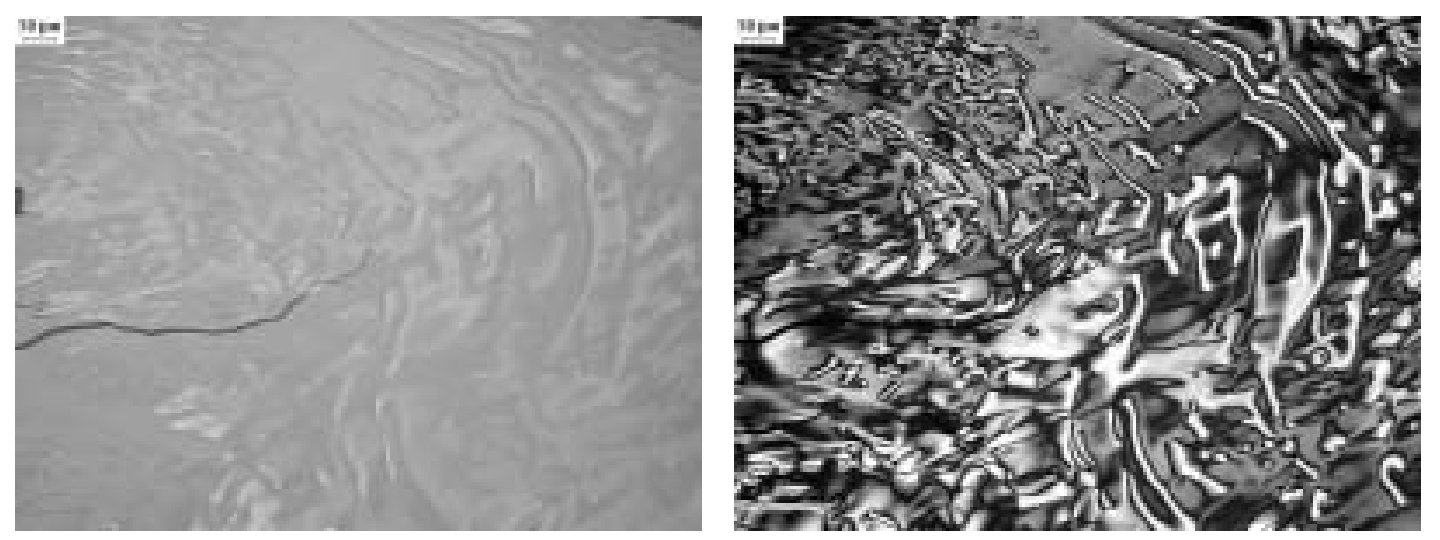

Figure 6.29 Green Coke Texture Induced by Heat Treatment. Magnification 500X

Samples of green coke were produced at heat treatment temperatures of $375^{\circ} \mathrm{C}$

and stirred with a wiper blade at 35 revolutions per minute (rpm). The images of the induced texture coke by the aforementioned conditions are shown below in Figures 6.30 to 6.37 . Figures 6.30 to 6.33 were observed at the plane parallel to the tangent of the reactor wall. This location showed the effects of the stress and was compared to the images taken perpendicular to the tangent of the reactor wall. Elongated vesicles and fine ribbon structures composed the image of Figure 6.30. Coarse lenticular structures of coke can be seen in Figure 6.31. The white colored figures in the backfield photo are entrained mounting epoxy. The elongated vesicles were shown in Figure 6.32 along with fine ribbon wall structures. The fine ribbon is further magnified and shown in Figure 6.33. Note the striated texture of the pore wall. 

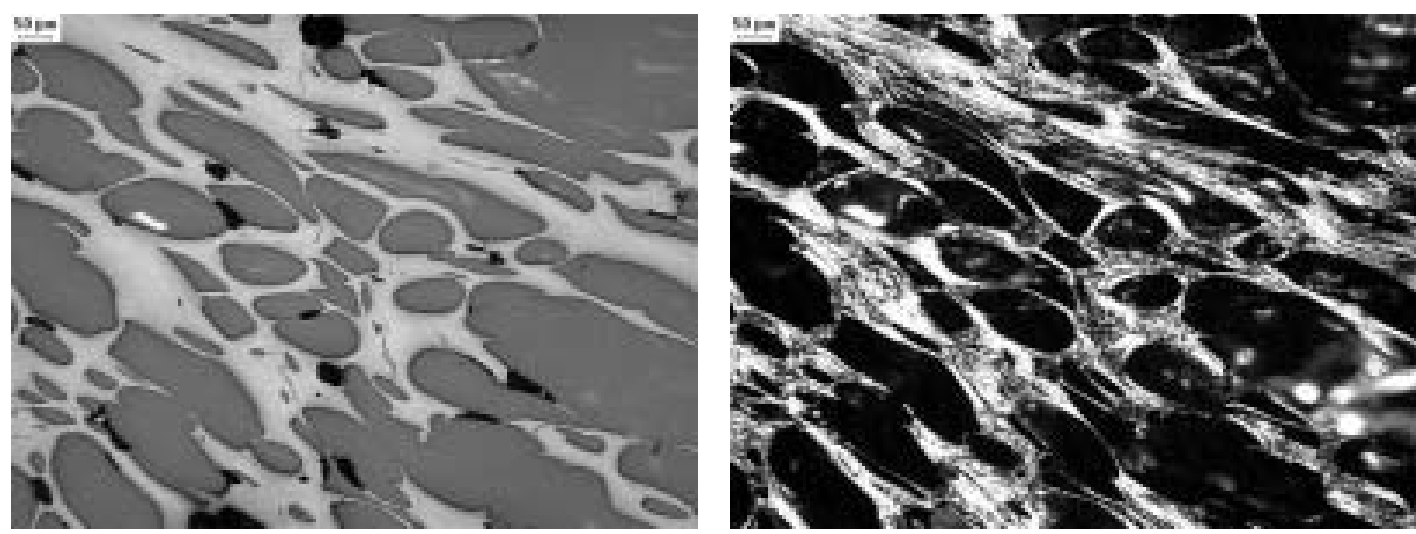

Figure 6.30 Green Coke Texture Produced from Thermal and Shear Stress. Magnification 100X
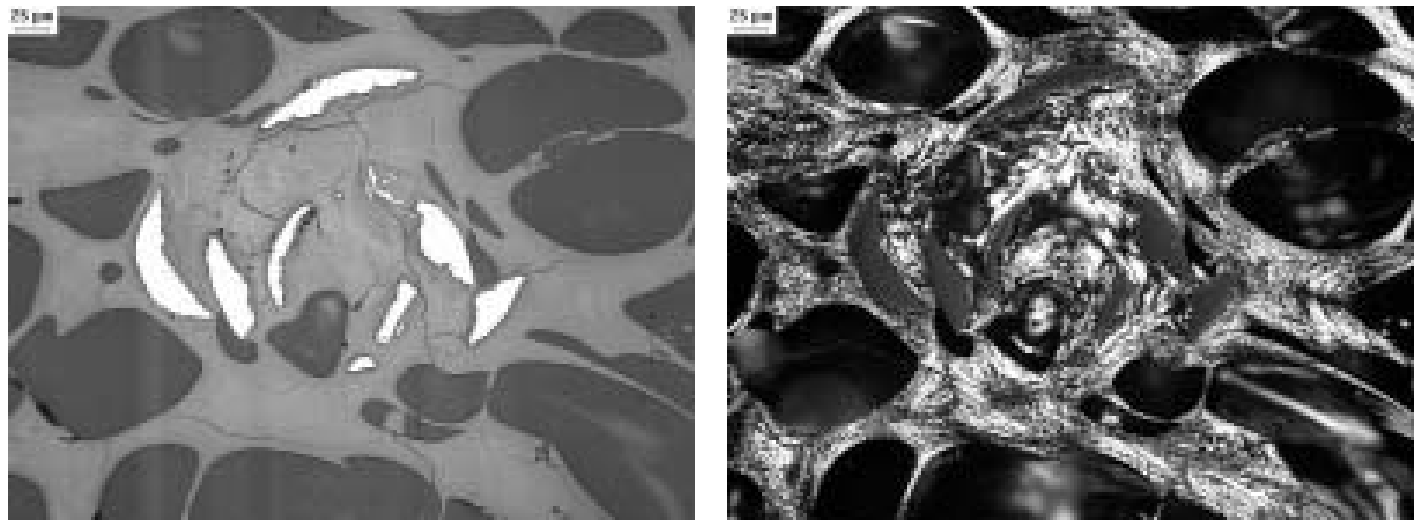

Figure 6.31 Green Coke Texture Produced from Thermal and Shear Stress. Magnification 200X
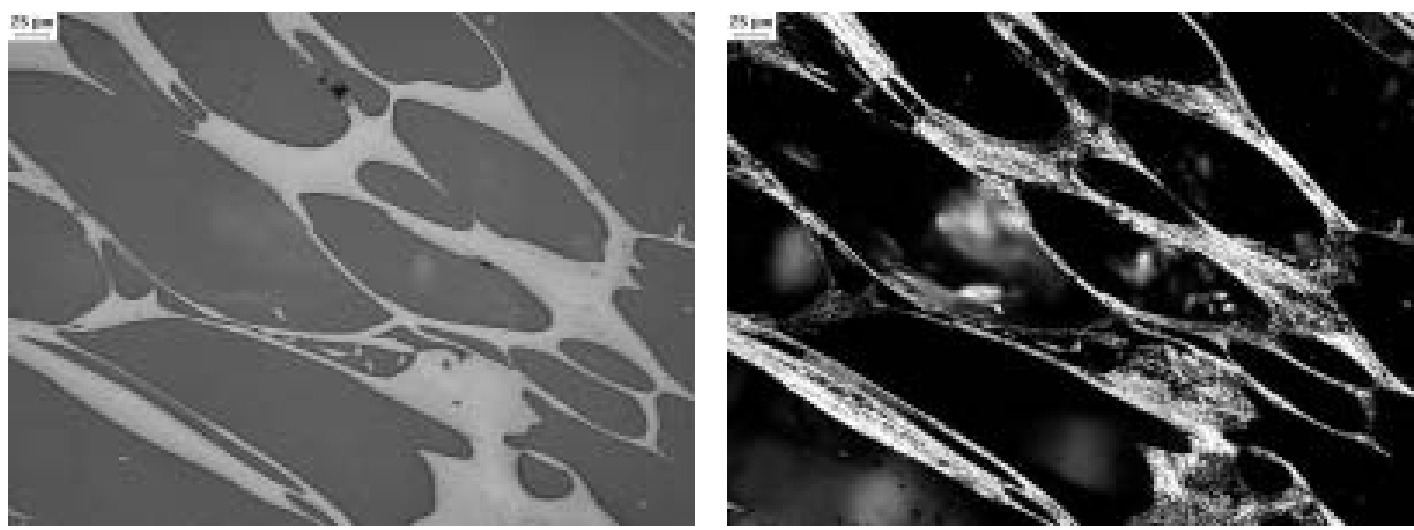

Figure 6.32 Green Coke Texture Produced from Thermal and Shear Stress. Magnification 200X 

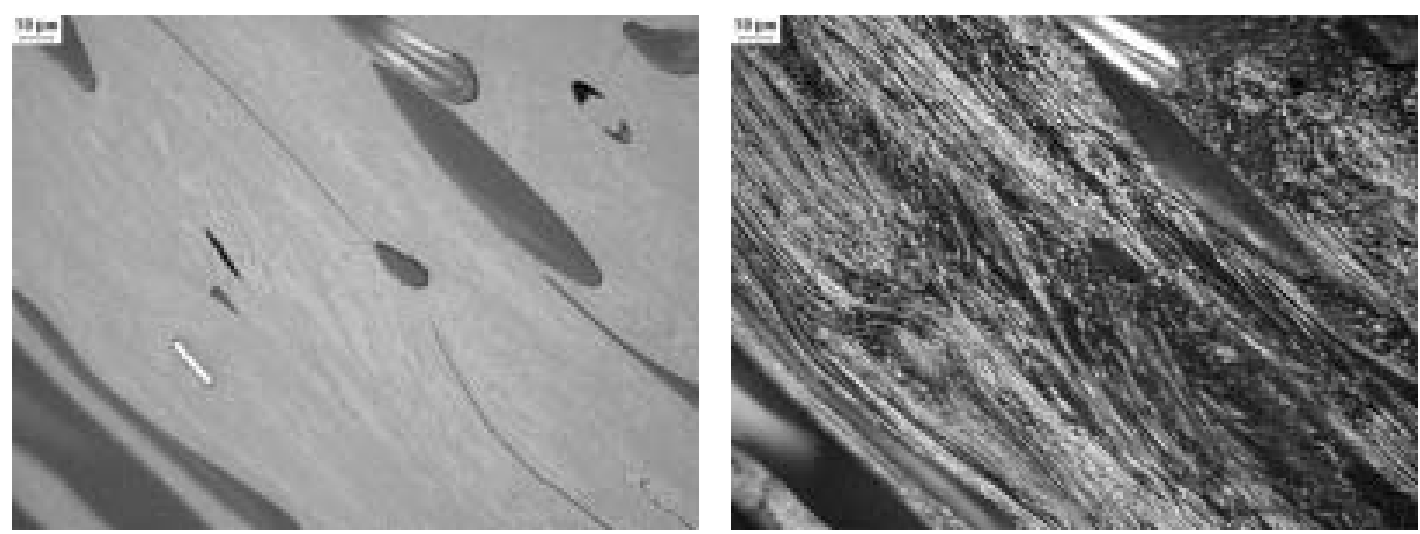

Figure 6.33 Green Coke Texture Produced from Thermal and Shear Stress. Magnification 500X

The coke sample T350_0 was also observed at an angle perpendicular to the tangent of the reactor wall. These images showed round vesicles and fine to medium lenticular arrangements. In Figure 6.34 there is a repeated circular pore structure. Figure 6.35 showed the lenticular structure, which is magnified in Figure 6.37. Even in Figure 6.37 there is no evidence of a ribbon structure. It also is composed of fine to medium lenticular structures with no visible flow domains.
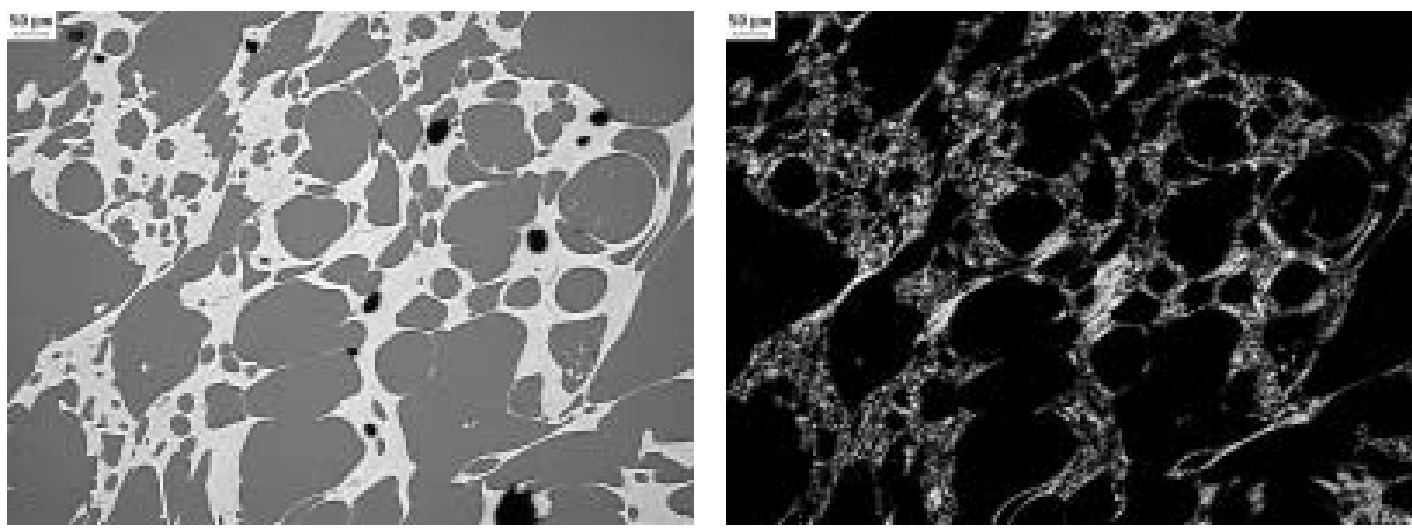

Figure 6.34 Green Coke Texture Produced from Thermal and Shear Stress. Magnification 100X 

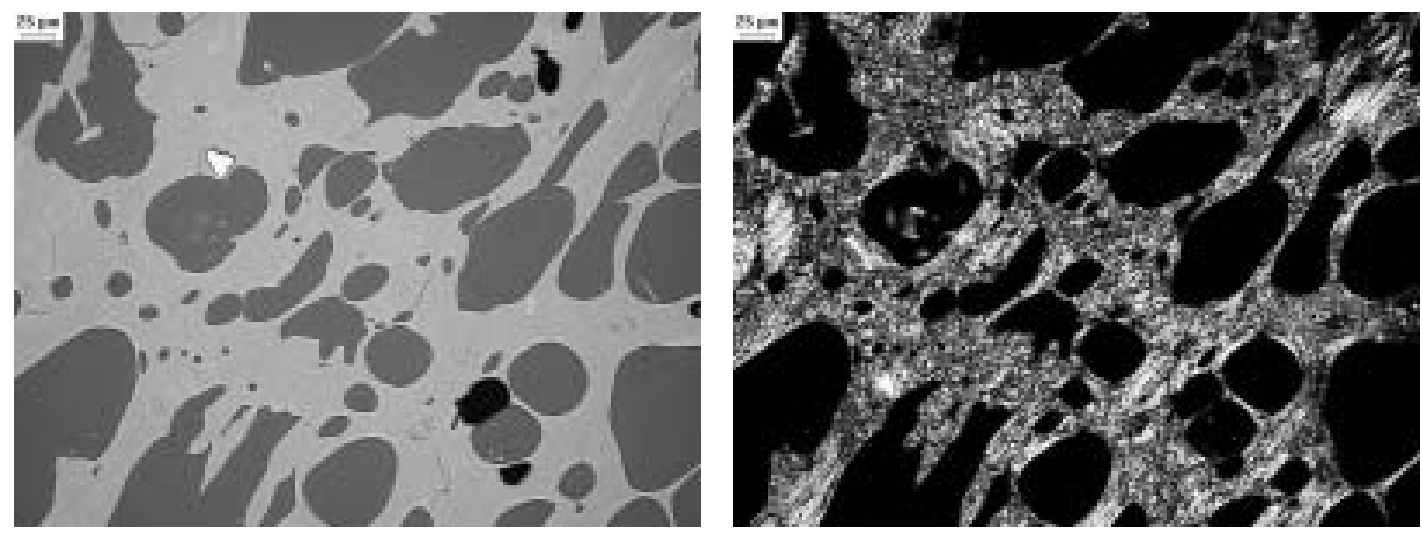

Figure 6.35 Green Coke Texture Produced from Thermal and Shear Stress. Magnification 200X
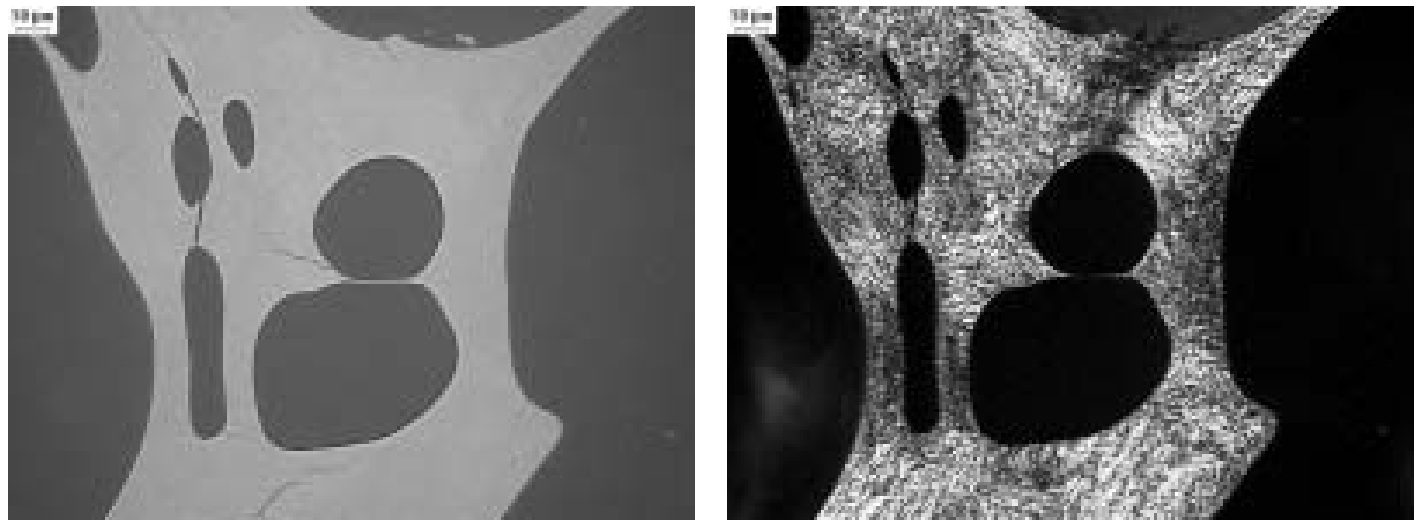

Figure 6.36 Green Coke Texture Produced from Thermal and Shear Stress. Magnification 500X
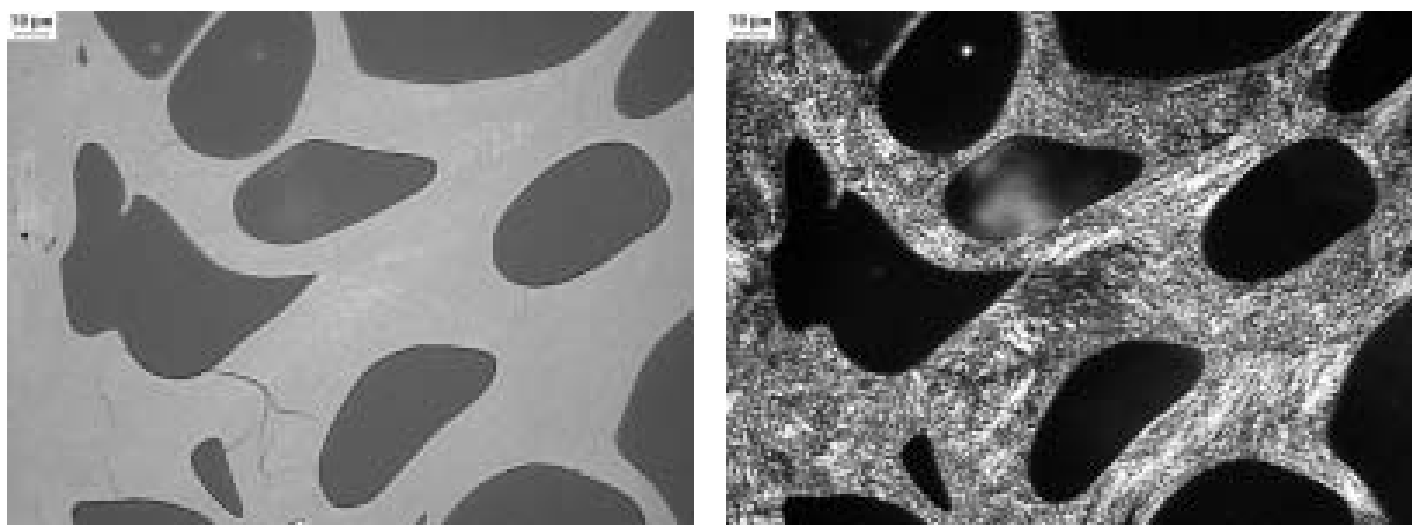

Figure 6.37 Green Coke Texture Produced from Thermal and Shear Stress. Magnification 500X

The following images (Figures 6.38 to Figure 6.41) were obtained by optical

microscopy of the coke sample T425_50. The coke was produced at $425^{\circ} \mathrm{C}$ and $35 \mathrm{rpm}$.

A mixed layer structure can be seen in Figure 6.38, with fine ribbon and coarse lenticular structures. Figure 6.39 showed that the stirring caused the vesicles to elongate. As seen previously, the vesicle walls contain fine ribbon structures. Figure 6.40 shows the 
magnified mixed layer structure with fine ribbon and coarse lenticular structures. And in Figure 6.41 fine ribbon structures are observed at high magnification. These images indicate a very anisotropic coke.
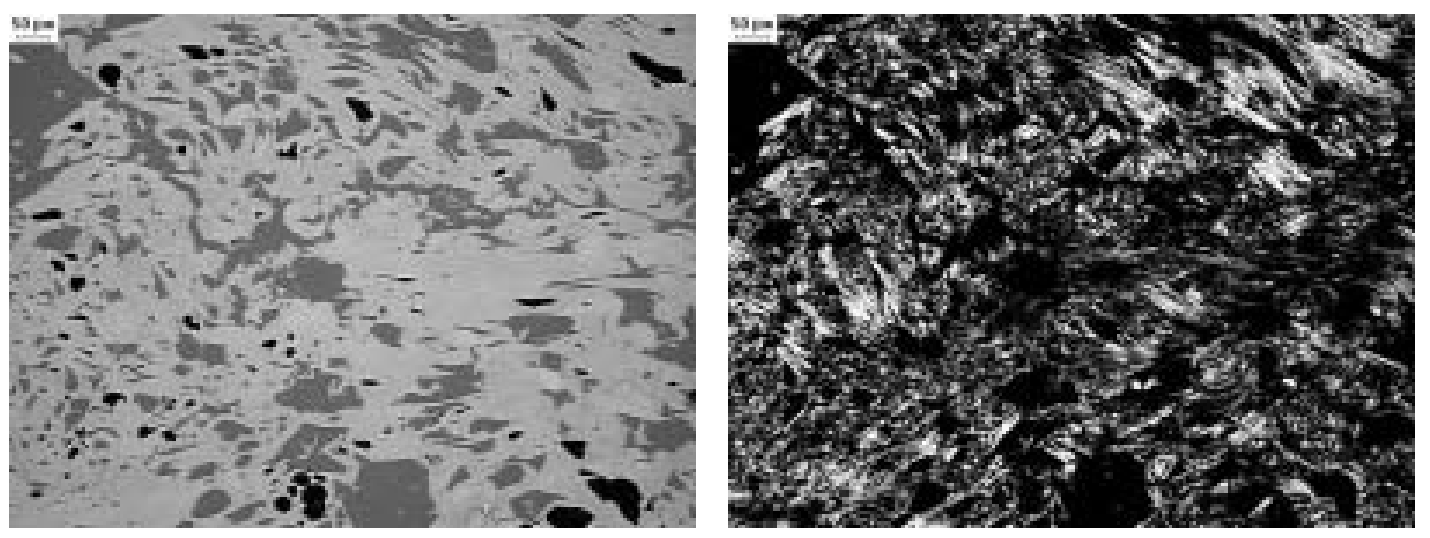

Figure 6.38 Green Coke Texture Produced from Thermal and Shear Stress. Magnification 100X
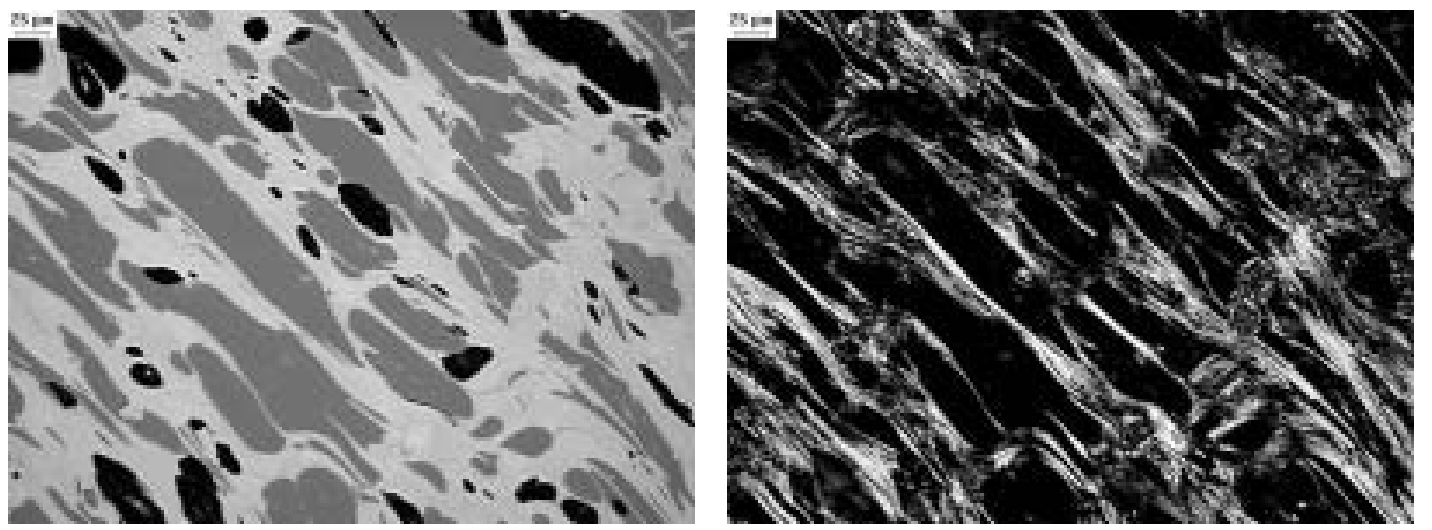

Figure 6.39 Green Coke Texture Produced from Thermal and Shear Stress. Magnification 200X
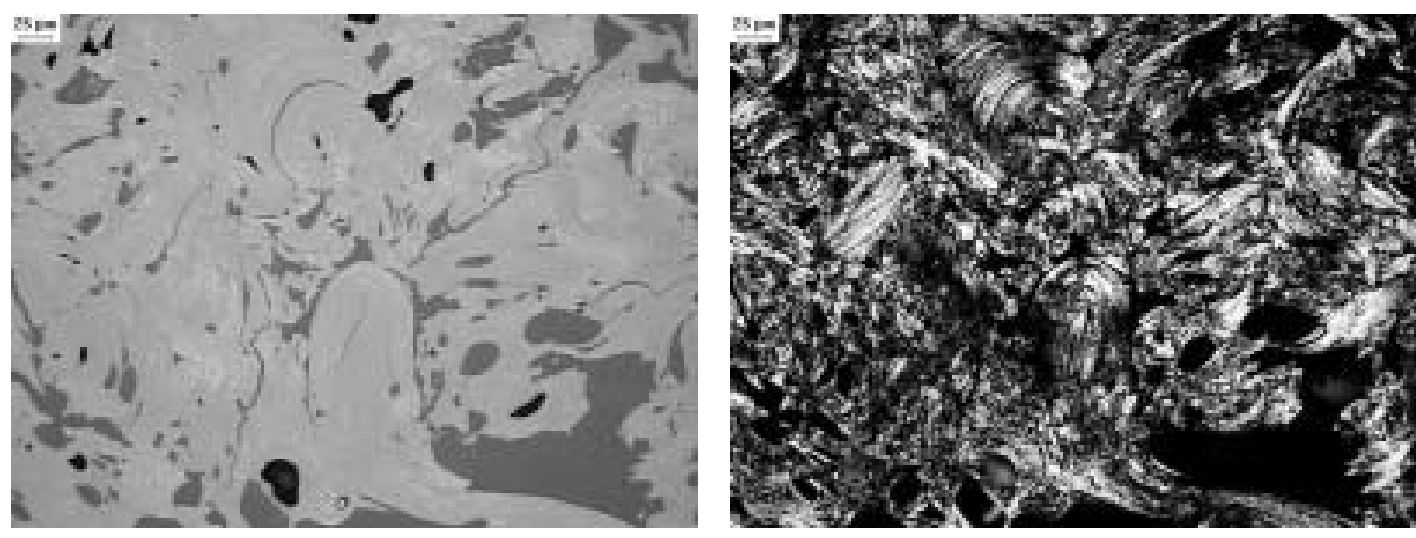

Figure 6.40 Green Coke Texture Produced from Thermal and Shear Stress. Magnification 200X 

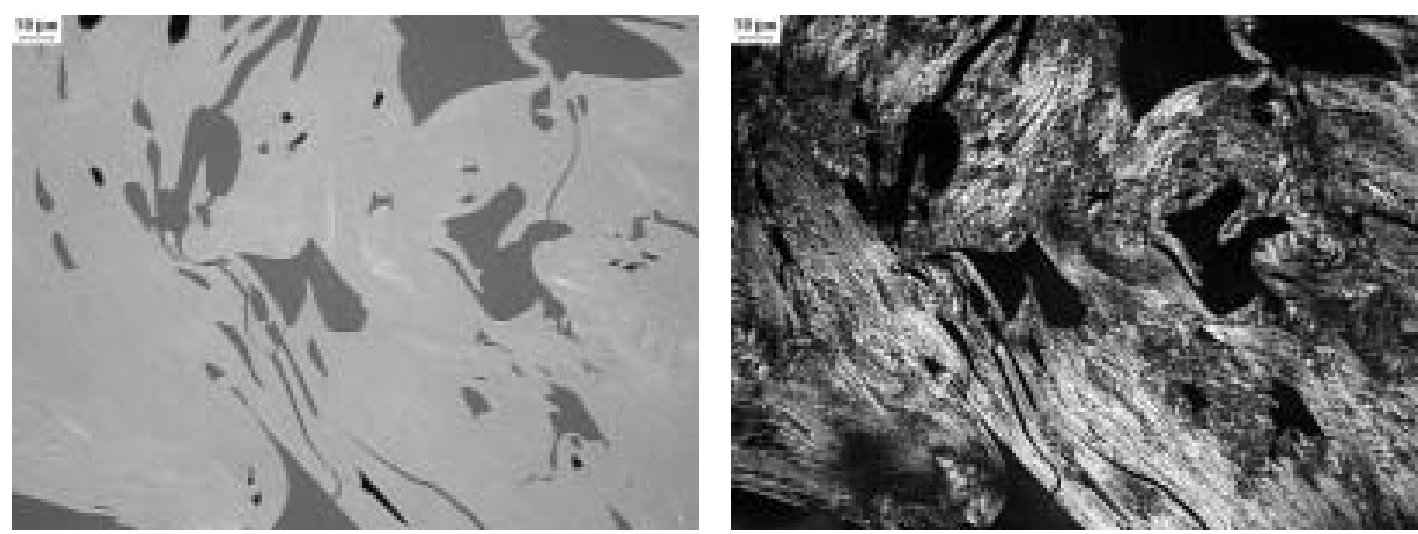

Figure 6.41 Green Coke Texture Produced from Thermal and Shear Stress. Magnification 500X

The images of coke from Figure 6.42 to 6.47 were obtained from the sample

T375_100, which was produced at $375^{\circ} \mathrm{C}$ and stirred at $75 \mathrm{rpm}$. Figure 6.42 shows a

typical sponge coke arrangement of large vesicles and thin pore walls. In Figure 6.43 and

Figure 6.44 a foreign body of coke can be seen. It appears to be of fine lenticular coke.

Other than the foreign body of coke, the structure has some fine ribbon and coarse

lenticular domains. In Figure 6.45 the image consists of mixed layer arrangement of fine ribbon and coarse lenticular domains with a few large vesicles. Seen in Figure 6.46 is fine ribbon domains which appear to be formed in turbulent flow. Some fine ribbon and coarse lenticular structures are shown at high magnification in Figure 6.47.
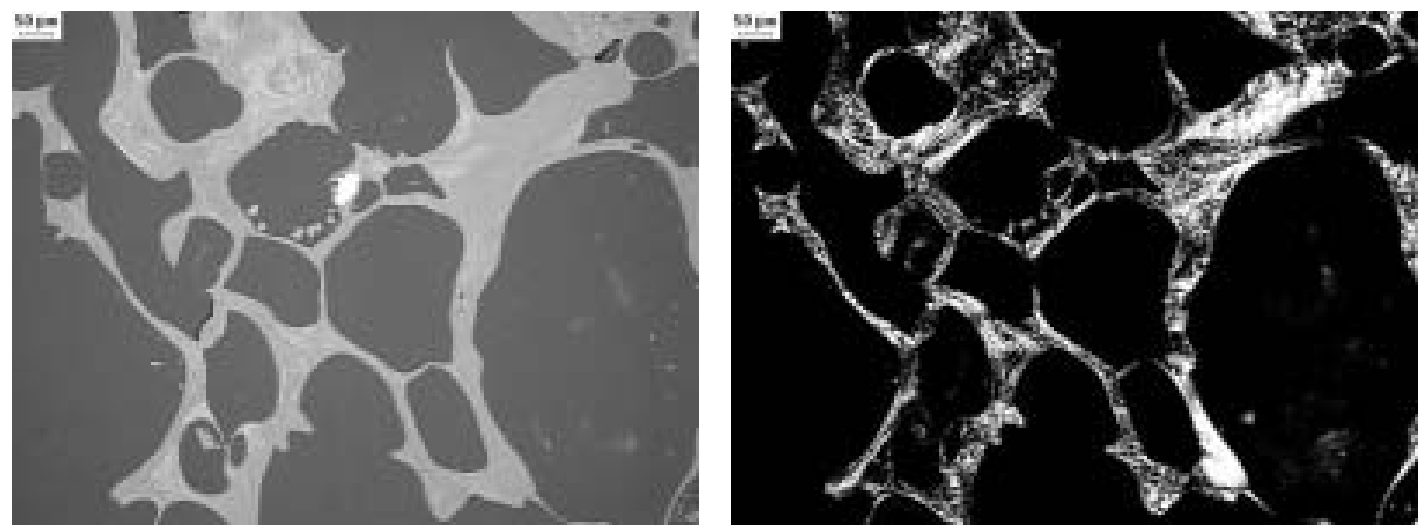

Figure 6.42 Green Coke Texture Produced from Thermal and Shear Stress. Magnification 100X 

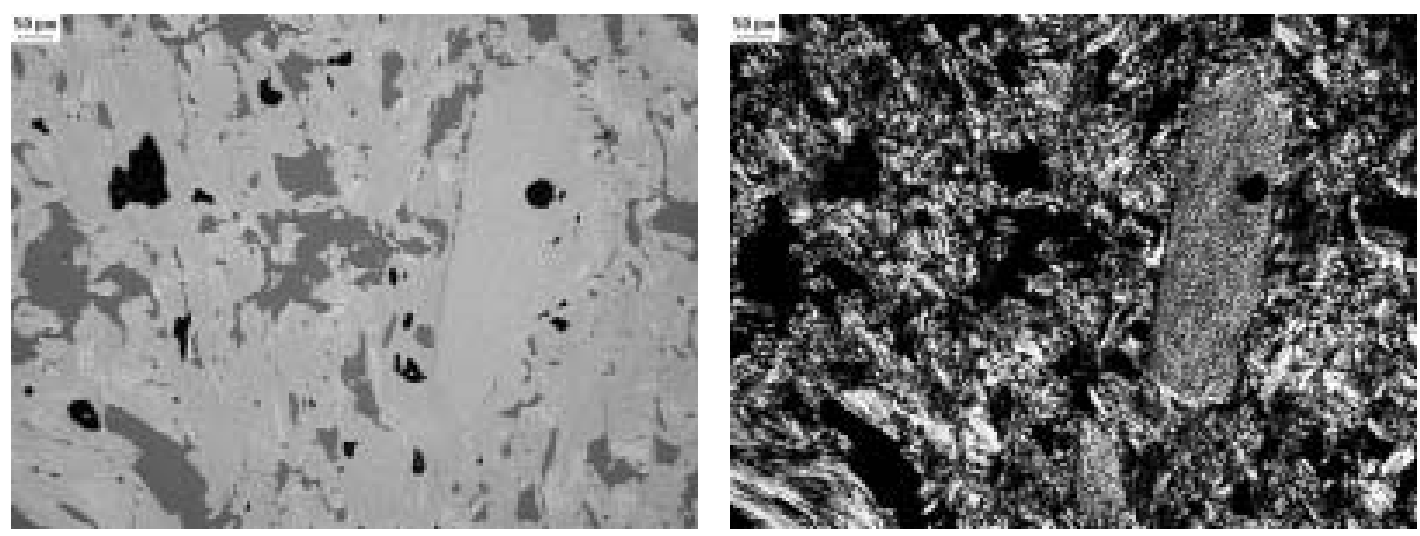

Figure 6.43 Green Coke Texture Produced from Thermal and Shear Stress. Magnification 100X
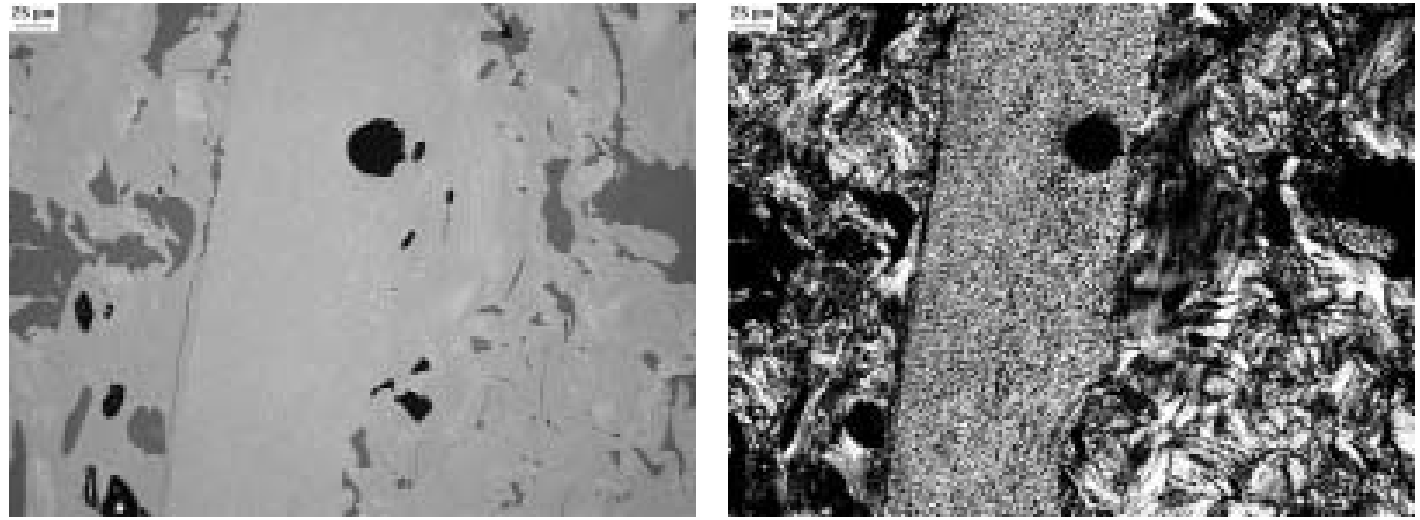

Figure 6.44 Green Coke Texture Produced from Thermal and Shear Stress. Magnification 200X
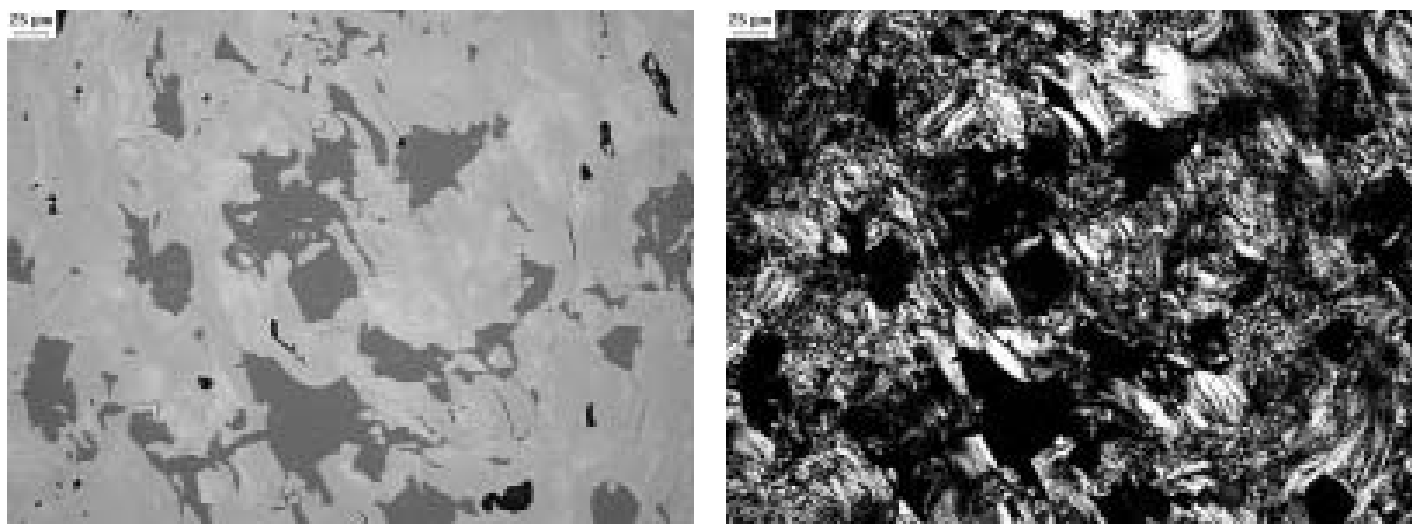

Figure 6.45 Green Coke Texture Produced from Thermal and Shear Stress. Magnification 200X 

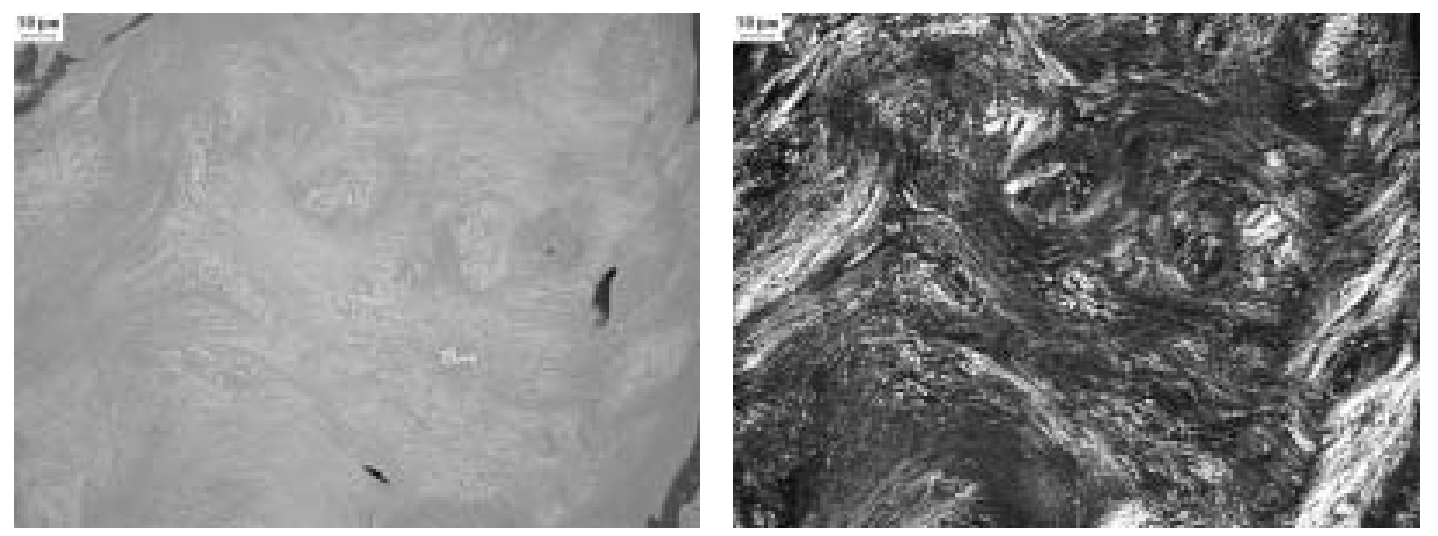

Figure 6.46 Green Coke Texture Produced from Thermal and Shear Stress. Magnification 500X
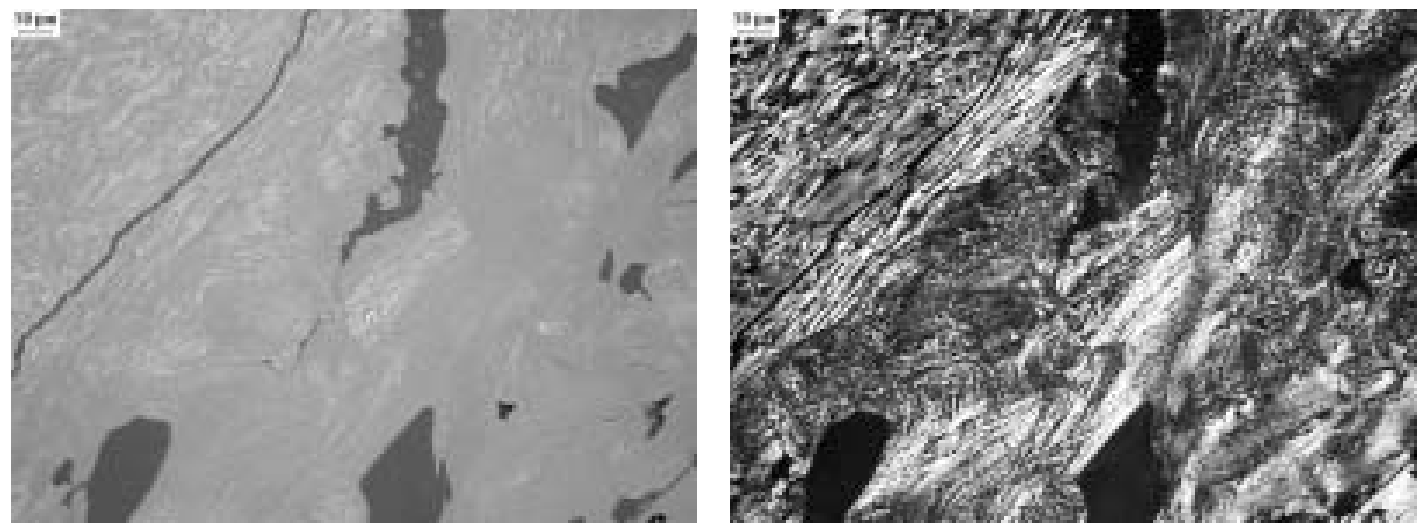

Figure 6.47 Green Coke Texture Produced from Thermal and Shear Stress. Magnification 500X

The subsequent images (Figure 6.48 to Figure 6.55) were obtained from sample

T425_100. The sample was produced at $425^{\circ} \mathrm{C}$ and stirred with the wiping blade at

75rpm. Figure 6.48 has large vesicles and some fine ribbon domains in the pore wall

structure. Figure 6.49 displays the dendrite like structure of the pore walls of highly

porous sponge coke. Fine ribbon domains are clearly shown in Figure 6.50. And also in

Figure 6.51, fine ribbon structures were formed of various flow domains. Although in

Figure 6.52 and Figure 6.53 there are large vesicles enclosed by fine ribbon and coarse

lenticular pore walls. The walls are thick and have a random domain orientation. Figure

6.54 shows medium ribbon domains. The image strongly indicates that high temperature and rapid stirring enhances the optical texture. Also in Figure 6.55 there is fine to medium ribbon domains with some large vesicles. 

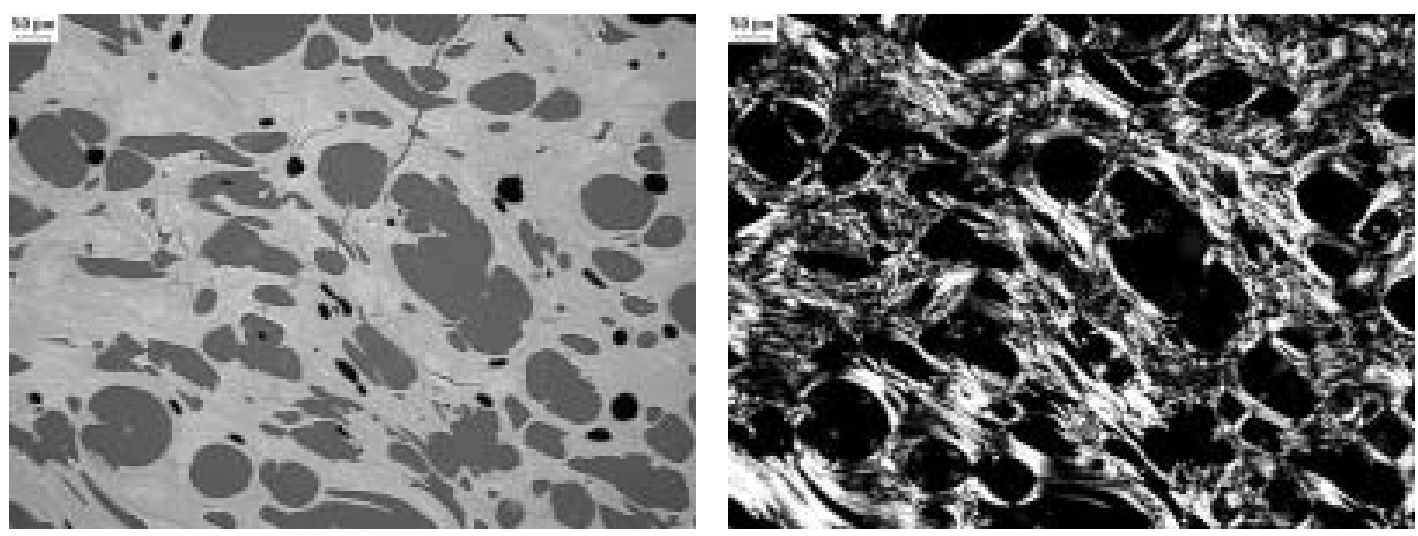

Figure 6.48 Green Coke Texture Produced from Thermal and Shear Stress. Magnification 100X
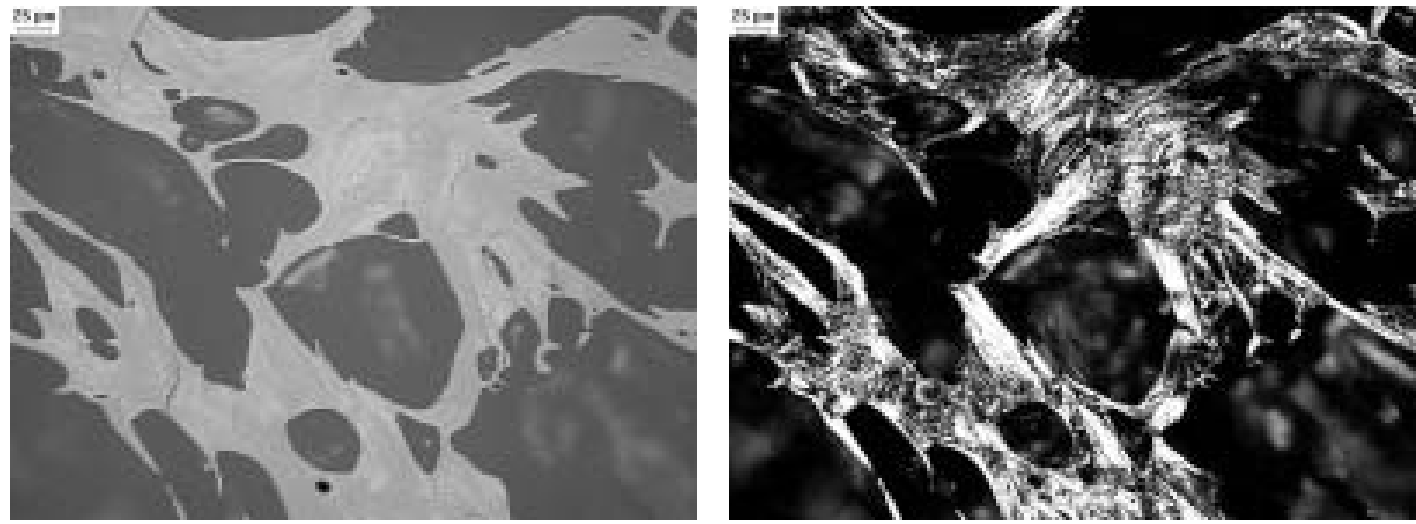

Figure 6.49 Green Coke Texture Produced from Thermal and Shear Stress. Magnification 200X
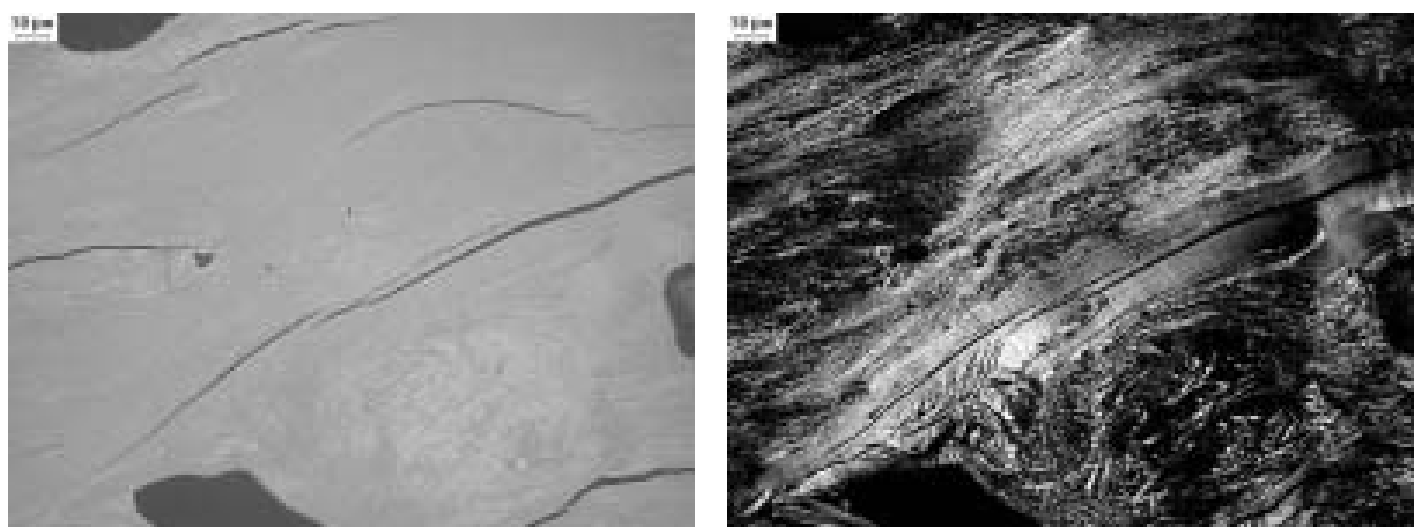

Figure 6.50 Green Coke Texture Produced from Thermal and Shear Stress. Magnification 500X 

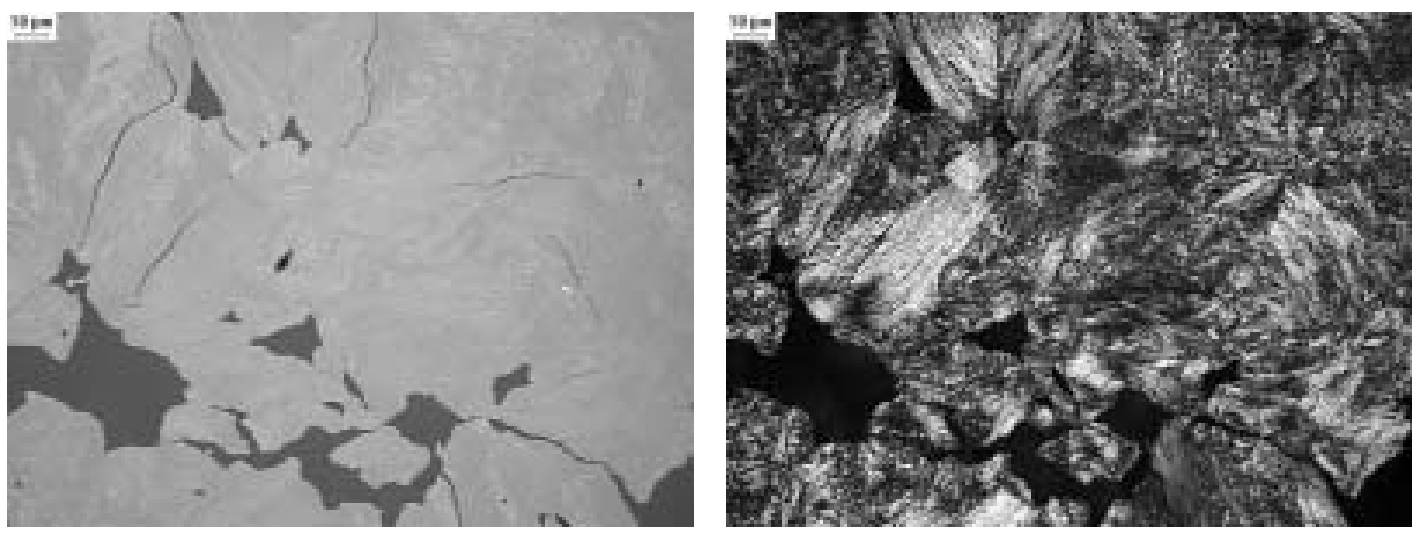

Figure 6.51 Green Coke Texture Produced from Thermal and Shear Stress. Magnification 500X
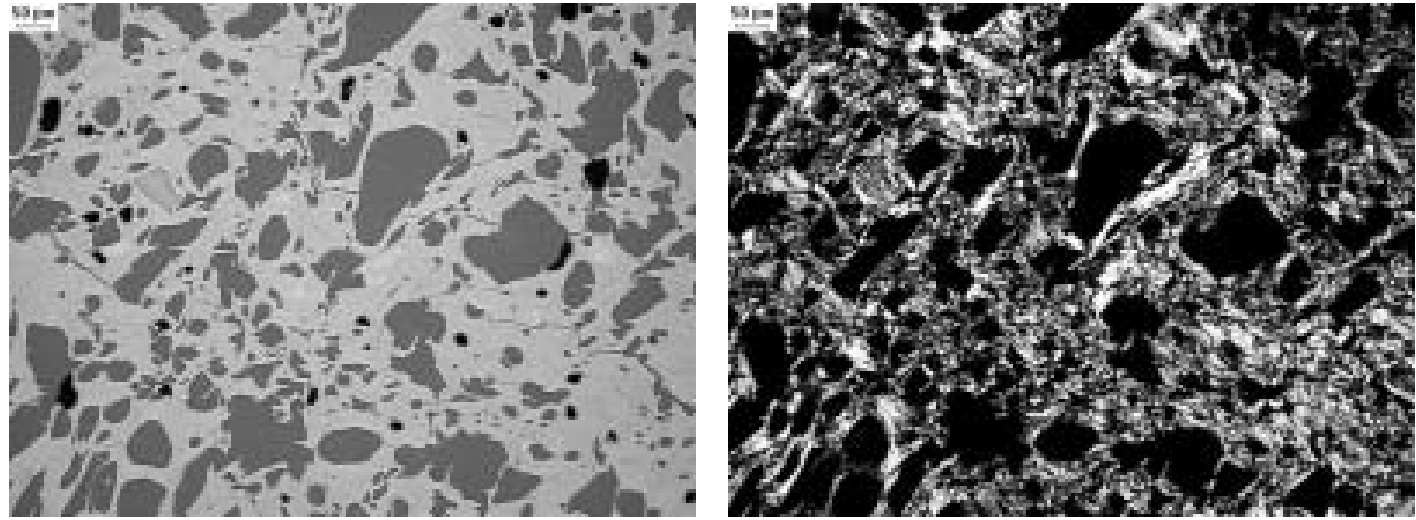

Figure 6.52 Green Coke Texture Produced from Thermal and Shear Stress. Magnification 100X
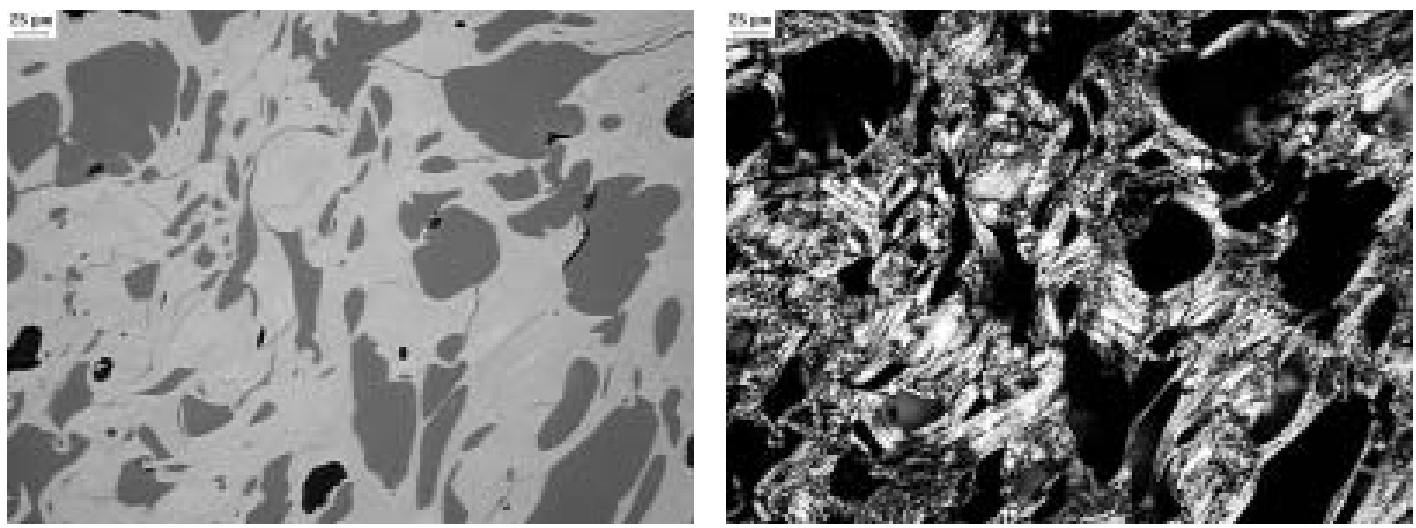

Figure 6.53 Green Coke Texture Produced from Thermal and Shear Stress. Magnification 200X 

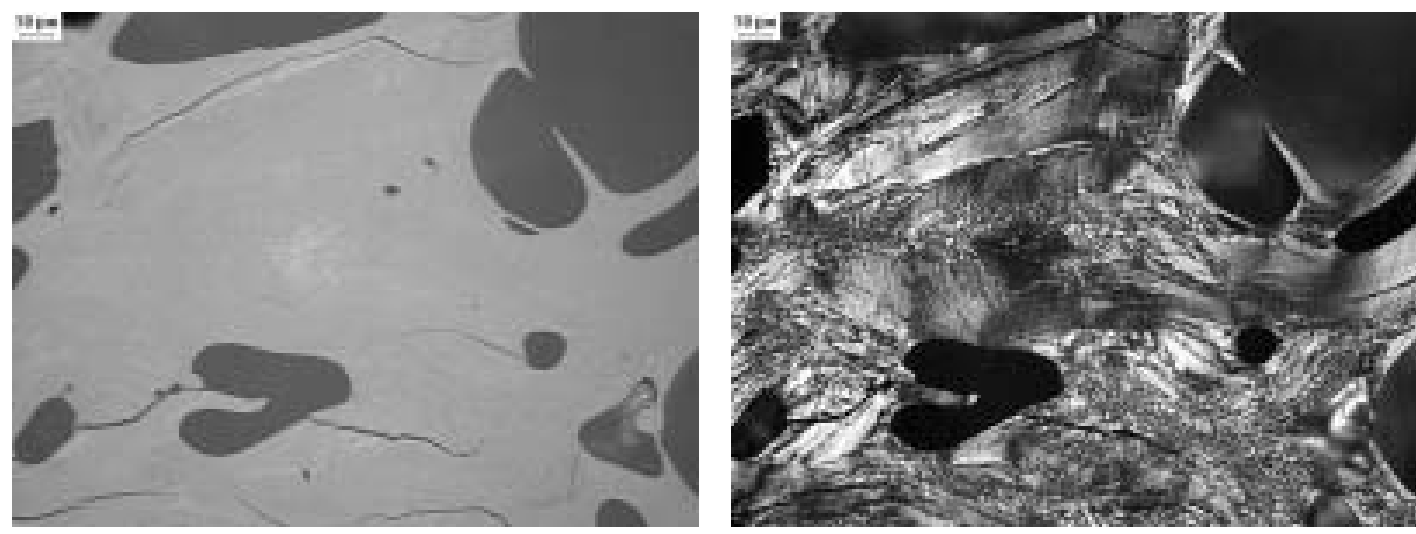

Figure 6.54 Green Coke Texture Produced from Thermal and Shear Stress. Magnification 500X
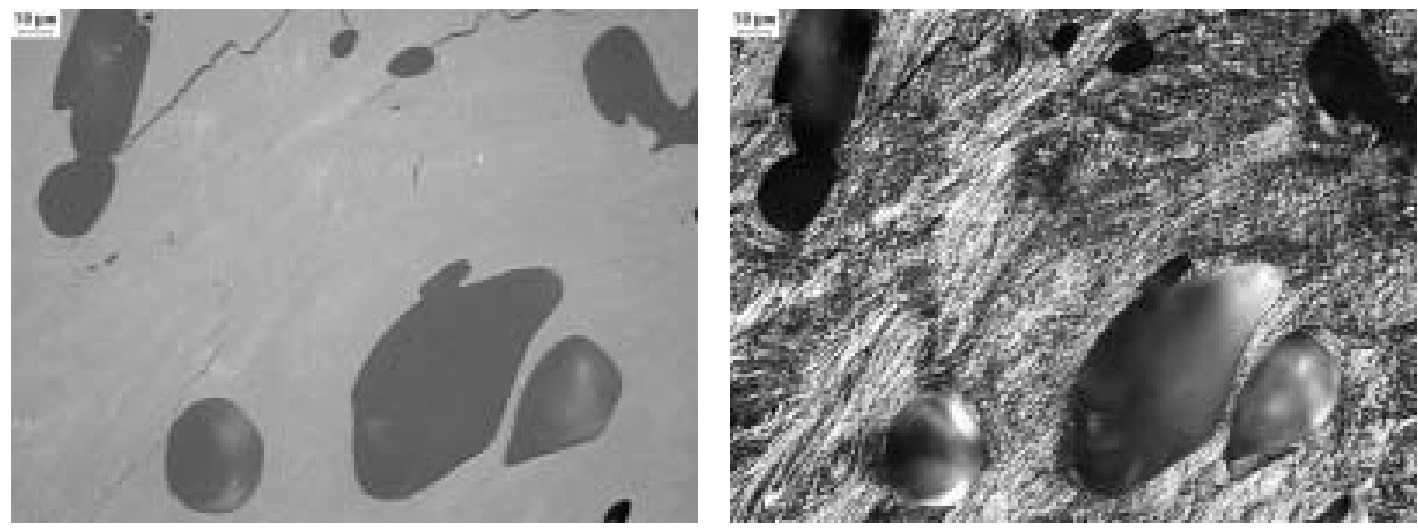

Figure 6.55 Green Coke Texture Produced from Thermal and Shear Stress. Magnification 500X 


\section{Conclusions}

The purpose of this research was to design and manufacture a mechanism by which the coke crystallinity could be manipulated using mechanical stress during pyrolysis. It was hypothesized that the degree of crystallinity would increase as a function of shear stress induced upon pitch during pyrolytic devolatilization. Such a mechanism and process would aid the production of anisotropic coke for the metallurgical industry.

Throughout this research several mechanisms were built and tested. It was found that the effected region of the molten pitch was rather small as a result of increased viscosity during devolatilization and the relative reactivity of the coal tar pitch. By using a flexible blade, the effected layer remained very small, while applying a proportional spring loaded force on the pitch. This mechanism proved to consistently apply a load and shearing stress to the material. The temperature and torque curves can be found in Appendix A. It was found that the measured outer skin temperature of the reactor was progressively hotter for the samples that were stirred at slower rates. This indicates that as some of the coke was formed on the inner surface of the reactor that it insulated the still molten pitch on the inside from the heater. Since the process temperature at the bottom center of the reactor controlled the heater controller, the cause of the difference of the surface temperature must have been due to the thermal gradient. This helps to explain the differences in the data. It has been shown in the literature that the ultimate heat treatment temperature is one of the most important factors controlling the development of carbon structures. 
The torque curves showed that the pitch remained very fluid during devolatilization. The value remained very low until the coke suddenly solidified. The ultimate value of the torque was not useful because the blade would catch on a solid piece of coke and then rapidly unload once it pulled past. This occurred until the blade wrapped around the shaft or the coke was fractured into small chunks. It did, however, provide an indication as to when the reaction had decomposed the pitch to a solid coke.

The stirring of the liquid pitch did have advantages which were observed optically. As the coke was removed from the vessel, the sheared coke was distinctly different from the unstirred coke. The two most notable differences were that there was no glossy metallic crust on the top surface of the sheared coke. This crust is referred to as the 'cauliflower' end of the coke in metallurgical coke examinations. The other difference seen in the sheared coke was the pore size. The sizes of the vesicles were significantly smaller. Comparisons of the polarized light micrographs indicate that the shear stress was influencing the formation of the coke as evident by Figure 6.32 and Figure 6.39 where the vesicles are clearly elongated. This was not true for the other images. The fine ribbon domain sizes seemed larger in the sheared coke sample images. This may have been a result of the devolatilization rate from stirring or the removal of the crust at the top of the coke.

The crystallite size was determined and found to be within 12 to $18.6 \AA$ for all the samples. The temperature would have greatly affected the crystalline growth. Thus the size would be dependant upon the location at which the sample was obtained. In the future isothermal reactions should be conducted in order to determine if a temperature 
gradient was in fact influencing the data. A very gradual temperature ramp and soak would be of interested for further investigations.

The reactor itself performed as expected. There were a few complications that were encountered throughout the carbonization process. Since the reactor was not designed to hold pressure, it was very challenging to keep the volatile gases from seeping around the stirring shaft. It was found that the cold trap unit collected the light tars in the vent line at the opening of the cold trap. Since a pressure caused leaks, it was determined that flowing the volatile gasses through the flame of a Bunsen burner would better dispose of the gases. Flaring proved to be the best way to dispose of the volatile gases without redesigning the reactor to be sealed.

As previously mentioned future investigations into shear coking should control the reaction temperatures at the outside reactor wall. The process temperature should be recorded and a temperature profile constructed. An interesting study would be to observe the pyrolytic devolatilization under polarized light using a heated stage and a rotating watch glass. The rotating watch glass would cause a shearing stress. The hot stage will cause the reaction, and the microscope, if equipped with a camera, could record the observed reaction and formations throughout the process. It would also be of interest to graphitize the samples and then analyze the XRD patterns of the crystalline structure. Xray diffraction of amorphous material can be conducted so long as the material has crystalline structure. These studies would be of interest to further investigate shear coking. 


\section{Bibliography}

Askeland, D. R. The Science and Engineering of Materials. 2nd Ed. PWS-Kent

Publishing: Boston, 1989.

Azaroff, L. V. and M. J. Bueger. The Powder Method In X-ray Crystallography. McGraw-Hill: New York, 1958.

Bragg, L. The Development of X-ray Analysis. Hafner Press: New York, 1975.

Callister, W. D., Jr. Materials Science and Engineering: An Introduction. 3rd Ed. John Wiley \& Sons: New York, 1994.

The Carbon Products Industry Vision for the Future, Industries of the Future, Carbon Products Consortium, WVU-NRCCE, P.O. Box 6064, Morgantown, WV 26506.

Charlier, J. -C., X. Gonze, and J. -P. Michenaud, "First-Principles Study of the Stacking Effect on the Electronic Properties of Graphite(s)," Carbon, Vol. 32, No. 2, 1994 pp. 289299.

Cullity, B. D. Elements of X-Ray Diffraction. Addison-Wesley: Reading, MA, 1978

Ellis, P. J., Paul, C. A. Tutorial: Petroleum Coke Calcining and Uses of Calcined Petroleum CokeCalcination Tutorial GLC, 2000.

Fitzer, E., Köchling, K. -H., Boehm, H. P., Marsh, H. "International Committee for Characterization and Terminology of Carbon 'Recommended Terminology for the Description of Carbon as a Solid'," Carbon, Vol. 67, No. 3, 1995.

Gray, R. and Gray, D. "Petrographic Analysis of Coke" Author's Private Collection, 2007.

Gray, R. J. and K. F. DeVanney, International Journal of Coal Geology, Vol. 6, 1986. pg 277-297.

Gallaher, M. P., Depro, B. M. "Economical Impact Analysis of Final Coke Ovens NESHAP” U.S. Environmental Protection Agency. EPA Contract No. 68-D-99-024. RTI Project No. 7647.003.0274, 2002

Klug, H. P. and L. E. Alexander. X-Ray Diffraction Procedures For Polycrystalline and Amorphous Materials. 2nd Ed. John Wiley \& Sons: New York, 1974.

Marsh, H., ed. Introduction to Carbon Science. Butterworths: Boston, 1989. 
Marsh, Harry, ed., Introduction to Carbon Technologies, Universidad de Alicante, 1997

Marsh, H. and J. Smith. "The Formation and Properties of Anisotropic Cokes from Coals and Coal Derivatives Studied by Optical and Scanning Electron Microscopy." Analytical Methods for Coal and Coal Products. Vol. II, Academic Press: New York, 1978.pp 371414.

McHenry, E. R, et al. "Development of Anode Binder Pitch Laboratory Characterization Methods", Light Metals 1998.

Montgomery, D. C. Design and Analysis of Experiments $5^{\text {th }}$ Ed. John Wiley \& Sons: New York, 2001.

Orac, T. H. and C. F. Chang. "CTE of Needle Coke-Testing Methods and Significance." Twentieth Biennial Conference on Carbon: Extended Abstracts and Program, American Carbon Society, University of California, Santa Barbara, June 23-28 1991. pp 196-197.

Schultz, J. M. Diffraction for Materials Scientists. Prentice-Hall: Englewood Cliffs, New Jersey, 1982. 


\section{Appendix A}

Data Acquisition Plots of Reaction Conditions 


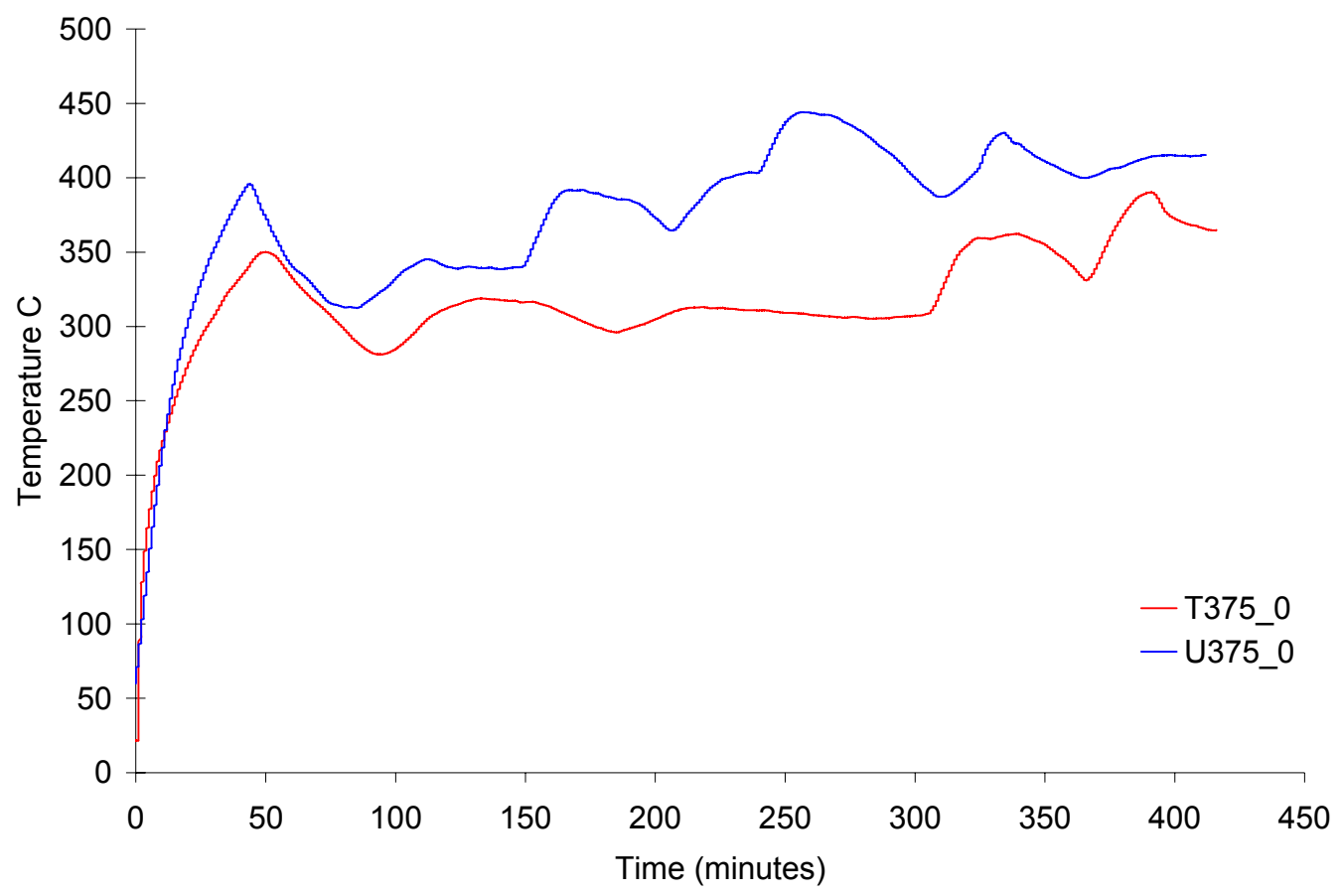

Figure A.1 Thermal Plot of the Outer Skin Temperature and Torque Curve for the Reactions Processed at $375^{\circ} \mathrm{C}$ and at $0 \mathrm{rpm}$

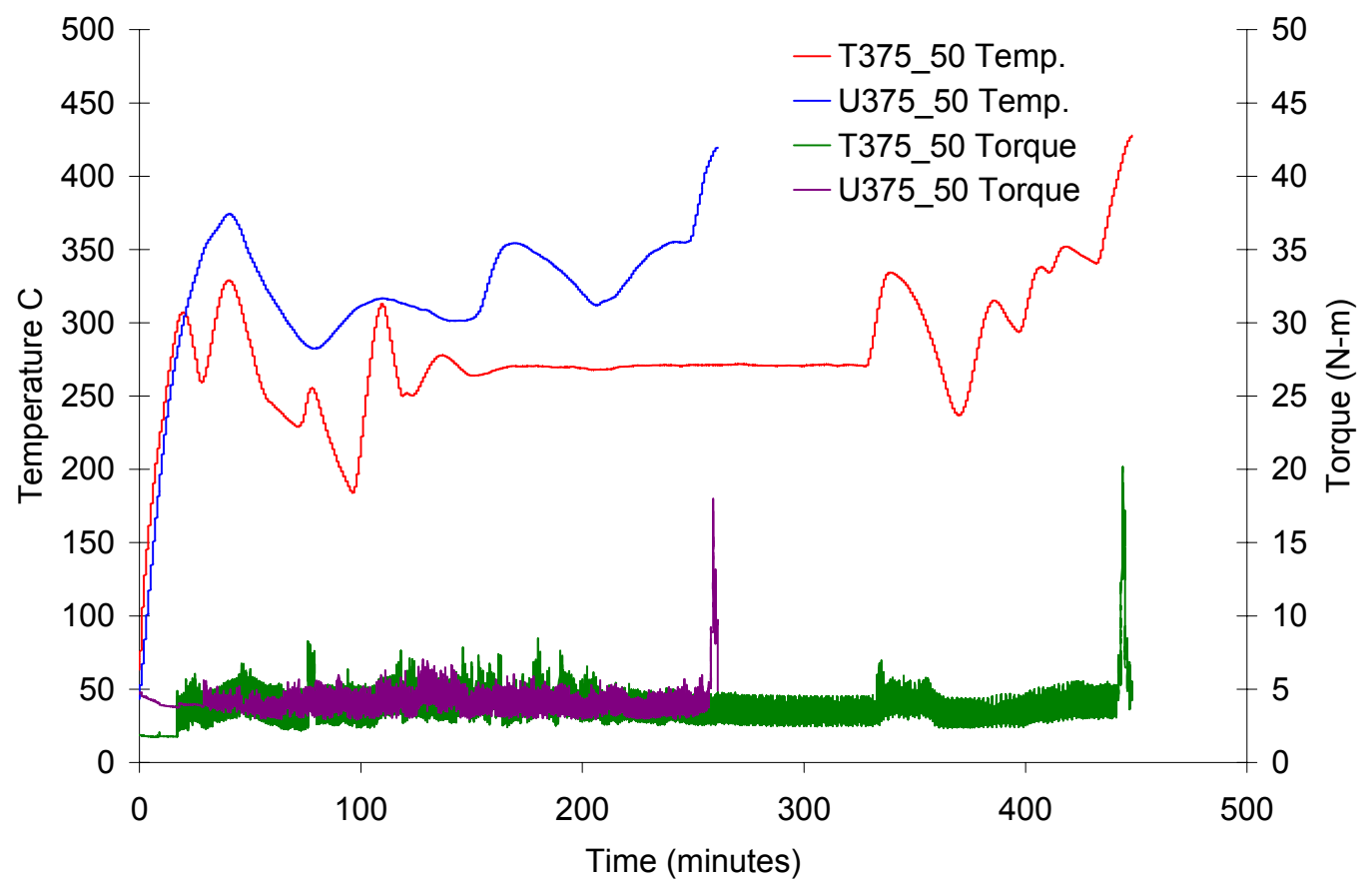

Figure A.2 Thermal Plot of the Outer Skin Temperature and Torque Curve for the Reactions Processed at $375^{\circ} \mathrm{C}$ and at $35 \mathrm{rpm}$ 


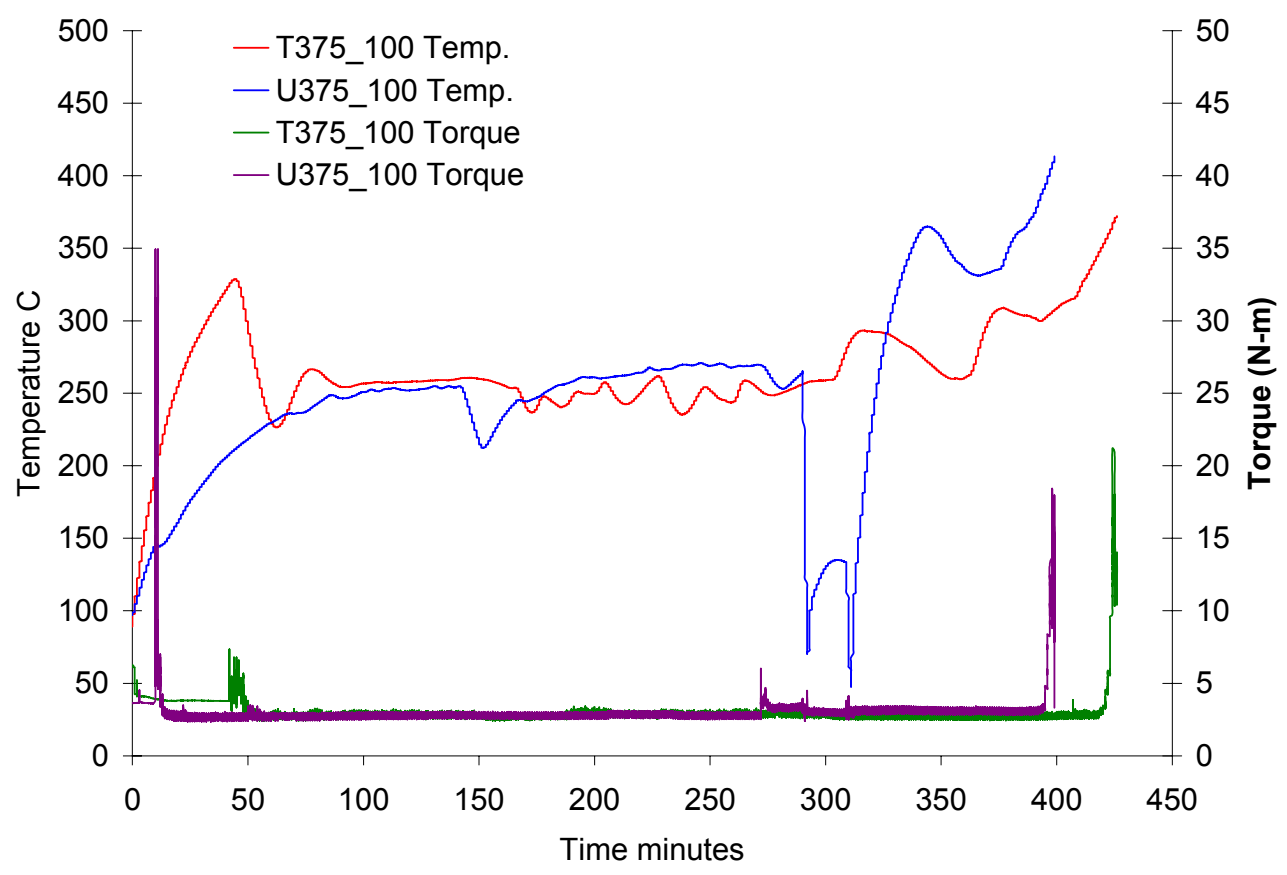

Figure A.3 Thermal Plot of the Outer Skin Temperature and Torque Curve for the Reactions Processed at $375^{\circ} \mathrm{C}$ and at $75 \mathrm{rpm}$

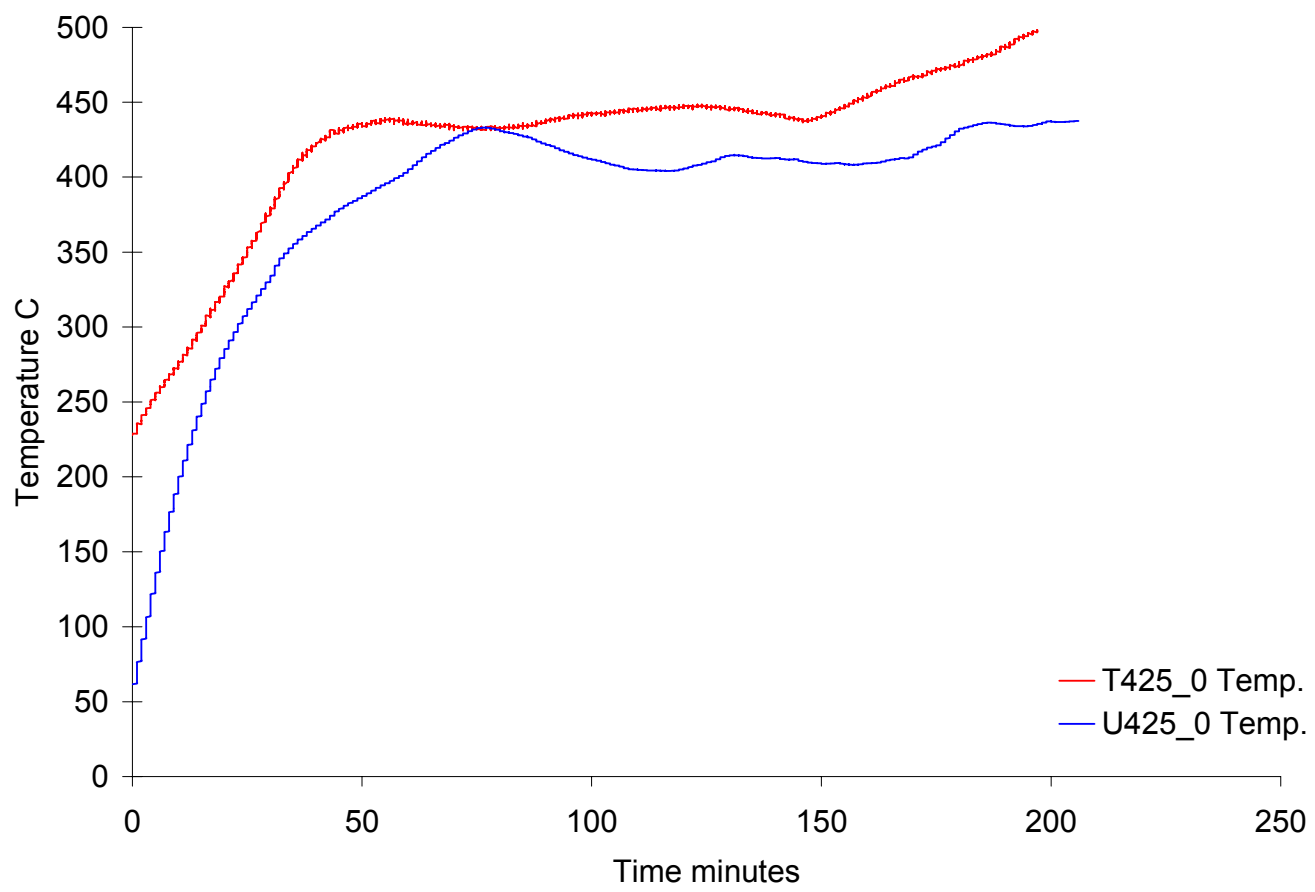

Figure A.4 Thermal Plot of the Outer Skin Temperature and Torque Curve for the Reactions Processed at $425^{\circ} \mathrm{C}$ and at $0 \mathrm{rpm}$ 


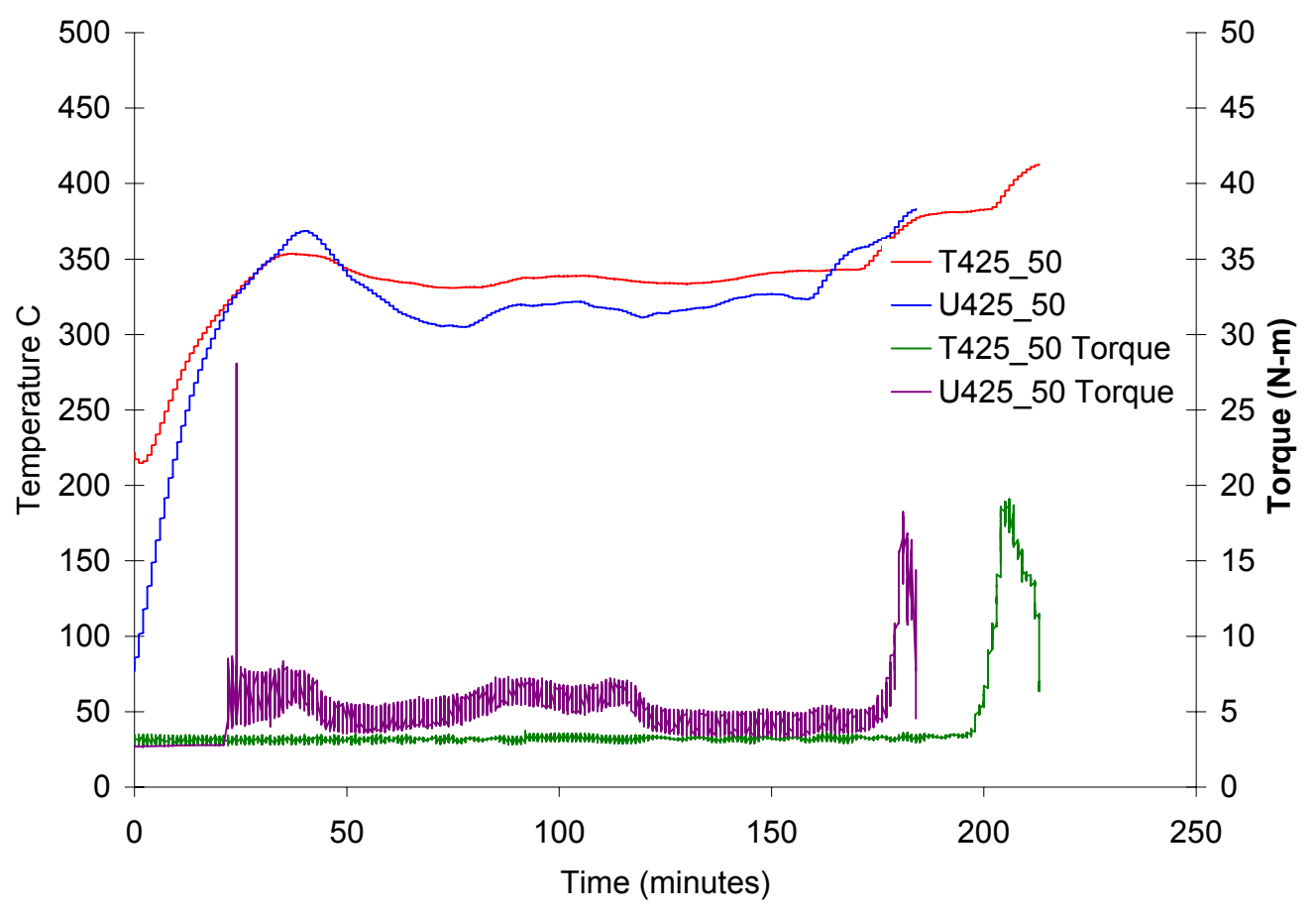

Figure A.5 Thermal Plot of the Outer Skin Temperature and Torque Curve for the Reactions Processed at $425^{\circ} \mathrm{C}$ and at $35 \mathrm{rpm}$

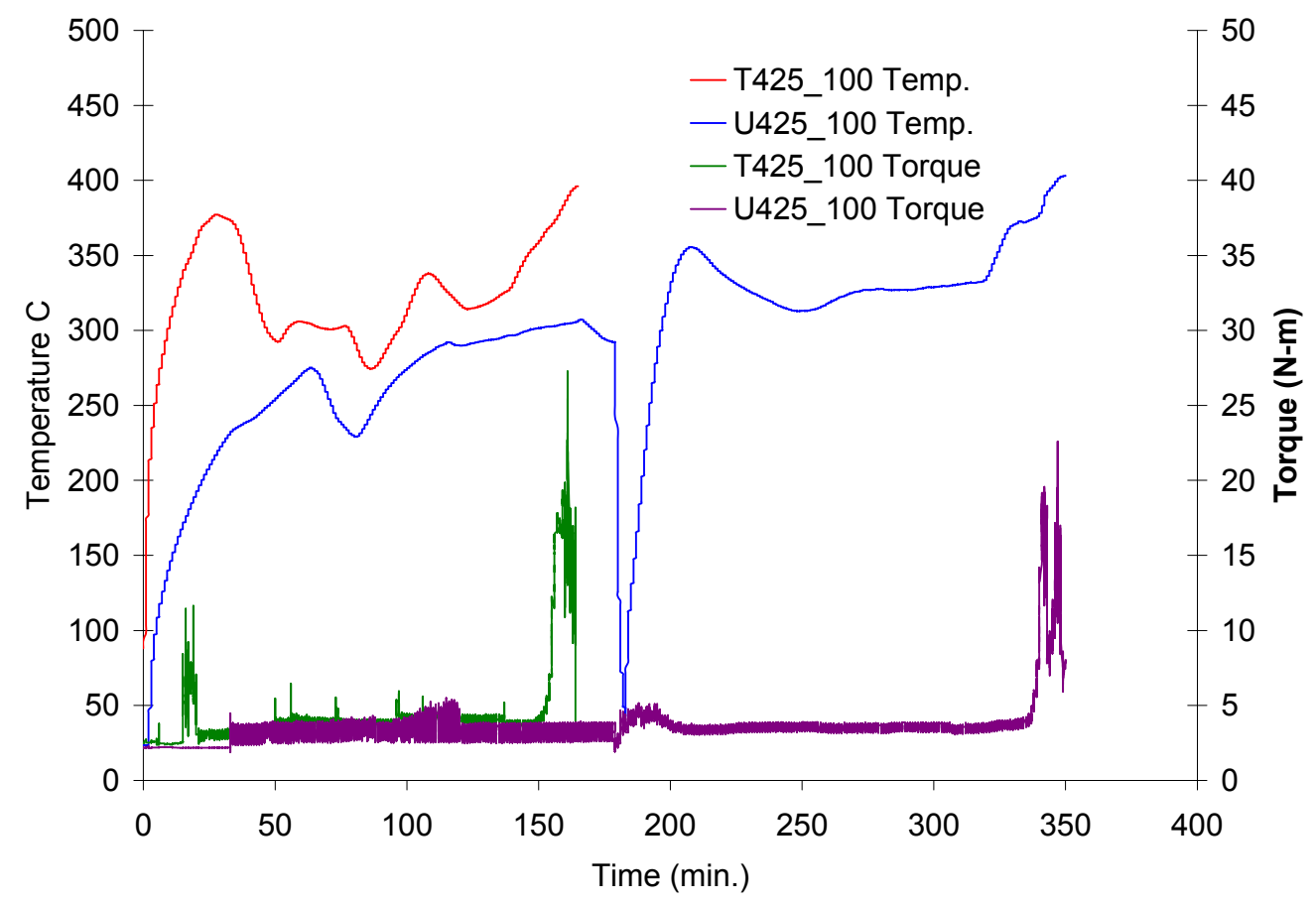

Figure A.6 Thermal Plot of the Outer Skin Temperature and Torque Curve for the Reactions Processed at $425^{\circ} \mathrm{C}$ and at $75 \mathrm{rpm}$ 